\title{
Weightism: Can Personality Characteristics Predict Prejudice in College Students?
}

John E. Damm

West Virginia University

Follow this and additional works at: https://researchrepository.wvu.edu/etd

\section{Recommended Citation}

Damm, John E., "Weightism: Can Personality Characteristics Predict Prejudice in College Students?" (2011). Graduate Theses, Dissertations, and Problem Reports. 3456.

https://researchrepository.wvu.edu/etd/3456

This Dissertation is protected by copyright and/or related rights. It has been brought to you by the The Research Repository @ WVU with permission from the rights-holder(s). You are free to use this Dissertation in any way that is permitted by the copyright and related rights legislation that applies to your use. For other uses you must obtain permission from the rights-holder(s) directly, unless additional rights are indicated by a Creative Commons license in the record and/ or on the work itself. This Dissertation has been accepted for inclusion in WVU Graduate Theses, Dissertations, and Problem Reports collection by an authorized administrator of The Research Repository @ WVU.

For more information, please contact researchrepository@mail.wvu.edu. 
Weightism: Can Personality Characteristics Predict Prejudice in College Students?

John E. Damm

\author{
Dissertation submitted to the \\ College of Human Resources and Education \\ at West Virginia University \\ in partial fulfillment of the requirements \\ for the degree of
}

\author{
Doctor of Philosophy \\ in \\ Counseling Psychology \\ Jeffrey Daniels, Ph.D., Chair \\ James Bartee, Ph.D. \\ Ed Jacobs, Ph.D. \\ Ed Etzel, Ed.D. \\ Richard Walls, Ph.D.
Department of Counseling, Rehabilitation Counseling, and Counseling Psychology
Morgantown, West Virginia
2011

Keywords: Obesity, stigmatization, personality, Big Five, bias 


\begin{abstract}
Weightism: Can Personality Characteristics Predict Prejudice in College Students?
\end{abstract}

John E. Damm

Bias toward individuals who are obese is one of the last bastions of permissible prejudice. The people who are obese report discrimination in a variety of settings; they experience it with families, employers, teachers, and health-care professionals. Research regarding obesity bias indicates that attribution of personal responsibility is correlated with negative attitudes toward individuals who are obese. Attribution of causality and resulting bias has been linked to specific personality characteristics, specifically the Big Five traits Agreeableness and Openness to Experience. The purpose of this study was to examine the relationship between personality characteristics and obesity bias. Students at a large mid-Atlantic University completed three measures; one personality measure, the NEO$\mathrm{PI}-\mathrm{R}$ and two measures of obesity bias, the Anti-fat Attitudes Questionnaire and a Weight Implicit Association Test. It was predicted that low Agreeableness and Openness to Experience was would predict anti-fat bias. Regression analyses did not indicate relationships between these variables, as expected. However, the obesity bias measures demonstrated bias was present within this sample. These findings are inconsistent with previous research regarding prejudice which used the NEO-PI-R. Limitations of this study, recommendations for future research, and clinical implications are discussed, including reducing myths regarding obesity, and advocacy for individuals who are obese. 


\section{Dedication}

This work is dedicated to my Lord and Savior Jesus Christ. I pray that I am able to use the education and training that he provided me, to glorify Him. 


\section{Acknowledgements}

At this time I would like to take the time to acknowledge the guidance and support I have received throughout my doctoral training and this dissertation. I would like to express my sincere thanks to my chair, Dr. Jeffrey Daniels and committee member, Dr. James Bartee. Their investment and dedication made completion of this work manageable and possible. I deeply appreciate their insights, efforts, and thoughtfulness throughout this dissertation process. Dr. Daniels patience with my incessant emails was admirable and greatly appreciated. I would like to thank Dr. Bartee for his unquestioned commitment to my education, internship placement and completion of my doctorate. I would also like to thank my other committee members, Dr. Etzel, Dr. Jacobs and Dr. Walls for their regular consultation, recommendations, and support on this project. Dr. Etzel's direction, time investment and friendship were invaluable. I would like to thank Dr. Deborah Hendricks for her help with statistical procedures. I would like to thank Margalit Persing for her editing expertise and presentation coaching. I would like to thank Vicki Railing for her support and guidance while I was a student both on and off campus. Her calm, reliable assistance and dedication to the small details decreased my stress as a doctoral student. I would like to thank the Clinical Psychology Department, particularly Danielle Nadorff for their tutelage and guidance with the Sona program. I would like to thank Dr. Sherry Cormier for her encouragement and her interest in my success. I would like to thank Roman Olynyk of West Virginia University and John Dowling of Washington and Jefferson College for their assistance with preparing this document for electronic submission. I would like to thank the staff of the counseling center at The College of William and Mary and particularly my Training Director, Dr. Carina Sudarsky-Gleiser, for their support and permitting time off to propose this dissertation. My time with them positively impacted me personally and professionally. I would like to thank my friends from the Counseling Psychology Department across several cohort classes I have been privileged to know who supported my progress and success. I would like to thank my life-long friend Andy Sarno for his support, humor, interest in my studies and assistance with the data management. Finally, I would like to thank my family for their support throughout my graduate education. I am forever indebted to my wife and soul mate, Jill. Her dedication and support was unwavering; her willingness to sacrifice was immeasurable. I would not have accomplished this without her. I would like to thank my children, Megan, Kieran and Taryn for their patience, support, tolerance and understanding. 
Table of Contents

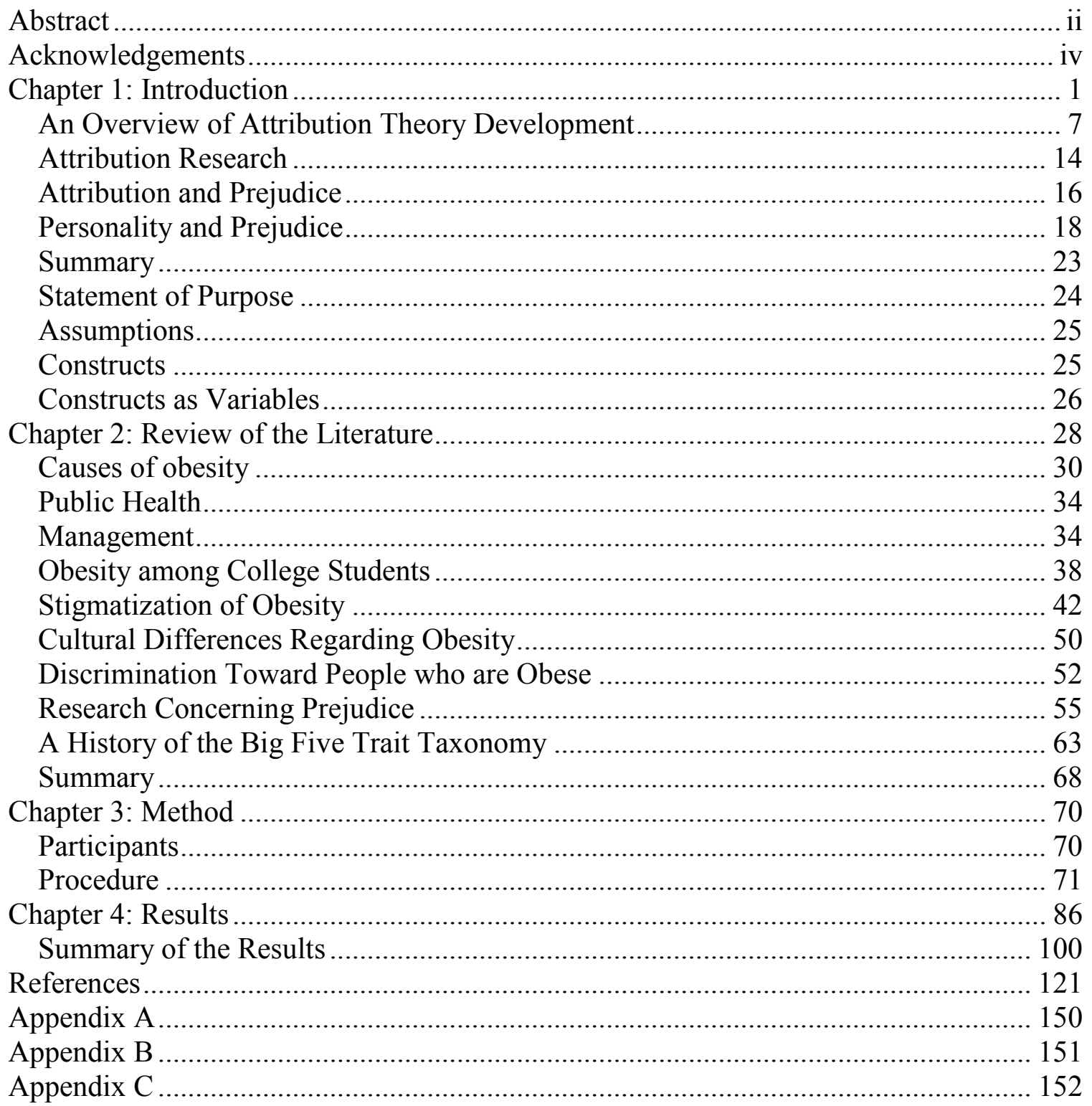




\section{List of Tables}

$\begin{array}{llr}\text { Table 1. Gender } & 84\end{array}$

$\begin{array}{llr}\text { Table 2. } & \text { Age } & 84\end{array}$

$\begin{array}{lll}\text { Table 3. } & \text { Ethnicity } & 85\end{array}$

$\begin{array}{lll}\text { Table } 4 . & \text { Class Rank } & 85\end{array}$

Table 5. Correlational Matrix of the IV and DVs Across Demographic Characteristics 86

Summary of Regression Analyses for Personality Variables

Table 6. Predicting Dislike of Obesity 89

Summary of Regression Analyses for Personality Variables

Table 7. Predicting Fear of Obesity $\quad 89$

Summary of Regression Analyses for Personality Variables

Table 8. $\quad$ Predicting Obesity Attribution (AAQ W scale) 90

Summary of Regression Analyses for Personality Variables

Table 9. $\quad$ Predicting Obesity Bias (AAQ Total Scores) 91

Summary of Regression Analyses for Personality Variables

Table 10. Predicting Obesity Bias (IAT D score) 92

Table 11. Descriptive Statistics of IV and DVs 93

Table 12. Duration $\quad 94$ 
Chapter 1: Introduction

Obesity is one of the nation's primary health concerns. In addition to their subsequent health complications, obese individuals must also contend with stigmatization and discrimination. Obese individuals report discrimination and prejudice at school, work, and within their families. Research on prejudice has heretofore focused on outgroups such as people with disabilities, African Americans, Gays, and the elderly. In recent years, researchers have attempted to understand prejudice among these groups through the lens of personality theory. Researchers have employed the Big Five model of personality theory to explore prejudice toward these out-groups (Allport \& Kramer, 1946; Bierly, 1985; Hartley, 1946). The "Big Five" personality traits are five broad factors or dimensions of personality developed through lexical analysis (Saucier \& Goldberg, 1996). The findings indicate significant correlations between personality factors of Openness to Experience and Agreeableness and prejudice toward the aforementioned groups. Thus far, research of this nature has not been conducted in order to examine prejudice toward obese people. I hope to determine if Openness to Experience and Agreeableness are also correlated with prejudice toward the obese.

The purpose of this study will be to address the absence of research regarding personality traits and prejudice toward obesity.

According to the National Centers for Disease Control (CDC, 2008), results from a national health survey conducted in 2003 and 2004 indicate that an estimated $66 \%$ of U.S. adults are either overweight or obese. In 1998, the National Institutes of Health developed guidelines for the assessment of obesity. The guidelines define of obesity based on research that relating Body Mass Index to risk of death and illness. A 24- 
member expert panel developed the guidelines that identified overweight as a BMI of 2529.9 and obesity as a BMI of 30 and above, which is consistent with definitions used in many other countries. The evidence is solid that the risk for various cardiovascular and other diseases rises significantly when someone's BMI is over 25 and that the risk of death increases as the Body Mass Index approaches and surpasses 30" (NIH News Release, 1998, paragraph 9). Of adults who reside in the United States over the age of 20 , an astonishing $32 \%$ were classified as obese. This upward trend has settled to some degree, but the CDC statistics indicate that obesity is at an all-time high.

Obesity is also correlated with numerous health concerns. Davis (2003) noted the following health problems as being co-morbid with obesity: cardiovascular diseases, hepatic diseases, orthopedic and neurological diseases, endocrine diseases and significant psychosocial complications. Some of these psychosocial issues include depression (Mustillo, 2003); increased emotional distress as adults (Mills \& Andrianopoulos, 1993); and a variety of interpersonal issues, such as social rejection by peers and poor interpersonal relationships (Obesity Action Coalition, 2008).

The CDC (2008) reported that medical expenses attributed to overweight and obese individuals accounted for $9.1 \%$ of the total U.S. medical expenses in 1998 (\$78.5 billion) and $\$ 92.6$ billion in 2002. Obesity has even been implicated as one of the correlates to global warming. Edwards and Roberts (2008) speculate that obese and overweight people require more fuel to transport them and food to feed them. The resulting food shortages and higher energy prices are considered to be factors that lead to global warming, according to the authors, as $20 \%$ of the greenhouse gas emissions stem from agriculture. 
In addition to the previously mentioned issues, obesity is related to a myriad of individual and societal issues, including discrimination toward obese individuals. - $\mathrm{Eggy}$ Howell says she will never forget the day the boss told her she either had to lose weight or lose her job. She weighed 280 pounds at the time and was working as a librarian. Feeling like she had no choice but to comply, Howell joined Weight Watchers" (Shkolnikova, 2008, p.1). Deborah Voigt, one of the world's leading opera singers, was fired from the Royal Opera House in the summer of 2004 due to her size (Lawless, 2008). Opera had traditionally been an occupation where larger body sizes had been acceptable. Voigt commented on the change in opera: $\subsetneq$ fo assume that one can weigh 300 plus pounds and still be viable on today's opera stage is naïve" (Lawless, 2008, pg 1). Discrimination toward the obese in the workplace has been documented by several researchers. Fonda (2000) reported lower wages for obese individuals; Pingatore, Dugoni, and Tindale (1994) found hiring discrimination based on obesity; and Klassen, Clayson, and Jasper (1996) found that overweight sales people were classified as being less successful. Carr and Friedman (2005) studied overweight and obese individuals and noted that obese professional workers were more likely to report employment discrimination and interpersonal mistreatment, versus thinner, non-professional workers. Obesity and discrimination warrants further investigation.

Research suggests that bias or prejudice toward obesity begins at an early age. Several researchers have noted this phenomenon, appearing as early as the age of four. Turnbull, Heaslip, and McLeod (2000) studied attitudes toward obesity among preschoolers. They found that four year olds held more negative attitudes toward overweight versus normal stimulus figures. Musher-Eizenman, Holub, and Miller (2004) 
noted similar attitudes among preschoolers. They also indicated that these children would least prefer the overweight figure as a playmate.

Puhl's (2001) literature review concerning discriminative attitudes and behavior toward obese people noted consistent findings of stigmatization and discrimination in the areas of employment, health care, and education. Within the health care arena, Puhl found that physicians tended to view obese patients as more non-compliant, dishonest, lazy, weak-willed, unintelligent, and unsuccessful than normal weight patients. Nurses described these individuals as non-compliant, overindulgent, lazy, and unsuccessful. Of the nurses surveyed, $31 \%$ preferred not to care for obese individuals and $24 \%$ agreed that obese individuals repulsed them. Psychologists were not immune from similar biases, which tend to diagnose obese clients as having more pathology, more negative attributes, more severe psychological symptoms, and worse treatment prognoses versus thinner or average-weight clients (Puhl, 2001).

The research confirms that obese who are obese experience stigmatization in many aspects of their lives. In an effort to combat this stigma, the U.S. government passed laws that prohibit discrimination on the basis of weight. Societal messages toward the obese are both overt and covert. Teachman, Gapinski, Brownell, Rollins, and Jeyaram (2003) wrote that being overweight was deemed blame-worthy by subjects. The authors noted that a bias existed toward obese people, depicting them as lazy (versus motivated), stupid (versus smart), and worthless(versus valuable). The authors noted that subjects valued the latter qualities, which they associated with thinner individuals. Schwartz, Vartanian, Nozek, and Brownell (2006) found that thinner people were more 
likely to automatically associate negative attributes ( $b a d$, lazy”) to fat people and explicitly described fat people as less motivated and lazier than thin people.

Fear of fat or fear of becoming fat was also investigated by these researches through an online survey of approximately 4000 respondents. Nearly half of the people responding to an online survey about obesity said they would give up a year of their life rather than be fat, while respondents in varying numbers between $15 \%$ and $30 \%$ also said they would rather walk away from their marriage, give up the possibility of having children, be depressed, or become alcoholic rather than be obese. Five percent and four percent, respectively, said they would rather lose a limb or be blind than be overweight. Research within the area of obesity and bias or stigmatization has found causation and locus of control to be key components in the negative appraisal of obese individuals. Tiggemann and Anesbury (2000) studied children in grades 4-6 and found that, regardless of the target subjects` age, gender, or weight, obesity was largely thought to be volitional and controllability was positively correlated with the extent of negative attitudes.

Research findings also indicate that these attitudes are not easily changed. Bell and Morgan (2000) and Jenks (1998) assessed whether pre-school children's negative attitudes toward obesity could be swayed through an educational program. Children were subdivided by age, 3-4 and 5-6. The younger children displayed a preference for thinner children to play with, whereas their older counterparts chose non-obese peers to study with. The authors found that information explaining obesity had minimal positive effect on children's attitudes and behavioral intentions toward a peer perceived as obese. 
Harris, Walters, and Waschull (1991) conducted similar research with adults. The authors attempted to change the negative attitudes of their subjects by providing relevant programming to their participants. In fact, these researchers provided factual information about obesity and exposed their subjects to obese models, models similar in appearance to the subject (except that they were obese) or no models. Subjects received education regarding obesity and it was determined that there was no effect on subject perceptions toward obesity. Surprisingly, neither -more educated" nor heavier subjects displayed a decrease in prejudice toward obesity.

It would appear that negative attitudes toward obesity are the result of an individual's belief that the condition is chosen and these subjects attribute this to some weaknesses in the individual. In fact, Klaczynski, Goold, and Mudry (2004) studied stereotypes toward obesity, self-esteem, and ideal thinness" among college students. They concluded that there was a positive correlation between negative attitudes toward obesity and self-esteem. These factors were both mediated primarily by the belief that obesity is caused by some personality shortcomings.

The research seems to suggest that people develop negative attitudes toward obesity at an early age and these beliefs continue into adulthood. Additionally, the participants included in these studies appear to develop negative attitudes because they believe that obesity is a willful act and not the result of an external factor or predisposition. Despite attempts to educate subjects otherwise, they cling steadfastly to their beliefs about obesity.

Crandall (1994) found that anti-fat prejudice was closely linked to attributions of controllability, which stem from underlying beliefs about causality in the physical and 
social world. The author reported that a significant proportion of the affective component of attitudes and prejudice toward groups is based on two interrelated factors: attributions of controllability and cultural value. Weiner, Perry, and Magnusson (1988) found that the attribution of controllability for fatness leads to social rejection. According to Weiner, An individual's obesity that is attributed to self-indulgence-a deficiency in =try ${ }^{6}$ gives rise to disliking of that person, whereas this is not the case if the obesity is ascribed to a physiological dysfunction — a deficiency in can“" (1980, p. 180).

Attribution theorists Zanjonc, Miller, Ross, Mitchell, and Nesbitt (as cited in Heffner, 2008) posit that there are two basic sources of our behavior - those influenced by situational/external factors and those influence by dispositional/internal factors. Fundamental attribution error and self-serving bias are suggested in the research as the two primary ways in which we are prone to interpret and assign causality. The fundamental attribution error" is a tendency to overestimate the internal and underestimate the external factors when explaining the behaviors of others. Self-serving bias" occurs when we equate successes to internal and failure to external attributes. When considering the assumption among children that obesity may be volitional, it appears that the fundamental attribution error is in effect — they are assigning internal causality for another's obesity.

\section{An Overview of Attribution Theory Development}

Attribution theory describes the rules that people use in their attempts to infer the causes of behavior, events and outcomes in order to understand and control their world (Weiner, Frieze, Reed, Rest, \& Rosenbaum, 1972). The origins of attribution theory can be seen in the works of Kurt Lewin, who is known for the oft-quoted dictum, There is 
nothing so practical as a good theory" $(1952$, p.169). Lewin $(1935,1938)$ is considered the founder of social psychology. Lewin's primary contribution to social psychology was the development of force field theory, which provided a framework for looking at the factors or forces that influence a social situation. His theory posits that forces are either driving movement toward a goal (helping forces) or blocking movement toward a goal (hindering forces). The origins of expectancy value theory, which suggests that behavior is a function of the expectancies one has and the value of the goal toward which one is working, can be attributed to Lewin (Graham \& Folkes, 1990).

Lewin's ideas influenced the work of psychologists including Julian Rotter and John Atkinson. Rotter (1966) is identified with social learning theory and was instrumental in developing a conceptual system that would be applicable to clinical issues and remain true to logical positivism (the idea that observational evidence is indispensable for knowledge of the world).

Rotter (1966) agreed with expectancy value theory, emphasizing that the strength of motivation to perform an action is determined by the reinforcement value of a goal and the expectancy of attaining that goal. Rotter was interested in identifying the determinants of expectancy of success. Through several experiments, James and Rotter (1958) explored expectancy of success estimates across tasks of skill and chance. They found individual differences in causal perception, which in turn result in different subjective probabilities of success and failure across various situations.

Rotter's (1966) contributions to attribution theory was the development of the Locus of Control Scale (LoCS). The I-E Scale (I-Internal, E-External) was constructed to measure individual differences in the personal construction of the world as 
skill (internal) or chance (external) related. Thus far, researchers have not determined that this scale successfully relates to differences in expectancy of success or expectancy of change (Weiner, Frieze, Kukal, Reed, Rest, \& Rosenbaum, 1991). It should be noted that the LoCS was used in numerous studies conducted from the late 1960s to the early 1980 s.

John Atkinson $(1957,1964)$ was also influenced by the work of Kurt Lewin. Atkinson believed that achievement strivings are partially mediated by individual differences in the -motive for success" and the -motive to avoid failure." These concepts were conceived as relatively stable dispositions which approach or move from achievement-related contexts. Atkinson proposed that motivation was presumed to be determined by the expectancy of success and the incentive value of success; the latter was defined as the amount of pride one experiences in attainment of a given goal. The author suggested that individual differences in achievement need (motives) were conceived as causal dispositions. Atkinson's theory was influenced by Rotter's thoughts concerning causal tendencies.

Atkinson also included expectancy (probability of success) and incentive as determinants of achievement performance. Atkinson stated that the incentive value of achievement success is higher for difficult versus easier tasks. In easy tasks, the incentive value of success (pride) is low because success is externally described (to the ease of the task). When a task is difficult, the incentive value is high because the attribution of success is internal.

A third prominent psychologist influenced by Lewin was Fritz Heider, who was a contemporary of Atkinson and Rotter. Heider (1958) was interested in causal perceptions 
within an achievement-related context. However, Heider was not examining causality from the perspective of an individual-differences theorist. Heider posited that behavior is influenced by both -ean" and try"; can in turn was conceived as the relation between ability and the difficulty of the task. Both ability and effort were considered internal to the actor and components of skill; objective task difficulty was an external determinant of behavior. By focusing on the perceived determinants of achievement performance, Heider also emphasized locus of causality in his theorizing.

Heider (1944) created a metaphor depicting people acting as scientists, trying to collect information in a reasonably rational way and reaching decisions regarding the causes of behavior. Heider proposed that people form beliefs or hypotheses about the motives of their behavior and those of others with whom they had interacted, and then acted on the basis of these beliefs. Heider $(1944,1958)$ constructed schemas or pathways through which people were held responsible for an action, based on attribution. The results of applying these rules range from a fully internal attribution (the person is wholly responsible) to a completely external attribution (the situation is solely responsible). Person factors include ability, motivation, and personality; situational factors include luck, influential others, and the elements of the environment. Heider suggested that the underlying mechanism of attribution is to maintain self-esteem and speculated that selfesteem is an affective response to one's self. Therefore, attributing negative outcomes to external factors and successes to internal factors maintains self-esteem. Obviously, the reverse would result in a loss of self-esteem.

Harold Kelley (1967) expanded and formalized Heider's theory by creating hypotheses regarding factors that affect the attribution formation. Kelley hypothesized 
that attributions were assigned based on three types of information: consensus, distinctiveness, and consistency. Consensus is defined as how an individual's behavior compares to that of his/her peers. Consensus is high when one acts similarly to one's peers; it is low when it is different. Distinctiveness is a comparison of one's behavior in difference situations. Distinctiveness is high when one's behavior in one situation is different from one's behavior in other situations; distinctiveness is low when one's behavior on a task is similar to behavior in other situations. Consistency is an indication of one's behavior on a task over time. Consistency is high when one's behavior is similar over time; it is low when one's behavior varies considerably over time. Kelley suggested that individuals ascribe behavior to internal causes when consensus is low, distinctiveness is low, and consistency is high. Individuals will make external attributions when consensus is high, distinctiveness is high, and consistency is low. Together, these three sources of attributional information are known as Kelley‘s cube.”

Bernard Weiner's contribution to attribution theory was built upon the works of Atkinson and Heider. Weiner's (1980) approach to attribution was partially focused on other dimensions or properties of causality, in addition to locus, internal or external. Weiner began with Heider's ability and effort distinction and surmised that, to the degree that these causes of achievement performance differentially predict some aspect of judgment or action, an additional distinction between causality other than internalexternal is needed.

Weiner defined or labeled the property distinguishing ability from effort as eausal stability." Stability refers to the variability of a cause over time. Ability was considered to be fixed, whereas effort was conceived as variable, subject to fluctuation 
over short periods. Weiner and colleagues (1972) speculated that because effort was variable, it would be linked with reward and punishment, which could then be used to influence expended effort. Consequently, rewarding or punishing ability had little function, because it was conceived as fixed.

In 1985 and 1986, Weiner expanded on Rotter's research, which contrasted skill (ability) with luck perceptions. Weiner determined that Rotter was comparing a respective internal, stable cause with an external, unstable cause. The resulting disparate expectancy shifts could be attributed to either the locus or stability dimension of causality. Weiner`s $(1985,1986)$ findings documented that expectancy shifts are determined by causal stability rather than causal locus. Therefore, failure due to lack of ability produces lower expectancy of success than failure perceived as due to a lack of effort, although both are internal determinants of behavior.

Weiner continued to investigate the significance of causal locus, proposed by Rotter and Atkinson. Atkinson (1957) proposed that causal locus must be associated with the value of goal attainment. Value was subsequently equated with affective reactions or pride in accomplishment, which was thought to be the incentive associated with goal attainment. Hence, the greater the degree to which one ascribes success to internal factors (self), the greater the sense of pride in the accomplishment.

Weiner (1979) attempted to determine other causal dimensions proposed under the concept of -entrollability." This was the outcome of studying poor strategy as a cause of failure when contrasted with a lack of effort. Controllability was considered independent of causal locus, because a cause could not be classified as internal and controllable (e.g., effort) or external and uncontrollable (e.g., aptitude). Therefore, locus 
and control, not locus of control seemed more accurate in describing causes such as ability, effort, luck, and strategy. Differential reward elicited by these two causes could be attributed to either dimension of causality.

Weiner $(1985,1986)$ eventually proposed that there are many potential affective responses to success and failure in addition to pride and shame, which were heretofore the only affects linked with achievement strivings. Weiner proposed that each causal dimension is linked with a specific (but unidentified) set of affects.

Weiner (1980) applied Kelley`s attribution model to achievement oriented behavior. Weiner's model posited that after an individual performs a task, she or he evaluates whether it was successful or unsuccessful and determines which factors might have caused of success or failure. Weiner hypothesized that attributions involved three factors: locus of control (internal versus external), stability (whether causes change over time), and controllability (whether the causes can be changed by the person). The outcomes of this attributional process produce changes in an individual's self-concept, which then are hypothesized to create changes in behavior. Weiner's model evolved and eventually moved from intrapersonal to interpersonal behavior (Weiner, 1990). Consequently, his metaphor eventually changed from the person as a scientist (conducting research) to the person as a judge (making a determination) regarding causal attribution.

Attribution theorists such as Heider, Miller, Ross, and Zajonc created constructs that became prominent in the development of attribution theory. As stated previously, two of these constructs describe common mistakes that people make in assigning attributes: - fndamental attribution error" and -self-serving bias." The fundamental 
attribution error" occurs when there is a tendency to overestimate the internal and underestimate the external factors when explaining behaviors of others. Heider (1958) would postulate that a driver who cuts someone off would be ascribed negative attributes (-idiot") without the offended person giving consideration to external factors (emergency) that might be present. Miller and Ross (1975) suggest that — sff-serving bias" occurs when we tend to equate successes to internal and failures to external attributes. For example, when Beth is promoted she assigns her success to her skills; if she is fired it is because her employer is a fool.

\section{Attribution Research}

Heider (1958) hypothesized that the underlying mechanism of attribution is to maintain self-esteem. This appears to be supported in research findings by Arkin, Appleman and Berger (1980) who conducted research in social anxiety and attribution. They found that individuals who rate high in social anxiety developed attributions designed to avoid embarrassment whereas the attributions of the subjects low in social anxiety directly enhanced self-esteem. Wyer and Frey (1982) reported that subjects ‘ responses to information regarding the validity of feedback concerning the outcome of their behavior were influenced by their desire to maintain a favorable self-image. Subjects who received negative feedback about their performance on an intelligence test disparaged intelligence tests in general. The subjects subsequently judged a report that they read about intelligence tests to be unfavorable. Thus, negative feedback was discounted by discrediting the source, thereby maintaining self-esteem. Tillman and Carver (1980) conducted research among college students regarding the implications of Kelley`s cube, self-serving bias, and attribution associated with success and failure. 
Regardless of their roles as actor or observer, subject success was attributed to internal factors whereas failure was attributed to external factors.

The findings of Wyer and Frey (1982) are also consistent with Cognitive Dissonance Theory, developed by Leon Festinger, who was also influenced by Lewin. Cognitive Dissonance Theory was the dominant research paradigm for social psychology in the 1960s (Weiner, 1990). This theory suggested that inconsistencies in individual beliefs or behaviors will cause an uncomfortable internal psychological tension, leading people to change their beliefs to fit their behavior, instead of changing their behavior to fit their beliefs. Wyer and Frey`s subjects evidently struggled to assimilate the false IQ results they were given and adjusted their beliefs to fit the testing outcome. Again, individual attributions may serve as a self-protection device.

Weiner (1980) conducted a study of causal attributions and affect regarding helpgiving behavior. The author developed a model from the data, suggesting that a temporal sequence of attribution-affect-action occurs. Subjects in the studies witnessed an individual fall down and experienced an immediate, reflexive affective reaction (startle or fear) to the event. The author presumed that subjects would decide to take action (help or avoid) by conducting a causal analysis. This entails an initial search by the subjects, attempting to determine what made the person fall. An ascription of drunkenness or illness gave rise to help or neglect responses, independent of an elaborated causal (dimensional) analysis. An elaborated causal analysis occurs consciously and/or unconsciously, and deliberately or automatically. Subjects considered the cause of the fall in terms of underlying properties, with the key dimensions in this instance being locus and control (perceived personal responsibility). Causal ascriptions appeared to 
relate weakly to health of the target but clearly to the subject's own affective reactions. Affect was strongly related to judgments of help or neglect. Thus, Weiner's model suggests that attributions of cause give rise to an affective reaction, which was the best predictor of an individual's help-giving behavior. Affect then becomes an important component in attribution theory, where cognition was once thought to be the primary mediator (Kanouse \& Hanson, 1972).

Attribution and Prejudice

Attribution theory provides a useful model to investigate biases, discrimination and perhaps prejudice against obese individuals. Dictionary.com (2009) defines discrimination as "Treatment or consideration of, or making a distinction in favor of or against, a person or thing based upon the group, class, or category to which the person or thing belongs rather than on individual merit." Prejudice is defined as "an unfavorable opinion or feeling for it before hand or without knowledge, thought or reason."

Crandall, D‘Anello, Sakalli, Lazarus, Wieczorkowska, and Feather (2001) developed an attribution-value model of prejudice. The authors studied over 900 subjects across six countries. They found that anti-fat prejudice correlated with locus of responsibility plus negative cultural values toward obesity. The researchers concluded that people are prejudiced against groups whom they feel have some negative attribute for which these individuals are held responsible. The authors consider the role of cultural values in the development of negative attributions.

Fiske, Cuddy, Glick, and Xu (2001) argue that stereotypes can be captured by two dimensions - warmth and confidence. The authors posit that subjectively positive stereotypes of warmth or confidence do not necessarily contradict prejudice, but are often 
functionally consistent with unflattering stereotypes on another dimension. Additionally, they suggest that two variables that have been long identified in inter-group relations, status and competition, predict dimensions of stereotypes. The authors conducted four studies investigating the following hypotheses: 1) perceived confidence and warmth differentiate out-group stereotypes; 2) many stereotypes include mixed ascriptions of competence and warmth, as defined by low ratings on one dimension coupled with high ratings on another; 3) stereotypes depict out-groups as competent to the extent that they are perceived as powerful and high status; and 4) stereotypes depict out-groups as relatively warm and nice to the extent that they do not compete with others.

Fiske et al. (2001) collected data from nine survey samples, which they report supported their hypotheses regarding stereotype content. The investigators utilized a variety of samples with a variety of group selection methods and their cluster analyses found evidence for the dimensional hypothesis that perceived confidence and warmth differentiate out-group stereotypes. The results also supported the mixed stereotypes hypothesis, indicating that many out-groups are viewed as confident but not warm, or not confident but warm. They also found social structural correlates of perceived warmth and confidence. For example, perceived social status predicted perceived confidence, whereas perceived competition predicted perceived lack of warmth. Finally, their fourth study addressed the emotional concomitance of different stereotype contents showing that pity, envy, contempt, and admiration differentiated the four combinations of perceived warmth and confidence. Groups that were viewed as confident but not competitive and warm were admired; out-groups that were confident but not viewed as warm evoked envy or jealousy. Out-groups that were considered warm but incompetent evoked pity or 
sympathy and groups that were considered incompetent and cold evoked feelings of disgust or contempt. It appears that the interplay between attribution and affect is supported by these findings. Attribution and specifically attribution theory appear to be at the crux of negative attitudes or bias toward the obese.

Personality and Prejudice

Psychological research has attempted to identify factors contributing to prejudice. This research highlights two primary explanations, based on either personality theory or social psychology. Personality explanation suggests that prejudice is caused by people's personality-related characteristics (e.g., Adorno, Frenkel-Brunswick, Levinson, \& Sanford, 1950; Altemeyer, 1981). The social psychology literature suggests that prejudice is the result of peoples' social group membership, social identity, social position, and situational factors (Guimond, Dambrund, Mischinov, \& Duarte, 2003). Within the personality-based model, there have been two theoretical frameworks that explain individual differences in prejudice. One line of research originates from Authoritarian Personality Theory (Adorno et al., 1950), which was later developed into the theory of Right-Wing Authoritarianism (RWA; e.g. Altemeyer, 1981, 1998). The second is Social Dominance Theory (Pratto, Sidanius, Stalworth, \& Malle, 1994; Sidanius \& Pratto, 1999) or the central individual difference variable Social Dominance Orientation (SDO). Researchers have argued whether these variables are measures of social attitudes/ beliefs or whether they belong in the personality domain.

Right-Wing Authoritarianism is a construct comprised of conventionalism, authoritarian submission, and authoritarian aggression. People who score high on a measure of RWA tend to favor traditional (conservative) values, are submissive to 
authority figures, are highly ethnocentric, and can be expected to act aggressively toward out-groups (Altemeyer, 1981, 1998). Previous research has shown that RWA is correlated negatively with openness to experience (Altemeyer, 1996; Heaven \& Bucci, 2001) and positively with conscientiousness (Heaven \& Bucci, 2001) and extroversion (Lippa \& Arad, 1999; Trapnel, 1994).

Social dominance orientation (SDO) can be seen as a general attitudinal orientation toward inter-group relations. Like RWA, SDO is a construct that is narrowly defined and could conceptually fall under some higher order, and general personality dimensions, such as the Big Five" personality theory. There have been two studies that have found SDO to be correlated negatively with Agreeableness (Heaven \& Bucci, 2001; Lippa \& Arad, 1999) and Openness to Experience (Heaven \& Bucci, 2001).

Ekehammar, Akrami, Gylje and Zakrisson (2004) state that the Five Factor model of personality is probably the most widely accepted of its kind. They suggest that the Big Five (Conscientiousness, Agreeableness, Neuroticism, Openness to Experience, and Extraversion) could be classified as core personality factors because of their substantial heritability coefficients and their early expression in temperament in human infants and other animal species (e.g., Bouchard \& Loehlin, 2001; Clark \& Watson, 1999). The authors also believe that these core factors are likely to occur causally prior to prejudice. They agree with McCrae and Costa (1996) who classified the Big Five personality as basic tendencies" positioned first in the causal chain. McCrae and Costa argue that attitudes are influenced both by basic tendencies and by contextual factors as -haracteristic adaptations." Ekehammar et al. maintain that within - learacteristic adaptations," RWA and SDO also occur prior to prejudice. This was based on their 
previous research where they found SDO and RWA mediating the effect of core personality (basic tendencies) on prejudice (Ekehammar et al., 2004).

In 2003, Ekehammar and Akrami examined the relationship of the Big Five personality factors with generalized prejudice (a composite of four types of prejudice: sexism, racism, prejudice toward the mentally disabled, and prejudice toward homosexuality). The results showed that Openness to Experience and Agreeableness displayed rather strong negative correlations with generalized prejudice. Also, in an unpublished study, McFarland (2001) reported that these two Big Five factors displayed the largest correlations with this generalized prejudice measure. Finally, Flynn (2005) found significant correlations between openness and various measures of racial prejudice.

In 2007, Ekehammar and Akrami furthered their examination of the relationship between personality and prejudice, using the Revised NEO Personality Inventory (NEO-PI-R). The NEO-PI-R contains five factor scales (Conscientiousness, Agreeableness, Neuroticism, Openness to Experience, and Extraversion) each of which contains six subscales or facets. For example, Competence, Order, Dutifulness, Achievement Striving, Self-discipline and Deliberation are facets of the Conscientiousness factor. These facets are intended to measure a discrete trait and thus contribute something over and above the five factors. Paunonen and Ashton (2001) showed that the facets add incrementally to the prediction of behaviors. These researchers chose to analyze the Big Five facets rather than factors to determine if the shift would improve the prediction of prejudice and increase the understanding of the nomological network underlying personality and prejudice. 
The authors chose this line of inquiry consequent to their empirical research and that of co-workers (Paunonen, 1998; Paunonen \& Ashton, 2001) displayed substantial benefits in using the facet rather than factor level when examining the relations of Big Five factors with various external variables. The authors suggested that this was the first study where Big Five facets were shown to be related to prejudice.

Ekehammar and Akrami (2007) reported the facets were significantly higher in power predicting prejudice than the factors. Using step-wise multiple regression analyses, the results showed that the total explained variance increased significantly when using facets rather than factors. Also, the facets, Tender-Mindedness (underlying the Agreeableness factor) and Values (underlying the Openness factor) were the most powerful single predictors of prejudice, outperforming corresponding factors as single predictors. Tender-Mindedness is defined as having attitudes of sympathy and concern for others and being moved by others' needs. Values are defined as readiness to reexamine social, political, and religious values. It might be that examining facets rather than factors reduced -signal to noise" ratio caused by other facets competing to explain accounted variance.

Ekehammar and Akrami (2007) also note that all of the Agreeableness facets (Modesty, Altruism, Trust, and Straight-Forwardness) displayed significant correlations with generalized prejudice, with the exception of the Compliance facet. Similarly, Openness to Experience facets (Fantasy, Aesthetics, Actions, and Values) displayed significant correlations with general prejudice, with the exception of the Ideas facet. Compliance was defined as unique, mild, and willing to forgive and forget; Ideas entails having intellectual curiosity and the act or pursuit of intellectual interests for their own 
sake. The researchers also found that Extraversion is a third Big Five factor that is significantly related to generalized prejudice; however, only three of the six facets contributed to the relationship. Warmth, Gregariousness and Positive emotions predicted general prejudice (in a negative direction), whereas Assertiveness, Activity, and Excitement -Seeking showed no statistically-related relations. Interestingly, the authors argued that perhaps Warmth should be included in the Agreeableness factor rather than Extraversion.

In addition to the NEO-PI- $\mathrm{R}$, the Implicit Association Test (IAT) is a second measure of prejudice which has been widely used in research. The IAT has been used to measure a variety of hidden associations, such as implicit racial and gender stereotypes, attitudes toward elderly people, and preferences for particular political candidates (Greenwald, McGhee, \& Schwartz, 1998; Nosek, Banaji, \& Greenwald, 2002). Implicit associations have even been detected in minimal group research, when people have no prior group experience yet display positive associations with in-group member names and negative associations with out-group member names (Ashburn-Nardo, Voils, \& Monteith, 2001). As with other measures of implicit stereotyping, IAT scores have also been linked to behavioral measures of discrimination. For instance, one study found that White students with pro-White IAT scores later treated a White conversation partner better than a Black conversation partner, as judged by independent raters who watched videotapes of the conversations (McConnell \& Leibold, 2001).

To date, there have only been a limited number of studies conducted that have reported data on the relationship between the Big Five personality factors and prejudice (Ekehammar \& Akrami, 2003, 2004, 2007; Saucier \& Goldberg, 1998). Ekehammar and 
Akrami (2003, 2004, \& 2007) concluded that Agreeableness and Openness to Experience are the Big Five factors most associated with generalized prejudice. According to Allport (1954) and Duckett (1992) generalized prejudice is the tendency to respond with prejudice toward any out-group. Generalized prejudice can be seen as a major motivating factor behind the development of an authoritarian personality theory (Adorno et al., 1950). Ekehammar and Akrami (2003) reported that four types of prejudice (racism, sexism, prejudice toward homosexuals, and prejudice toward people with mental disabilities) are highly correlated and form a single factor, or generalized prejudice.

\section{Summary}

The literature relevant to the present study indicates that bias and discrimination against obesity do exist (Jenks, 1998; Pagan \& Davila, 1997; Rothblum et al., 1990). Obesity bias is correlated with negative attributions regarding the causes of obesity, negative attributions concerning the characteristics of obese people, and societal disdain (Crandall, 1994; Klaczynski et al., 2004; Puhl, 2001; Teachman, et al., 2003).

Attribution theory provides a framework through which prejudice can be understood and studied. The theories of Heider, Rotter and Weiner regarding locus and control as causal links of attribution are supported by research such as that conducted by Crandall and colleagues (2001), Teachman, et al. (2003), and Tiggemann and Anesbury (2000). The ascription of personal responsibility is a critical component in the development of prejudice against the obese. Crandall et al., (2001) reported that people are prejudiced against groups whom they feel have some negative attribute for which these individuals are held responsible. 
Research using personality theory research identified two theoretical frameworks to explain individual differences in prejudice: Right-Wing Authoritarianism (RWA; e.g., Altemeyer, 1981, 1998) and Social Dominance Orientation (Pratto, Sidanius, Stalworth \& Malle, 1994; Sidanius \& Pratto, 1999). High scorers on measures of RWA and SDO favor in-group vs. out-group orientation; people who report high RWA scores also favor traditional values. Research has shown that RWA is correlated negatively with Openness to experience (Altemeyer, 1996; Heaven \& Bucci, 2001) and positively with Conscientiousness, which are two of the Big Five personality factors. Similarly, two studies have found SDO to be correlated negatively with Agreeableness (Heaven \& Bucci, 2001; Lippa \& Arad, 1999) and Openness to Experience (Heaven \& Bucci, 2001).

The study of prejudice has been undertaken from several perspectives. Researchers of Personality theory, specifically the Big Five Theory, have discovered a correlation between Agreeableness and Openness to Experience with generalized prejudice. This line of inquiry has been applied to the study of sexism, racism, prejudice toward the mentally disabled, and prejudice toward homosexuality and the elderly (Allport \& Kramer, 1946; Bierly, 1985; Hartley, 1946). Ekehammar and Akrami`s (2003) study of prejudice toward Gays/Lesbians and people with mental disabilities found that these are highly correlated to form a single factor, or as Allport suggested, $\mathrm{A}$ trait of personality."

\section{Statement of Purpose}

To date, there are no studies investigating Big Five personality traits and prejudice toward obese individuals. This study is proposed to address this gap in the literature of prejudice, obesity, and personality traits. The purpose of this study is to 
determine personality traits that differentiate individuals who are intolerant of obesity from those who are more accepting of individuals who are overweight.

\section{Assumptions}

This study does not include measurements of body fat. References to overweight (fat") individuals occur in the Anti-fat Attitudes Questionnaire items, and pictures of overweight individuals will be presented within the Implicit Association Test. Therefore, an operational definition of obesity, such as the CDC guidelines, does not seem prudent. Participants will be presented with images of people (IAT) who are obviously overweight. The AAQ items refer to people who are obese or overweight as - $\mathrm{ft} . "$ However, this study does not focus on the measurement or severity of obesity. Therefore, for the purposes of the study, obesity will be defined as excessive body weight.

\section{Constructs}

1. Personality-the Big Five factors and their constituent traits can be summarized as follows (Costa \& McCrae, 1992):

- Openness: appreciation for art, emotion, adventure, unusual ideas, curiosity and variety of experience.

- Conscientiousness: a tendency to show self-discipline, act beautifully, and aim for achievement; planned rather than spontaneous behavior.

- Extraversion: energy, positive emotions, surgency and the tendency to seek stimulation and the company of others.

- Agreeableness: a tendency to be compassionate and cooperative rather than suspicious and antagonistic towards others. 
- Neuroticism: a tendency to experience unpleasant emotions easily, such as anger, anxiety, depression, or vulnerability; sometimes called emotional instability.

2. Anti-fat Attitudes: prejudice, bias or discrimination of an individual based on the individual's excessive body fat.

\section{Constructs as Variables}

Personality will be used as an independent variable which will be measured on an interval scale, by a T-score. Anti-fat attitudes will be dependent variables measured in two distinct ways. One will be an ordinal measure (Likert scale) and the other an interval measure (differences in reaction time).

Operational definitions. Personality (the construct) will be defined by using the NEO $-\mathrm{PI}-\mathrm{R}$ (Costa \& McCrae, 1992). T-scores generated by the scales (C., A., O., N., E.) will provide interval measures of personality traits. T-scores greater than 65 will be considered to indicate the presence of clinically significant levels of the personality trait(s). However, for the purposes of this study, all T-scores will be included and analyzed as continuous variables.

Anti-fat attitudes (the construct) will be measured using the Anti-fat Attitude Questionnaire (AAQ; Crandall, 1994) and the Implicit Association Test (IAT; Greenwald, McGhee, \& Schwartz, 1998). The AAQ consists of 13 items incorporating a five-point Likert scale. As the item scores increase, anti-fat bias will increase. Higher scores on the AAQ represent greater degrees of anti-fat bias.

The IAT is a computerized, performance-based procedure that uses response latencies to assess the strength of association between a pair of concepts (e.g., thin and 
fat) and a pair of attributes (e.g., good and bad). The difference in average response latencies for categorizing items between these two sets of trials provides an index of the strength of association between the concepts and the attributes, referred to as a $D$ score. Greenwald, Nosek and Banaji (2003) developed a scoring procedure to compute $D$ scores, using an algorithm. A description of the steps needed to compute a $D$ score using this algorithm is located in Appendix (A). Again, greater reaction times or scores reflect greater levels of bias. 


\section{Chapter 2: Review of the Literature}

This chapter is divided into five sections. The first section addresses obesity, weight dissatisfaction, and depression. The following section reviews the literature regarding the stigmatization of obesity. Next is a discussion of cultural differences regarding bias toward individuals who are obese. The fourth section contains an overview of the topic of discrimination toward obese people. The final section provides an overview of research findings regarding prejudice, including attribution theory, emotion and prejudice, and personality theory.

Glancing at the magazine rack at any checkout counter, the average consumer is made aware of the growing number of magazines and articles devoted to weight loss. The weight loss industry in the United States is booming. Americans spent $1,000 \%$ more on weight loss-related materials in 2000 than in 1960 (Bloch, 2003). Although fitness is commendable, Americans appear to be obsessed with weight loss and more specifically, thinness and most certainly with body fat. Not surprisingly, it appears that the national fixation on weight loss occurs at a time when the rate of obesity is increasing. The Center for Disease Control (2008) notes that our current rate of obesity is $32 \%$ for adults, ages 20 and older, leveling off but at an all-time high.

\section{Classification}

Obesity is a condition in which excess body fat has accumulated to the extent that health may be negatively affected (World Health Organization, 2000). In absolute terms, obesity is an increase of body adipose mass. However, the most common clinical methods used to estimate obesity are body mass index (BMI) in terms of its distribution 
via the waist to hip ratio (Sweeting, 2007). Obesity is currently defined as a Body Mass Index greater than 30 (World Health Organization, 2008; CDC, 2008).

A third means of classifying obesity is body fat percentage. Body fat percentage represents the total body fat expressed as a percentage of total body weight. It is generally agreed that men with more than $25 \%$ body fat and women with more than $33 \%$ body fat are obese (Schwarz, 2007). Direct attempts to determine body fat are often expensive and difficult. One of the most accurate methods is to weigh a person underwater, which is known as hydrostatic weighing. Two other simpler and less accurate methods for measuring body fat are therefore more widely used. The first is the skin fold test, in which a patch of skin is precisely measured to determine the thickness of the subcutaneous fat layer. However, this has not adequately been evaluated in obese subjects (Kopelman, Caterson, Stock, \& Dietz, 2005). The second measure is bioelectrical impedance analysis, which uses electrical resistance. Bioelectrical impedance, however, has not been shown to prove an advantage over BMI. Therefore, the routine use of these tests is discouraged (National Institute for Health and Clinical Excellence, 2006).

\section{Effects on Health}

Contemporary health and wellness research has implicated obesity in a variety of health problems. Davis (2003) indicates that the following conditions are co-morbid with obesity: cardiovascular, hepatic, orthopedic, neurological, endocrine diseases, and very significant psychosocial complications. Consequently, obesity has been found to lower life expectancy (Haslam, 2005). 
Obesity is one of the leading preventable causes of death worldwide (Barness, Opitz, \& Gilbert-Barness, 2007; Mokdad, Stroup, \& Gerberding, 2004; Allison, Fontaine, Manson, Stevens \& Vitallie, 1999). Large-scale American and European studies have found that mortality varies with BMI; the lowest risk is found at a BMI of $22.5-25 \mathrm{~kg} / \mathrm{m}$ (Calle, Thun, Petrelli, Rodriquez, \& Heath, 1999). Obesity increases the risk of death in current and former smokers, as well as in those who never smoked (Manson, Willett \& Stampfer, 1995). A BMI of over 32 has been associated with a doubled mortality rate among women over a 16 year period (Peeters, Barendregt, Willekens, Mackenbach, Al Mamun \& Bonneux, 2003) and obesity is expected to cause an excess of $111,000-$ 350,000 deaths per year in the United States (Allison, Fontaine, Manson, Stevens \& Van Itallie, 1999). Obesity on average reduces life expectancy by six to seven years (Grundy, 2004).

In terms of morbidity, a number of physical and mental conditions have been associated with obesity. This cluster of conditions is commonly reflected in the metabolic syndrome (National Institute for Health and Clinical Excellence, 2006). Metabolic syndrome is a combination of medical disorders, which includes diabetes mellitus type II, high blood pressure, high cholesterol and high triglyceride levels (Bray, 2004). Obesity is also related to other complications. Some of these are directly caused by obesity and others are indirectly related through mechanisms sharing a common cause such as poor diet and sedentary lifestyles.

\section{Causes of obesity}

Individually, most cases of obesity are thought to be explained by a combination of excessive caloric intake, lack of physical exercise, and genetic susceptibility, with a 
smaller number of cases due solely to genetics, medical reasons or psychiatric illness (Bleich, Cutler, Murray, \& Adams, 2008). On a societal level, increasing rates of obesity are believed to be due to an easily accessible diet (Pool, 2001), car culture and mechanized manufacturing (Nestle, 2000).

Diet. The widespread availability of nutritional guidelines (Flegal, Carroll, Ogden, \& Johnson, 2002) did little to address the problems of overeating and poor dietary choices (Wright, Kennedy-Stephenson, Wang, McDowell, \& Johnson, 2004). In the period of $1971-2000$, obesity rates in the United States increased from $14.5 \%$ to $30.9 \%$ (Caballero, 2007). During the same time period, an increase occurred in the average amount of calories consumed. For women, the average increase was 335 calories per day (1542 calories in 1971 and 1877 calories in 2004) while for men the average increase was 168 calories per day (2450 calories in 1971 and 2618 calories in 2004). Most of these extra calories came from an increase in carbohydrate consumption rather than an increase in fat consumption (Malik, Schulze \& Hu, 2006). The primary sources of these extra carbohydrates are sweetened beverages, which accounted for almost $25 \%$ of daily calories in young adults in America (Olsen \& Heitman, 2009). Consumption of sweetened drinks is believed to be contributing to the rising rates of obesity (Rosenheck, 2008).

Agricultural policy and techniques in the United States and Europe have led to lower food prices. In the United States, subsidization of corn, soy, wheat and rice through The U.S. Farm Bill has made the main source of processed food cheap compared to fruits and vegetables (mdPassport, 2008). As societies become increasingly reliant on energy-dense, large portion, fast-food meals, the association between fast food 
consumption and obesity becomes more concerning (Lin, Guthrie, \& Frazao, 1999). In the United States consumption of fast food meals has tripled and calorie intake from fast food has quadrupled between 1977 and 1995 (Pollan, 2007).

Sedentary lifestyle. A sedentary lifestyle plays a significant role in obesity (Kopelman, Caterson, Stock, \& Dietz, 2005). Worldwide there has been a large shift toward less physically demanding work (Ness-Abramof \& Apovian, 2006) and currently at least $60 \%$ of the world's population does not get sufficient exercise (Borodulin, Laatikainen, Joulevi \& Jousilahti, 2008). This is primarily due to increasing use of mechanized transportation and greater prevalence of labor saving technology in the home (Ness-Abramof \& Apovian, 2006). World trends and active leisure time physical activity are controversial. The World Health Organization (2008) indicates that worldwide people are taking up less active recreational pursuits. Yet, a study from Finland (Brownson, Boehmer, \& Luke, 2005) found an increase in activity, while a study from the United States found leisure time physical activity has not changed significantly (Gortmaker, Must, Sobol, Peterson, Colditz \& Dietz, 1996).

Studies in children and adults have found an association between the number of hours of television watched and the prevalence of obesity (Tucker \& Bagwell, 1991; Vioque, Torres, \& Quiles, J. 2000). A 2008 meta-analysis found that 63 of 73 studies $(86 \%)$ showed an increased rate of childhood obesity with increased media exposure, and rates increasing proportionally to time spent watching television (Newsletter, 2000).

Genetics. The percentage of obesity that can be attributed to genetics varies from $6 \%$ to $85 \%$ depending on the population examined (Chakravarthy \& Booth, 2004). The thrifty gene hypothesis (Farooqi \& O`Rahilly, 2006) postulates that certain ethnic groups 
may be more prone to obesity in an equivalent environment. Their ability to take advantage of rare periods of abundance by storing energy as fat would be advantageous during times of varying food availability, and individuals with greater adipose reserves would be more likely to survive famine.

Obesity is also a major feature in a number of rare genetic conditions: PraderWilli syndrome, Bardet-Biedl syndrome, MOMO (Macrosomia, Obesity, Macrocephaly and Ocular) syndrome, leptin receptor mutations, congenital leptin deficiency, and melanocortin receptor mutations (MC4R). Leptin (Greek leptos meaning thin) is a 16 $\mathrm{kDa}$ protein hormone that plays a key role in regulating energy intake and energy expenditure, including appetite and metabolism. Melanocortin receptors are members of the rhodopsin family of 7-transmembrane, G- protein coupled receptors. Defects in MC4R are a cause of autosomal dominant obesity. In people with early-onset severe obesity (defined by an onset before ten years of age and body mass index over three standard deviations above normal), $7 \%$ harbor a single locus mutation; an alteration of an allele in a specific location of the individual's DNA chain (Rosen, Bosaeus, Tolli, Lindstedt \& Bengtsson, 1993).

There is little evidence to support the commonly expressed view that some obese people eat little yet gain weight due to a slow metabolism. On average, obese people have greater energy expenditure than thin people. This is because it takes more energy to maintain an increased body mass (Choi, Atkinson, Karlson \& Curhan, 2005). Obese people also under-report how much food they consume compared to those of normal weight (Kopelman, Caterson, Stock, \& Dietz, 2005). 


\section{Public Health}

The prevalence of obesity increased to the extent that in 1997, the World Health Organization formally recognized obesity as a global epidemic (Caballero, 2007). The World Health Organization predicts overweight and obesity may soon replace more traditional public health concerns, such as under-nutrition and infectious diseases as the most significant cause of poor health (Loscalzo, Fauci, Braunwald, Dennis, Houser \& Longo, 2008). Obesity is a public health and policy problem because of its prevalence, costs and health effects (Satcher, 2001).

\section{Management}

Diet and exercise. The main treatment for obesity consists of dieting and physical exercise. Diet programs may produce weight loss over the short term (Shick, Wing, Klem, McQuire, Hill \& Seagal, 1998) but keeping this weight off can be a problem and often requires making exercise and a lower calorie diet a permanent part of a person's lifestyle (Tate, Jeffrey, Sherwood,\& Wing, 2007). Success rates of long-term weight loss maintenance are low and range from 2-20\% (Weiss, Galuska, Kettel, Gillespie, \& Serdula, 2007). In a more structured setting, however, $67 \%$ of people who lost greater than $10 \%$ of their body mass maintained or continued to lose weight one year later (Anderson, Konz, Frederich \& Wood, 2001). An average maintained weight loss of more than $3 \mathrm{~kg}$ or $3 \%$ of total body mass could be sustained for five years (Williamson, Pamuk, Thun, Flanders, Byers \& Heath, 1995).

Medication. Two anti-obesity medications are currently approved by the FDA for long-term use (CBC, 2007). Orlistat, which reduces intestinal fat absorption by 
inhibiting pancreatic lipase and sibutramine acts in the brain to inhibit deactivation of neurotransmitters norepinephrine, serotonin and dopamine, possibly decreasing appetite.

Surgery. The most effective, but also most risky treatment for obesity is bariatric surgery. Bariatric surgery is the use of surgical interventions to treat obesity. Due to potential complications, bariatric surgery is only recommended for individuals determined to be severely obese (BMI $>40$ ) who have failed to lose weight with dietary modification and pharmacological treatment. The most common procedures entail reducing the volume of the stomach (adjustable gastric bands), thus producing a quicker sensation of satiation; and reducing the length of bowel (gastric bypass surgery) that food will be in contact with; thereby reducing absorption. Band procedures are reversible, whereas bowel shortening procedures are not.

Complications from weight loss surgery are frequent. A study of insurance claims of 2,522 individuals who had undergone bariatric surgery showed $21.9 \%$ had complications during the initial hospital stay and a total of $40 \%$ risk of complications in the subsequent six months. This was more common in those over the age of 40 and led to increased health care expenditures. Common problems were gastric dumping syndrome in about 20\% (bloatedness and diarrhea after eating, necessitating small meals or medication), leaks at the surgical site (12\%), incisional hernia (7\%), infections $(6 \%)$ and pneumonia (4\%). Mortality was $0.2 \%$ (Gabriel, 2006).

In addition to the aforementioned medical concerns, there are several psychosocial issues that may be in some ways more damaging to obese individuals. An overview of these issues will be addressed in the following sections. Obesity, Depression, and Weight Dissatisfaction 
Mustillo (2003) studied depression and childhood obesity. Although the author could not definitively demonstrate causality, it was posited that a biological link between obesity and depression existed among children. Lawson (2003) conducted a study of preadolescent children and determined that the longer the child was overweight, the more prone he or she was to develop depressive disorders. It may be that obesity is co-morbid with depression, in terms of genetic predisposition. The possibility exists that obese people become depressed because of their physical limitations, co-existing health concerns, and/or prejudices they experience because they are overweight.

Depression is not linked only to obesity, but to overeating as well. TanofskyKraff and colleagues (2004) conducted a study measuring depression in adolescents who were also binging. The researchers found that $45 \%$ of the females in their study and $16 \%$ of the males (both groups between the ages of 13 and 14) reported a history of binge eating. The presence of binge eating was directly linked to subject reports of experiencing depressive symptoms. Mills and Andrianopoulos (1993) found that individuals who experienced early onset childhood obesity demonstrated a greater frequency of psychiatric symptoms and higher degrees of psychological distress and symptomatology than did subjects who developed obesity during adolescence or adulthood. These findings supported the belief that childhood obesity is characteristically associated with greater levels of internal conflict and symptomatology, which continues to exacerbate and later manifest itself in adult psychopathology. As was discussed previously, these conditions were noted as co-morbid, although causality was not purported and the questions of why weight in and of itself would cause an individual to be more depressed was not addressed. 
Mills and Andrianopoulos propose a link between obesity and psychopathology and that this could begin in childhood, and continue into adulthood. Some of the covariance between depression and obesity could be explained by the individual's perception of self and the resulting discord with society's current penchant for thinness. Thelen, Powell, Lawrence and Kuhnert (1992) studied 2nd-, 4th-, and 6th- grade, nonobese girls and boys. It was determined that there is an increasing concern of being or becoming overweight, and concerns about eating food, history of more dieting, and greater desire for thinness, as age increased. Fourth and Sixth grade girls reported more concern and dissatisfaction with becoming overweight than 2 nd- grade girls. There were no gender differences among 2nd-graders. Dissatisfaction and concern of becoming overweight increased significantly for girls in the $6^{\text {th }}$ versus the $2^{\text {nd }}$ grade. There were no differences noted across male students. This study suggests that girls in these age groups are more concerned about food, dieting, and being overweight than boys, and their concern evidently increased with age.

Similarly, Kostanski, Fisher, and Gullone (2004) noted that body image dissatisfaction changed significantly across age, gender, and body weight groups. The researchers determined that although dissatisfaction was present in both children and adolescents, dissatisfaction with body weight increased significantly with age in both sexes. Not surprisingly, underweight children were the most satisfied, whereas overweight children were the least satisfied with their weight. There was a curious finding among the young males. Overweight males wanted to be thinner whereas thinner ones wanted to gain weight. The researchers speculated that body image dysmorphism 
existed where there is a concern among young males about being too thin, which may cause them to feel inadequate or inferior because of their smaller size.

Sorbara and Geliebter (2002) studied body image disturbance as a composite of distortion, discrepancy, and dissatisfaction. These factors were related to gender, binge eating, race, and onset of obesity. The authors noted that there was greater body image disturbance among Caucasians than African Americans or Hispanics, for both males and females. For Caucasians, body image disturbance was due mainly to distortion by overestimating body size and to more dissatisfaction. The authors speculated that Caucasians felt more pressure from society to be thin. Males overestimated body size (distortion) more than females, but suffered less dissatisfaction, perhaps because they were more accepting of their appearance. The authors found that Caucasians were more likely to be binge eaters and develop early onset obesity than African Americans or Hispanics.

Sorbara and Geliebter (2002) speculated that body dissatisfaction might result more from the perceived discrepancy from ideal body size than from distortion of body image. They reported that disturbance was more related to distortion, than to discrepancy, and only lastly to dissatisfaction. They posited that dissatisfaction was not synonymous with disturbance and that it may be more related to discrepancy from the ideal than distortion of body image. If so, then dissatisfaction may be the result of attempting to achieve an unreachable, socially generated standard.

\section{Obesity among College Students}

Obesity is problematic within the general population, and as these studies suggest, a growing problem among college students as well. The American College Health 
Association (2006) reported that nearly one out of every 10 United States college students is obese and $21.9 \%$ is overweight. Attending college is an opportunity for young adults to explore their independence, personal growth and decision-making. It is also a time for managing increased stress levels, separation from family and the lack of guidance regarding accessibility of copious amounts of high caloric food. "The freshman $15 "$ is cliché, but reflects the tendency for college freshmen to gain approximately 15 pounds during their first year of college. Researchers are finding that the number of overweight college students is increasing, along with associated health problems. According to researchers at the University of New Hampshire (Science Daily, 2007), one third of the 800 undergraduate students enrolled in a general education nutrition course were overweight or obese. Sixty percent of the male students had high blood pressure and $8 \%$ of the males suffered from metabolic syndrome (high blood pressure, insulin resistance and cholesterol abnormalities).

Levitsky, Halbmaier and Mrdjenovic (2004) conducted a study regarding college freshman weight gain, a.k.a. "the freshman 15;" sixty students were included in the study. They were weighed at the beginning of the semester and again, 12 weeks later. They also completed a questionnaire concerning their lifestyle factors (exercise, sleep, eating habits) during the previous 12 weeks. The mean weight change of $1.9 \mathrm{~kg}(4.2 \mathrm{lbs}) \pm$. during that time was significant. The authors reported that weight change was also considerably greater than that observed in the general population. Two regression models were conducted to explain variance in weight gain. The first model accounted for $58 \%$ of the total variance; the two variables that best accounted for weight gain included 
consumption of evening snacks and consumption of high-fat foods, each accounting for $12 \%$ of the variance.

The second regression model included initial weight as a covariate. The authors found that this model accounted for a greater percentage of the total variance, $71 \%$. In this model, consumption of junk foods accounted for $24 \%$ of the variance, and was the best predictor of weight gain. The next best predictor was recent dieting, which accounted for $9 \%$ of the variance.

Pargman (1969) conducted one of the first studies to determine the prevalence of obesity among college students. The author reviewed participants health records to make a determination of the presence of obesity. The identification of obesity was made through the use of height and weight tables. Females who exceeded the upper limits of their appropriate weight range (according to their height) by $25 \%$ or more were considered to be obese. Males were considered obese if they exceeded their appropriate weight range by $20 \%$ or more. Pargman found that $2.25 \%$ of the 2343 participants were obese. More males (42), than females (12) were considered obese. However, the author noted that some of the males might have been misclassified as obese (rather than muscular) due to the use of height and weight charts, a clear limitation of this study.

Adderley-Kelly (2007) conducted a study of undergraduate female health sciences students, in order to measure the prevalence of obesity. A BMI greater than 25 defined being overweight, while a BMI of greater than 30 defined obesity in this study. The author utilized a convenience sample. Eligibility requirements included students enrolled in a college health science program; the participants in good health, and not taking weight affecting medication. The population was predominantly African-American. Adderley- 
Kelly found that over $40 \%$ of the sample was overweight (24.8\%) or obese (18.4\%). The researchers noted that the percentage of male participants was very small (13\%), and that obesity occurred at a much higher rate in females (45\%) than males (11\%). Relatively similar numbers were obtained by Carroll, Lee, Kaur, Harris, Strother and Huang (2006). These authors also investigated the relationship between smoking and weight loss strategies among college students, and found that $29 \%$ of the 300 participants were overweight (BMI > 25).

Nelson, Gortmaker, Subramanian, Cheung and Wechsler (2007) conducted the first study of obesity among college students that reported to have included a nationally representative sample in the United States. The researchers were interested in obtaining data regarding prevalence, trends, and social disparity in obesity, within this population. Their data was obtained from the Harvard School of Public Health (HSPH) College Alcohol Study (CAS), a nationally representative sample of students attending four-year colleges in the United States. The sample included 119 colleges that obtained CAS data samples in 1993 and 1999. The data included participant height and weight, both of which were considered to be reliable measures. Body mass indices were calculated from the available reported heights and weights.

Nelson et al. (2007) reported that the number of students classified as overweight (in a study of 24,613 participants) increased from 1993 (21.6\%) to 1999 (26.8\%). They found that obesity, overweight, and class II obesity (BMI > 35) all increased significantly from 1993 to 1999, but rates differed by gender, race/ethnicity, socio-economic position and years in school. Males were significantly more likely to be overweight and obese. Compared to whites, African-American and Hispanic males were more likely to be 
overweight; Asian males were less likely to be overweight. Students of lower SEP (socio-economic position) had higher rates of overweight. African-American females were significantly overweight, compared to their white counterparts . However, this was not the case for Hispanic females. Additionally, significantly higher rates of overweight and obesity occurred among college students in their junior or senior years.

\section{Stigmatization of Obesity}

Literature supports the position that obese individuals experience a variety of negative stereotypes regarding weightism" or fatism." Goffman (1963) and Allon (1982) wrote of the stigmatization of people who are obese in the United States. Goffman (1963) wrote that people consider obesity to be an abomination of the body and this was one of three types of stigmatizing conditions (including tribal stigmas; i.e. race and religion, and blemishes of individual character; i.e., weak-willed, dishonesty).

Previously, abomination of the body heretofore included physical handicaps and disfiguring conditions. Allon (1982) described obesity as being most debilitating because it is easily visible whereas religious membership, sexual orientation, and substance abuse are more easily concealed. Prose (2003) wrote, Stigmatized because their addiction to food is so visible and its consequences, the obese find themselves ridiculed, rejected and repulsed by many of those who do not over-indulge" (p. v). Thus, there is no escape from societal judgment for obese individuals. Yu and Bowers (2000) reported that as recently as February 1999, San Francisco created a law making it illegal to discriminate in employment, housing, and public-access theaters based on height or weight. The authors posited fat hatred is the last acceptable prejudice" (p. 101). 
What are the stereotyped qualities of obese people? Teachman and colleagues (2003) wrote that average weight and obese people reported similar levels of dislike for obese individuals. They found that there was no protective in-group bias" when obese subjects gave their feedback regarding other obese individuals. Being overweight was deemed blameworthy by the subjects. The authors also noted a bias existed toward antifat/pro-thin, lazy versus motivated, stupid versus smart, and worthless versus valuable. Obese individuals were labeled with the negative adjectives whereas thin people were viewed in a much more positive light. Crandall's (1994) study of obesity and prejudice purports that if obesity is believed to be volitional, then people denigrate and stigmatize obese people. However, Crandall's study was conducted with an eye toward stereotypes of obese African Americans. The author found that there are similar stereotypes for both African American and obese individuals; mainly that they are tazy, sinful, lacking discipline and self-denial" (p. 885).

Perez-Lopez, Lewis, and Cash (2001) measured anti-fat attitudes versus other prejudicial and gender-related attitudes. The authors were interested in determining attitudes toward obesity versus sexism, racism, and homophobia in gender-related attitudes. They found that the combination of demographic and attitudinal variables predicted anti-fat attitudes. Anti-fat attitudes were stronger for Caucasian males and gender-typed individuals compared to women, African Americans, and androgynous individuals, respectively. The researchers controlled for demographics, weight-related variables, and social desirability. They found that gender-role egalitarianism, homophobia, and racism significantly correlated with anti-fat attitudes. It may be that the participants of the Perez-Lopez, et al. study corroborated Goffman's (1963) stigmatizing 
conditions (tribal stigmas, abomination of the body, and blemishes of individual character). These results suggest that obese subjects were categorized together with some of the most -utcast" groups in our society.

Schwartz, Vartanian, Nosek, and Brownell (2006) investigated the influence of one's own body weight on implicit and explicit anti-fat bias. The authors measured implicit and explicit anti-fat attitudes and obese stereotypes among an online sample of 4283 individuals. The subjects were thought to be representative across the weight spectrum, from underweight to morbidly obese. The mean BMI was 29 (range, 11 to 88); $3 \%$ were underweight $(\mathrm{BMI}<18.5), 41 \%$ were normal weight (BMI, 18.5 to 24.9$), 21 \%$ were overweight (BMI, 25.0 to 29.9), 21\% were obese (BMI, 30.0 to 39.9), and 14\% were extremely obese $(\mathrm{BMI} \geq 40.0)$. The respondents also indicated their willingness to make a range of personal sacrifices in exchange for not being obese.

Because of reports of attitudes being vulnerable to response bias, social desirability concerns, and other demand characteristics, researchers often assess implicit attitudes using performance-based measures such as the Implicit Association Test. Implicit attitudes are thought to reflect evaluations that people are either unwilling or unable to report, either because of self-presentation concerns or because they are unaware of their biases. Therefore, Schwartz et al. (2006) assessed implicit attitudes and stereotypes using the IAT; all respondents first completed an IAT measuring obesity bias and one of two versions of an obesity stereotype IAT. The first measure provided stimuli including representations of fat people (fat, overweight, and large) and thin people (slim, thin, and skinny) and these were paired with the attributes, such as good (wonderful, joyful, and excellent) and bad (terrible, nasty, and horrible). Test-retest reliabilities of the 
IAT average about $\mathrm{r}=.60$ (Greenwald, Banaji, Rudman, Farnham, Nosek, \& Mellott, 2002) and IAT measures evidence high internal consistency (Cronbach`s alpha about equal to .80 and often higher; Greenwald \& Nosek, 2001). Nosek, Greenwald, and Banaji, (2007) conducted a review of 103 studies that utilized the IAT. They found an average $r=.27$ for prediction of a wide collection of behavioral, judgment and physiological measures by IAT measures.

The obesity stereotype pairings included the attributes of laziness (lazy, slow, and sluggish) and motivation (motivated, determined, and eager). The alternative version of the stereotype IAT included non-stereotypic attitudes: anxious, tense, and nervous. The authors (Schwartz et al., 2006) postulated that the two IATs were designed to reveal whether lazy stereotypes about obese individuals were purely evaluative or whether they were specifically associated with a quality of laziness (Nosek, Greenwald, \& Banaji, et al., 2007).

The authors (Schwartz et al., 2006) found that all of the weight groups studied exhibited significant anti-fat bias and that there was an inverse relationship between individual weight and the level of observed bias. Thinner people were more likely to automatically associate negative attributes (bad, lazy) with fat people, to prefer thin people to fat people, and to explicitly describe people who were fat as lazy as and less motivated than thin people. However, when the lazy stereotype was contrasted with another negative attribute (anxiety), obese and non-obese people exhibited equally strong implicit stereotyping. When examined with the results of the attitude IAT, the authors suggest that group membership might influence liking of a group, but not necessarily stereotypes or beliefs about the group. 
Schwartz et al., (2006) also found a substantial proportion of the respondents indicated a willingness to endure aversive life events in order to avoid being obese. Of the total sample, $46 \%$ indicated that they would give up one year of life rather than being obese and 30\% reported that they would rather be divorced than obese. In each case, thinner people were more willing to sacrifice aspects of their health or life circumstances than were heavier people. Perhaps having experienced the negative effects of their weight, overweight and obese individuals may be in a better position to consider the types of hypothetical trade-offs among the scenarios that were presented in the study.

Cossrow, Jeffrey and McGuire (2001) studied weight stigmatization and found that participants reported the experience of being treated differently or poorly due to their weight. They also reported being teased, harassed, insulted, judged negatively, or insulted with slurs and perceived discrimination in interactions. A point that is noteworthy is that the subjects of the study felt that this occurred at home, among friends, with strangers, and in the work setting. Female subjects reported feeling stigmatized more than male subjects.

Spake (2004) reported that average-weight children not only chose obese peers last as playmates, but they would choose children with physical deformities and missing limbs as playmates before obese children. (Although the physical deformities may not have been considered severe by some, this writer suspect that missing limbs would be somewhat upsetting to most children.) That they would choose obese children last speaks to the avoidance response that Americans have for overweight individuals.

Kunz (1999) studied the perceived stigma of being overweight and eating/socially disordered behaviors for her dissertation. The author determined that perceived stigmas 
associated with being overweight were positively related to weight problems and reported eating and socially disordered behavior. After studying female subjects, Kunz concluded that if a woman internalized the stigma of being overweight, the likelihood of weight problems and weight-disordered behavior increased.

It seems weight alone is not the issue; how one feels and thinks about weight plays a significant role in the development of weight-related problems. Quinn (1999), and Quinn and Crocker (1999) examined the stigma of being overweight in relation to an individual's identification with the so-called Protestant work ethic. Subjects who felt that If one works hard, one succeeds," "People get what they deserve in life;" "Work is valued over laziness", and so on, reported a negative attitude toward obesity. Endorsing the Protestant work ethic related to decreased psychological well-being in those subjects who perceive themselves as overweight. This seems to be consistent with attribution theory and the findings of the Teachman et al. (2003) study. In their study, overweight people were blameworthy and seen as stupid, lazy, and worthless. These characteristics are the antithesis of the Protestant work ethic. Therefore, it seems reasonable that overweight individuals who accept this work ethic would experience cognitive dissonance and decreased psychological well-being (Teachman et al., 2003).

If obese individuals in fact experience bias and stigma, is the issue definitively related to their weight/appearance? Is there a covariate that occurs with obesity that would explain why these individuals report the aforementioned experiences? If so, then weight loss alone should not improve their daily functioning. However, Herpertz, Kielmann, Wolf, Langkafel, Senf, and Hebebrand (2003) conducted a literature review concerning psychosocial functioning after surgery to treat obesity. The researchers found 
that mental health and psychosocial status, including social relations and employment opportunities, improved for the majority of people after undergoing bariatric surgery. Subjects also reported an improvement in general quality of life. Additionally, psychiatric disorders and psychopathologic symptoms decreased, post-surgery. Perhaps being obese and internalizing societal opinions about what it means to be obese is what causes decline in functioning among obese people.

Thus far, this researcher has examined the day-to-day biases experienced by obese people in their relationships with friends, family, loved ones, and co-workers. Although it appears that these stigmas are widespread, certainly one might expect that mental health practitioners would not harbor these same prejudices or biases. Unfortunately, research shows that this is not the case. Davis (1998) studied fat bias among psychologists and its impact on clinical judgment and treatment planning. The author found that the client's weight significantly influenced the participants' provisional diagnosis, treatment goals, estimation of client effort, and predicted prognosis. The psychologists who participated generally voiced more negative views of overweight clients. This study was conducted with members of the American Psychological Association (APA) who completed questionnaires using the same client throughout. The client included in the packets containing the questionnaires was changed to appear either fat or non-fat. Rothblum et al. (1990) delved into the issue of client obesity and gender on therapy judgment among psychologists. Like Herpertz et al (2003) it was determined that psychologists who practice therapy are negatively influenced by client weight, to some degree. Psychologists tended to rate obese clients as more negative in appearance and more embarrassed, in comparison to case presentations where non-obese clients were 
depicted. The psychologists also rated obese clients softer and kinder than non-obese clients. However, there were no significant differences in the treatment of the client, regardless of weight. This study seems to reflect the participating psychologists ${ }^{6}$ discomfort toward obesity. Yet, they seemed capable of preventing weightism from affecting their treatment of the client.

Hassel, Amici, and Thurston (2001) studied client weight in relation to biases in clinical judgment of mental health professionals. The researchers included Christian and non-Christian mental health workers, who had not previously been studied as distinct groups. Overall, mental health workers ascribed more pathology and negative attributes to obese versus normal weight clients. Interestingly, there was no significant difference in views between Christian and non-Christian mental health workers.

Touster (2000) wrote that psychologists not only held biases against weightism, but that they are complicit in maintaining negative attitudes toward the obese. The author claims that overweight people are under-represented, compared to the U.S. population, in the Psychology of Women and Introductory Psychology textbooks. Touster believes that psychologists have perpetuated negative attitudes about obesity, by their omission of pictures of overweight women in their texts.

The studies reviewed provide an overview regarding stigmatization of obese people in the United States. This review of the literature demonstrates that obesity in and of itself is not the only issue; societal perceptions about the condition also causes problems for overweight people. It seems reasonable to assume the perception" of obesity is based primarily upon visual information. Pierce and Wardle (1996) studied body size, parental appraisal, and self-esteem in blind children, ages 9-11. The authors 
found that the children possessed positive views of self-presentation with no differences across weight or gender. However, lower self-esteem emerged in children who thought that they were judged by their parents as being too thin. Conversely, being fat, being appraised as fat, or believing that they are thought of as fat by their parents showed no effects on self-esteem. (The authors hypothesized that there may be an innate desire or possible need for a more robust stature, bigger presence or feeling of weight among blind children, that superseded any acquired negative attitudes toward being fat). The children may have viewed weight positively because it gave them a greater sense of strength or power in their non-seeing world. One could also postulate that weight or obesity was not an issue of self-esteem because the children could not make comparative judgments about this condition, based on sight. It could be that the visual stimulus of obesity or thinness plays a part in stigmatization.

\section{Cultural Differences Regarding Obesity}

Weightism or fatism is undoubtedly present in America. However, research suggests gender and ethnicity affect bias of obesity or weightism. Hebl and Heatherton (1998) studied obesity stigma among Black and White undergraduate women. These subjects were asked to rate photographs of Black and White females depicted as thin, average weight, or large. White females rated large women, especially White women, lower on attractiveness, intelligence, job success, relationship success, happiness, and popularity. Greenburg and LaPorte (1996) found that Caucasian males preferred thinner female subjects as compared to African-American men. Certainly, one can surmise that part of the pressure that Euro-American women feel to lose weight is related to EuroAmerican male preference for thinness. Similarly, Olby (2003) found that whereas 
Caucasian and Hispanic subjects (male and female) preferred smaller-framed women, African-American subjects did not find smaller women to be as attractive.

However, Black women did not display the same denigration of large women as their Caucasian and Hispanic counterparts, especially when rating other Black women (Olby, 2003). The results demonstrated a significant difference in Black versus White role models, weight salience, and subculture beliefs about obesity. Black subjects evidently did not identify with mainstream beliefs about obesity.

Miller and Downey (1999) conducted a meta-analysis of studies conducted on self-esteem and being overweight among obese males and females. Being overweight was negatively correlated with self-esteem. Effect sizes were larger for studies based on self-perceived weight in comparison to studies where actual weight was utilized. Effect sizes were also larger for women $(46.38, p<.001)$ than for men $(15.38, p<.001)$. The authors hypothesized that being overweight was a greater psychological burden for women.

Not surprisingly, being overweight and self-esteem issues were less highly correlated in a minority sample, in comparison to White and predominantly White samples. However, minorities did not completely escape the mainstream cultural emphasis on weight. This study suggests that the more acculturated a minority woman becomes to mainstream U.S. values, the more she ascribes to negative stereotyping of obesity (Miller \& Downey, 1999). This bolsters the position that weightism is learned, rather than an innate predisposition against fat. Conversely, Striegel-Moore, Schreiber, Pike, and Wilfley (1995) found that Black preadolescent females possessed a greater desire for thinness in contrast to White females of the same age group. 
Finally, Johnsen, Spring, Pingatore, Sommerfeld, and MacKirnan (2002)

investigated acculturation of Hispanic women regarding the American beliefs regarding obesity and smoking. The level of acculturation to American society predicted participant attitudes where ethnicity did not. As acculturation increased, subjects were more likely to develop negative attitudes toward obesity and viewed smoking more positively.

\section{Discrimination Toward People who are Obese}

The literature review described thus far crystallizes the effects of stigmatization toward obese people across cultures in the United States. Not only is there a palpable prejudice, but discrimination toward this population is also evident. Rogge (2004) interviewed 13 obese individuals and five family members. The participants revealed frequent experiences of stigmatization and discrimination on the basis of obesity. The subjects reported that they were reminded on a daily basis, through encounters with family, peers, health care providers, and strangers, that they were inferior to those who are not obese.

In 2001, Puhl conducted a review of the literature concerning discriminative attitudes and behavior against obese people. She noted that clear and consistent findings of stigmatization and discrimination occurred in three broad life areas, namely, employment, health care, and education. The author noted the following results of studies: controlling for income and grades, parents provided less college financial support for their overweight versus their thin children; of teachers surveyed, $28 \%$ noted that becoming obese is the worst thing that could happen to a person; and that $24 \%$ of nurses interviewed noted that they were repulsed by obese people. 
Discrimination of the obese in the work world was documented by Fonda (2000). The author studied 7000 men and women born between 1931 and 1941. The individuals included in this study possessed a Body Mass Index greater than 35. Fonda found that in 1992 , the net worth of obese women was $40 \%$ less than that of normal weight women. By 1998, obese women's net worth was $60 \%$ less than that of normal-weight women, within the cohort. The study controlled for health, age, gender, marital, and professional status. Coy (2000) reported that women more than 65 pounds overweight earned $7 \%$ less than average-weight women. Pagan and Davila (1997) reported that women pay a penalty (in terms of earnings) for their obesity, versus their male counterparts. They speculated that this was in part due to occupational mobility. Men evidently sorted themselves into jobs that offset any penalty for obesity. The researchers speculated that men may have lower values regarding moving across occupations than women. Similarly, Fonda's results noted that there were no differences in terms of weight and wealth for men.

Appearance, and thus obesity evidently plays a part in hiring decisions. Pingatore, Dugoni, and Tindale (1994) found that body weight accounted for $35 \%$ of the variance in hiring decisions. It was also noted that women suffer greater discrimination in hiring based on weight than men. Again, it appears that women suffer greater discrimination than men in terms of weight.

Klassen, Clayson, and Jasper (1996) conducted a study among sales people to determine if the salesperson weight was an issue in the perceived successfulness of the store. Klassen found that if the salesperson was described as obese, the store was perceived as being less successful regardless of the gender of the salesperson or the type 
of store. Rothblum et al. (1990) studied the effects of the degree of obesity in apparent employment discrimination. The 367 women and 78 men in the study were classified into one of three groups: average, obese and very obese. The researchers found that very obese subjects reported more types of employment discrimination, school victimization, and lower socioeconomic status than average subjects.

In a similar vein, Carr and Friedman (2005) were interested in determining if obese individuals were truly discriminated against or merely viewed in a negative light. The authors argued that stigmatization is a process of both negative attitudes and discriminatory behavior. They utilized data from the Midlife Development in the United States Survey (MIDUS), which was a random survey of more than 3000 men and women, ages 25 to 74, in 1995. All MIDUS participants were asked to report their height and weight. BMI was calculated based on the formula where BMI $=$ Kilograms $/$ Meters squared. Continuous BMI scores were coded into six categories, based on cut points defined by the National Heart Lung and Blood Institute guidelines (1998). The six categories are underweight (BMI of 18.5 or lower), normal (BMI between 18.5 and 24.9), overweight (BMI between 25 and 29.9), obese I (BMI between 30 and 34.9), obese II (BMI between 35 and 39.9), and obese III (BMI of 40 or higher). The authors combined the latter two categories due to the small number of cases in the obese III category.

Carr and Friedman (2005) found that compared to normal-weight persons, obese II and III persons were more likely to report institutional and day-to-day interpersonal discrimination. Within this group, professional workers were more likely than nonprofessionals to report employment discrimination and interpersonal mistreatment. Obese II and III persons reported lower levels of self-acceptance than normal-weight 
persons, yet this relationship is fully mediated by the perception of the one who is discriminated against due to body weight or physical appearance. All of the obese subjects reported discrimination at work and interpersonally; however, only the most obese individuals reported health-care related discrimination. Carr and Friedman (2005) posited that their results provided compelling evidence that obese people are stigmatized and that the stigmatization transcended negative evaluations by others.

\section{Research Concerning Prejudice}

Goffman (1963) and Allon (1982) would agree that apathy (or worse) toward outgroups is common and the aforementioned research suggests that it occurs crossculturally. There does not appear to be language, time, or national boundaries that limit bias or prejudice. The majority of research in American Psychology on prejudice is focused on race and gender. The study of prejudice toward obesity is relatively new and elaborate models are scarce.

Attribution theory. Crandall, et al. (2001) proposed an attribution-value model of prejudice. The authors note that an apparent theme of anti-fat antipathy research is that beliefs about the social world promote prejudice. Consequently, the attribution of controllability for fatness leads to rejection (Weiner, Perry, \& Magnusson, 1988). Crandall (1994) found that anti-fat prejudice was closely linked to a Puritan work ethic (self-determination). Crandall argued that the attributions of controllability stem from underlying beliefs about causality in the physical and social world and that these are intricately related to social ideology. Therefore, Crandall suggested that a significant amount of the affective component of attitudes and prejudice toward groups is based on two inter-related factors: attributions of controllability and cultural value. 
Crandall et al. (2001) conducted a study of 970 participants (538 women and 432 men) residing within six nations; the United States, India, Poland, Venezuela, Turkey and Australia. Nearly all of the participants were students and a questionnaire containing four sections was administered. The questionnaire contained items that assessed fat prejudice, cultural value of fatness, attributions of controllability and demographics. The authors found a negative cultural value for fatness and a tendency to hold people responsible predicted anti-fat prejudice. More significantly, a multiplicative hypothesis was supported; people with both a negative value for fatness and a tendency to hold people responsible were more anti-fat than could be predicted from cultural value and attributions alone. Interestingly, subsequent analyses showed that this effect appeared primarily in individualistic countries. The authors believe that the attribution-value model proves to be a good fit to fat prejudice in individualistic countries, but the results were not as compelling in the collectivistic countries. They speculated that the cause of prejudice in collectivistic cultures does not appear to rely so highly on individual responsibility.

Recent research not only validates that attribution predicts anti-fat bias but prejudice can be reduced or exacerbated dependent upon causal information about obesity. O‘Brien, Puhl, Latner, Mir and Hunter (2010) studied reduction of anti-fat sentiment among pre-service health students. Seeking to reduce explicit and implicit anti-fat prejudice, students were assigned to one of three tutorial conditions. One condition presented an obesity curriculum on the controllable reasons for obesity (i.e., diet/exercise). A prejudice reduction condition presented evidence on the uncontrollable reasons for obesity (i.e., genes/environment), whereas a neutral (control) curriculum 
focused on alcohol use in young people. Measures of implicit and explicit anti-fat prejudice, beliefs about obese people, and dieting were taken at baseline and postintervention. The results demonstrated that anti-fat prejudice can be reduced (genetic, environmental causes) or exacerbated (obesity is controllable) depending on the causal information provided about obesity.

Emotion and prejudice. Fiske et al. (2002) conducted a study to determine how people sort socio-cultural groups into categories and what emotions those groupings evoke. The authors surveyed students and non-students and found that subjects tend to rate groups along two primary dimensions: warmth (whether the group is friendly, trustworthy, or sincere) and competence (whether the group is skillful and capable). Consequently, these ratings are associated with one of four emotions: disgust, pity, pride, and envy.

For example, subjects rate groups such as homeless people, people addicted to drugs or poor people, low on both warmth and competence, provoking them to feel disgust (Fiske et al., 2002). In contrast, subjects rated elderly, along with the disabled and developmentally challenged people high on warmth but low on competence, provoking them to feel pity. Subjects tended to rate middle-class, White Americans high on both warmth and competence, provoking them to feel pride or what Fiske et al. call feelings of in-group or reference group warmth and affiliation. Finally, subjects tend to rate those who are rich, Jewish, or Asian as low on warmth and high on competence, provoking them to feel envy.

Personality theory. Fiske (1998) noted that stereotyping and prejudice are complex phenomena. Over the past 50 years social and personality psychologists have 
conducted research to explain prejudice. Fiske identified two primary approaches: stable factors within the individual (internal attributes or personality characteristics) (e.g., Adorno, Frenkel-Burnswick, Levenson, \& Sandford, 1950; Altemeyer, 1998; Duckitt, Wagner, du Pluessis, \& Birim, 2002; Ekehammar \& Akrami, 2003) or factors linked to the outside world, such as social identity, social self-categorization or social position (e.g., Guimond, 2000; Guimond, Dambrun, Michinov \& Duarte, 2003; Reynolds, Turner, Haslam \& Ryan, 2001; Schmidt, Branscombe \& Kappen, 2003). The personality approach identifies two major theoretical frameworks used to explain prejudice, namely Authoritarian Personality Theory or Right-Wing Authoritarianism (RWA; e.g., Altemeyer, $1981 \& 1998$ ) and the theory of Social Dominance Orientation (SDO; e.g., Pratto, Sidanius, Stallworth, \& Malle, 1994).

Generalized prejudice is the tendency to respond with prejudice toward any outgroup (Allport, 1954; Duckitt, 1992). Allport (1954, p.68) wrote that - oe of the facts of which we are most certain is that people who reject one out group will tend to reject other out groups. If a person is anti-Jewish, he is likely to be anti-Catholic, anti-Negro, and anti-any out-group.” Generalized prejudice can be seen as a major motivating factor behind the development of an authoritarian personality theory (Adorno et al., 1950). Unfortunately, fewer tests have been developed to study the concept of generalized prejudice. However, Hartley (1946), Allport and Kramer (1946) and Bierly (1985) found that prejudicial attitudes toward gays/lesbians, African Americans, women, and elderly people were correlated. Recently, Ekehammar and Akrami (2003) reported that four types of prejudice (racism, sexism, prejudice toward homosexuals, and prejudice toward people with mental disabilities) are highly correlated and form one single factor. 
Altemeyer $(1996,1998)$ argued that Right Wing Authoritarianism is an individual difference or personality variable. RWA focuses on intra-group perceptions or social and ideological attitudes (Duckitt et al., 2002) and could conceptually be placed in the interface between personality and social psychology. RWA is a narrowly defined construct that may conceptually fall under higher order and general personality dimensions similar to the Big Five personality factors. Previous research has shown that RWA is correlated negatively with openness to experience (Altemeyer, 1996; Heaven \& Bucci, 2001) and positively with conscientiousness (Heaven \& Bucci, 2001) and extroversion (Lippa \& Arad, 1999; Trapnel, 1994).

There is also a body of research that indicates that RWA is a powerful predictor of prejudice and attitudes toward out-groups in a variety of cultures. Research indicates that RWA correlates with negative attitudes toward African Americans (Altemeyer, 1998; Lambert \& Chasteen, 1997), homosexual people (Altemeyer, 1998; Lippa \& Arad, 1999), women (Altemeyer, 1998), people of Jewish faith (McFarland, Ageyev, \& Abalakina, 1993), and prejudice toward Turkish immigrants in the Netherlands (Verkuyten \& Hagendoorn, 1998). Social dominance orientation (SDO) can be seen as a general attitudinal orientation toward inter-group relations. Like RWA, SDO is a construct that is narrowly defined and could conceptually fall under some higher order, general personality dimensions, such as the Big Five" personality theory. There have been two studies that have found SDO to be correlated negatively with Agreeableness (Heaven \& Bucci, 2001; Lippa \& Arad, 1999) and Openness to Experience (Heaven \& Bucci, 2001). 
Social dominance orientation (SDO) can be seen as a general attitudinal orientation toward inter-group relations, reflecting whether an individual generally prefers that relations be equal versus hierarchical (Pratto et al., 1994). Thus, high SDO people tend to promote inter-group hierarchies and rank social groups in a superiorinferior hierarchy. Social dominance orientation is seen to be an individual difference in personality variable with putative evolutionary roots (Pratto et al., 1994). The concept focuses on inter-group perceptions or social and ideological attitudes and values (Duckitt et al., 2002) and could, like RWA, be placed in the interface between personality and social psychology.

An alternative hypothesis was offered by Mischel $(1968,1973, \& 2004)$ and Mischel and Shoda (1995). These researchers suggested that behavior could not be predicted solely by personality traits, but rather by their interaction within a situational context. Mischel argued that individual differences would not be expressed in consistent cross-situational behavior, but instead, he suggested that consistency would be found in distinctive wide, stable patterns of if-then situation-behavior relations that form contextualized, psychologically meaningful personality signatures."

These signatures of personality were revealed in a large observational study of social behavior across multiple repeated situations over time (Mischel \& Shoda, 1995). Contradicting classical assumptions, the data showed that individuals who were similar in average levels of behavior (i.e., aggression) differed from each other predictably and dramatically in the types of situations in which they aggressed. The authors correctly predicted that these situations were characterized by highly psychologically informative if-then behavior signatures. The research suggests a new way to conceptualize and 
assess both stability and variability of behavior as produced by the underlying personality system, and that has provided insight into the dynamic processes within the system itself (Mischel, 2004).

Thus far there have only been a few studies conducted that have reported data on the relationship between the Big Five personality factors and prejudice (Ekehammar \& Akrami, 2003; Saucier \& Goldberg, 1998). Ekehammar and Akrami (2003) examined the relationship of Big Five personality factors to generalized prejudice (a composite measure based on scores from four types of prejudice). The authors concluded that Agreeableness and Openness to Experience are the Big Five factors most closely associated with generalized prejudice. When using all Big Five factors for predicting generalized prejudice in a linear, multiple regression analysis, Ekehammar and Akrami (2003) discovered a fairly high predictive power (cross validated $R=0.56$ ) with Agreeableness and Openness to Experience, showing, as expected, the largest regression rates.

Garza (2007) writes that one of the major limitations in the Big Five model and other prominent trait evaluation theories is that they have a limited power to actually predict behavior in specific circumstances. It has been shown that expectations of people's behavior that are predicted based on Big Five evaluations of the personalities only correlate with actual behavior $30-40 \%$ of the time (Glietman, Friedlund \& Reisberg, 2004). Evidently, the model demonstrates some predictive power although it cannot be considered to anticipate behavior very strongly. McAdams (1992) suggests that one reason that the model does not have strong predictive power is that the categories are so 
broad that they cannot account for all the important nuances of personality, and thus fall short in fully predicting behavior.

Additionally, Mischel (2004) explained the low predictive power by emphasizing the importance of another factor which consists of moment-by-moment situations people. However, Mischel noted that although people do act differently in various situations, some patterns of behavior exist that predict how people act in specific kinds of situations (Gleitman, Friedlund, \& Reisberg, 2004).

Although the aforementioned findings are noteworthy, these limitations pertain to the use of the Big Five in predicting behavior, not their correlation with attitudes or biases. Previous research documents the correlation between Agreeableness and Openness to Experience and prejudice to be fairly high.

Fiske stated; $\mathrm{It}^{\mathrm{t}} \mathrm{s}$ not illegal to have a bad thought or feeling in your head, what really matters is the behavior" as cited in (Chamberlin, 2004, p.34). Behavior is not always reflective of beliefs and prediction of behavior is complex. Bagozzi (1981) examined volitional behavior and attitudes through a causal modeling methodology. He reported that attitude influences behavior only through its impact on intentions. The data supported a causal role for attitude determining behavior, albeit indirectly (through intention). However, the coefficient relating attitude to intention is only moderate in magnitude; the ultimate effect of attitude on behavior is relatively small. In sum, attitude does appear to influence behavior, but its impact is a relatively small one.

Within personality research, RWA and SDO fall between personality and social psychology, with roots in core personality constructs, as defined later (e.g., Akrami \& Ekehammar, 2006). Asendorpf (2003) suggested that core personality traits are based on 
genetic differences and/or early childhood experiences, with limited susceptibility to social and contextual influences later in life. Surface traits, in contrast, are personality characteristics that are susceptible to social and environmental influences. The fivefactor (Big Five) model of personality (see, e.g., McCrae \& Costa, 1996, 1999) is probably the most widely accepted model of personality structure. Bouchard and Loehlin (2001) and Clark and Watson (1999) suggest it is reasonable to classify these factors as core personality factors because of their substantial heritability coefficient and their early expression in temperament in human infants and in animal species.

Researchers of the Big Five factors have conducted studies of prejudice toward several groups (Ekehammar \& Akrami, 2003, 2004, 2007; Saucier \& Goldberg, 1998) through administration of the NEO-PI-R. In this study and previous studies conducted utilizing the NEO-PI-R to measure prejudice, it should be noted that the studies were measuring prejudicial attitudes or beliefs rather than behavior. This measure was not used to predict prejudicial behavior, but rather as a means to determine personality traits that correlate with prejudicial beliefs.

\section{A History of the Big Five Trait Taxonomy}

One starting place for a shared taxonomy is the natural language of personality description. Researchers such as Allport and Odbert (1936) turned to the natural language as a source of attributes for a scientific taxonomy. This work, beginning with the extraction of all personality relevant terms of the dictionary, has generally been guided by the lexical hypothesis (Saucier \& Goldberg, 1996). The lexical hypothesis posits that most of the socially relevant and salient personality characteristics have become coded in the natural language (Allport, 1937). Most of the personality 
vocabulary contained in the dictionaries of a natural language provides an extensive, yet finite, set of attributes that people speaking the language have found useful in their daily interactions (Goldberg, 1981).

Allport and Odbert (1936) conducted a seminal lexical study of the personality relevant terms in an unabridged English dictionary. Their complete list amounted to almost 18,000 terms. The authors believed that organizing these thousands of personality attributes into a satisfactory taxonomy would keep psychologists busy indefinitely. In an attempt to make the list more manageable, Allport and Odbert defined four major categories of personality traits. The first category included personality traits (e. g., sociable, aggressive and fearful), which they defined as "generalized and personalized determining tendencies -- consistent with stable modes of an individual's adjustment to the environment"(p. 26). The second category included temporary states, moods and activities such as afraid, rejoicing and elated. The third category is considered highly evaluative for personal conductor reputation, such as excellent, worthy, average or irritating. The last category included physical characteristics, capabilities and talents, terms of doubtful relevance to personality (i.e., abortive, acerbic, acidulous), and terms that could not be assigned to any of the other three categories.

Norman (1967) elaborated Allport and Odbert's initial classification and divided the domain into seven content categories: stable "biophysical" traits, temporary states, activities, social roles, social effects, evaluative terms, anatomical and physical terms, as well as ambiguous and obscure terms not considered useful for personality descriptive purposes. These categories illustrate that the personality lexicon in the natural language includes a wealth of concepts. Both Allport and Odbert (1936), and Norman (1967) 
classified the terms obtained from the dictionary into mutually exclusive categories. An inspection of the classifications quickly shows that the categories overlap, and have diffuse boundaries, leading some researchers to conclude that distinctions between classes of personality descriptors are arbitrary and should be abolished (Allen \& Potkay, 1981).

In an attempt to create a taxonomy that was able to make distinctions and reduce overlap of categories, Cattell (1943) utilized the Allport and Odbert list as a starting point for his multidimensional model of personality structure. Due to the vast number of terms included in the list, Cattell began with a subset of 4500 trait terms. Cattell was eventually able to reduce the 4500 trait terms to a mere 35 variables, employing both semantic and empirical clustering procedures, as well as his own reviews of the personalogical literature available at the time. Using this relatively small set of variables, Cattell conducted several oblique factor analyses and concluded that he had identified 12 personality factors, which eventually became part of his 16 Personality Factors (16 PF) questionnaire (Cattell, Eber \& Tatsuoka, 1970).

Cattell's work stimulated other researchers to examine the dimensional structure of trait ratings. Several investigators were involved in the discovery and clarification of the big five dimensions. Fiske (1949) constructed much simpler descriptions from 22 of Cattell's variables; the factor structures derived from self ratings, ratings by peers, and ratings by psychological staff members were highly similar and resembled what would be later known as the Big Five. To clarify these factors, Tupes and Christal (1961) reanalyzed correlation matrices from eight different samples, ranging from air men with no more than high school education to first-year graduate students, and it included ratings by 
peers, supervisors, teachers, or experienced clinicians in settings as diverse as military training courses and sorority houses. In all the analyses, Tupes and Christal found "five relatively strong and recurrent factors, and nothing more of any consequence" (1961, p. $14)$.

This five-factor structure has been replicated by Norman (1963), Borgatta (1964), and Digman and Takemoto (1981) in lists derived from Cattell‘s 35 variables. These factors are typically labeled: Extraversion or Surgency (talkative, assertive, energetic); Agreeableness (good-natured, cooperative, trustful); Conscientiousness (orderly, responsible, dependable); Emotional stability versus Neuroticism (not neurotic, not easily upset); and Intellect or Openness (intellectual, imaginative, independent minded). These factors eventually became known as the "Big Five" (Goldberg, 1981) — a title chosen not to reflect their intrinsic greatness but to emphasize that each of these factors is extremely broad.

A number of analyses have confirmed the predictive value of the Big Five across a wide range of behaviors. Saulsman and Page (2004) examined the relationships between the Big Five personality dimensions and each of the 10 personality disorder categories in the Diagnostic and Statistical Manual of Mental Disorders (DSM - IV). Across 15 independent samples, the researchers found that each disorder displayed a unique and predictable five-factor profile. The most prominent and consistent personality predictors underlying disorders were positive associations with Neuroticism and negative associations with Agreeableness.

Considerable research has been conducted on the Big Five. This has resulted in both criticism (Block, 1995) and support for the model (Costa \& McCrae, 1995). Critics 
argued that there are limitations to the scope of the Big Five as an explanatory or predictive theory. It is argued that the Big Five does not explain all of human personality. The methodology used to identify the dimensional structure of personality traits, factor analysis, is often challenged for not having a universally-recognized basis for choosing among solutions with different numbers of factors. Another frequent criticism is that the Big Five is not theory driven. It is merely a data-driven theory of certain descriptors that tend to cluster together under factor analysis.

While researchers in the lexical tradition were accumulating evidence for the Big Five, the need for an integrative framework became more pressing among researchers who studied personality with questionnaire scales. In the early 1980s, Costa and McCrae developed the NEO-Personality Inventory (eventually published in 1985) to measure three broad personality dimensions: Neuroticism, Extroversion and Openness to Experience. The authors realized that their NEO-system closely resembled three of the Big Five factors, but it did not encompass traits in the Agreeableness and Conscientiousness domains. Therefore, they extended their model with preliminary scales measuring Agreeableness and Conscientiousness domains. In several studies McCrae and Costa (1985 \& 1987) demonstrated that their five questionnaire scales converged with and adjective-based measures of the Big Five, although their conception of Openness seemed broader than the Intellect or Imagination factor emerging from the lexical analyses (Saucier \& Goldberg, 1996). In 1992, Costa and McCrae published the 240-item NEO-Personality Inventory, Revised (NEO $-\mathrm{PI}-\mathrm{R})$. This inventory permitted differentiated measurement of the Big Five dimensions in terms of six specific facets per factor. 


\section{Summary}

This review of the literature demonstrates that bias and discrimination against obesity does appear to exist (Cossrow, Jeffry \& McGuire, 2001; Schwartz, Vartanian, Nosek, \& Brownell, 2006). Research has demonstrated that children of preschool age demonstrate a negative attitude toward obese figures (Musher-Eizenman et al., 2004). Similar negative attitudes or biases also exist in adults (Puhl, 2001). Obese individuals find it more difficult to obtain wages comparable to that of average weight people (Coy, 2000) and that obesity was a factor in hiring decisions (Pingatore, 1994).

Attribution theory provides one explanation of this bias. Teachman, et al. (2003) found that individuals who possess a Protestant work ethic perceived obese individuals in a more negative light. The underlying assumption is that obesity is volitional, resulting in the ascription of blame to the obese individual.

The study of prejudice has been investigated from several perspectives. Personality theory, specifically the Big Five, proposes a negative correlation between Agreeableness and Openness to Experience with generalized prejudice. This line of inquiry has been used to study prejudice in populations such as Gay/Lesbian individuals, African-Americans, women, and the elderly (Allport \& Kramer, 1946; and Bierly, 1985; Hartley, 1946). Ekehammar and Akrami‘s (2003) study of prejudice toward homosexuals and people with mental disabilities found that these are highly correlated to form a single factor, or as Allport suggested, a trait of personality." To date, there are no studies investigating Big Five personality traits and prejudice toward obese individuals; my study proposes to address this gap in the literature. Therefore, the 
purpose of this study is to determine personality traits that differentiate individuals who are intolerant of obesity from those who are more accepting of individuals who are obese. 


\section{Chapter 3: Method}

This study evaluated the relationships between personality characteristics related to prejudice and anti-fat bias, by means of several data sources and quantitative analyses. The methods described in this chapter are divided into six subsections: (1) participants; (2) procedure; (3) instruments; (4) research design; (5) research questions/hypotheses; and (6) statistical analyzes.

\section{Participants}

Participants consisted of undergraduate students, ages 18-22, from a large, east coast university. The volunteers were recruited for participation from psychology classes, and all participants received course credit for participation. Additionally, all participants were eligible for a random drawing of $\$ 50.00$ for their participation in this study. Each participant earned 1.5 extra credit points for completing the instruments employed in this study. One recommendation noted in the IRB literature limits extra credit earned through participation to 5\% (or less) of the total course grade (Tickle \& Heatherton, 2002). All participants were asked to complete three measures and were not divided into groups.

Estimated sample size was calculated through an a priori power analysis. The alpha level was set at .05; power (1-ß) was set at .95 and effect size was .15 (moderate effect size). A two-tailed, linear multiple regression power analysis was computed using five predictor variables. It yielded a total minimum sample size of 89 participants. In the interest of greater power and generalizability, the committee for this dissertation asked for approximately 200 participants. 
Demographic information was collected for each participant, and included ethnicity, class rank/age, and major area of study, height, weight, and sex. These potential mediating variables were then examined to determine if any differences exist among these groups regarding anti-fat bias or prejudice.

\section{Procedure}

Undergraduate students attending an east coast university during the fall of 2010 were invited to participate in this study. Undergraduate psychology students interested in earning extra credit were directed to the University Research Participation System, Sona, by their professors. An advertisement for this study was also placed in the university's Personal Announcements section of the Mix homepage. All potential participants were directed to the following website, in order to enter the system: http://wvu.sonasystems.com/.

For identification and privacy purposes, a unique 5-digit ID number was generated for each participant who registered with the program. This number was also used to track extra credit. Students who registered were provided a list of the available studies and directed to Body Image, Parts A and B, to participate in this research study. The NEO-PI-R and the AAQ were recreated on-line within the Sona system (Part A). The IAT (Part B) was an external study; it was created independently of the Sona system; thus the participants were directed to an external website through Sona by clicking $\nleftarrow$ iew external website." The IAT website address was:

http://research.millisecond.com/dammpsych/BodyImageiat.web. 
Each participant was able to review a brief abstract and description of the research before proceeding with this study. The abstract indicated: (a) that participants were to complete all measures that dealt with self-perception and perception of others , (b) approximately how long participation in the study would take (50-60 minutes). After choosing to continue, students then reviewed an informed consent form which included: the expiration date of the study, the IRB approval number, contact information and privacy information. Students were informed that participation was always voluntary and they could withdraw from the study at any time. Participant questions were addressed prior to beginning the study via the email address included in the contact information.

The order of administration of the questionnaires was counter-balanced to decrease the possibility of order effects. Participants were also asked to provide some demographic information (see Appendix B). No identifying information was collected, but participants were given the option of including their email address if they wished to receive a summary of research findings. Since some participants might have been offended by the pejorative wording of items contained in the Anti-fat Attitudes Questionnaire (Treally don't like fat people much."), time was allotted to discuss participant concerns, upon completion of the questionnaires, by contacting this researcher via email.

\section{Instruments}

Anti-fat Attitudes Questionnaire. Crandall‘s (1994) 13-item AAQ was used to assess explicit anti-fat attitudes. This measure comprised of three subscales (Dislike, Fear of Fat, and Willpower). The Dislike subscale assesses individual antipathy toward 
fat people. The Fear of Fat subscale assesses personal concerns about becoming fat. The Willpower subscale assesses the belief that being overweight is a matter of personal control or lack thereof. Items were scored on a nine -point Likert scale (1=very strongly disagree to $9=$ very strongly agree). The AAQ is a 13 item questionnaire with three scales, Dislike, Willpower and Fear of Fat, each with 7, 3 and 3 items, respectively. The minimum, maximum and average potential scores for the Dislike subscale are 0,21 and 63, while the minimum, maximum and average scores for Willpower and Fear of Fat are 0,12 and 27, respectively. The minimum, maximum and average possible scores for the AAQ total scores are 0,52 and 91, respectively. Cronbach's alpha coefficients for each of the subscales were reported to be sufficient $(0.85,0.84$ and 0.79 , respectively).

Implicit Association Ttest. The IAT (Greenwald, McGhee, \& Schwartz, 1998) is the most widely used and therefore the most thoroughly tested measure of implicit attitudes. IAT is thought to measure implicit attitudes by examining the automatic associations between various attitude objects and various evaluative attributes (Greenwald et al., 1998). Specifically, the IAT measures how closely associated any given attitude object (e.g., a flower or an insect) is with an evaluative attribute (e.g., pleasant or unpleasant words) and assumes that the more closely related the objects and attributes are, the stronger the implicit attitude is.

Consider, for example, an IAT experiment designed to measure attitudes toward insects and flowers. The IAT involves five stages of activity. In the first stage, participants categorize target words that are relevant to the attitude objects. In the case of insects and flowers, this means that participants first categorize words (e.g., cockroach 
and rose) as either insect words or flower words by pressing a key with their left hand if it is an insect word and pressing a different key with their right hand if it is a flower word. In the second stage, participants categorize a different set of words (e.g., happy and rotten) as either pleasant or unpleasant by pressing a key with their left hand if it is an unpleasant word and pressing a different key with their right hand if it is a pleasant word. These first two stages are learning stages in which participants become familiar with the categorization tasks. In the third stage, the previously learned categorizations are combined. Participants are instructed to press a key with their left hand if any given word is either an insect word or an unpleasant word and to press a different key with their right hand if any given word is either a flower word or a pleasant word. In the fourth stage, the response keys are reversed. Participants then must press a key with their right hand if the word is an insect word and press a different key with their left hand if the word is a flower word. In the final stage, the new attitude object categorization practiced in Stage 4 is combined with the categorization of the evaluative attributes learned in Stage 2. In the case of insects and flowers, participants are instructed to press a key with their left hand if any given word is either a flower word or an unpleasant word and to press a different key with their right hand if any given word is either an insect word or a pleasant word.

An overall IAT score is obtained by taking the difference in response times between the two combined stages. Individuals who respond more quickly when pleasant and flower are paired together on the same response key than when pleasant and insect are paired together are said to have more positive associations toward flowers than toward insects. Conversely, individuals who respond more quickly when pleasant and 
insect are paired on the same response key than when pleasant and flower are paired together are said to have more positive associations toward insects than toward flowers.

What consistently emerges with the IAT is that people are quicker to respond when generally liked items are paired with positive words than when generally disliked items are paired with positive words. The IAT reveals that people have more positive associations with flowers than with insects and with musical instruments than with weapons (Greenwald et al., 1998). The IAT has already been used to demonstrate cognitive bias in a number of populations, including overweight men and women (Wang, Brownell, \& Wadden, 2004).

Test-retest reliabilities of the IAT average about $r=.60$ (Greenwald, et al. 2002) and IAT measures have exhibited high internal consistency, with Cronbach's alpha around .80 and often higher (Greenwald \& Nosek, 2001). Nosek, Greenwald, and Banaji (2007) conducted a review of 103 studies that utilized the IAT. They found average $r=$ .27 for the prediction of a wide collection of behavioral, judgment, and physiological measures by IAT measures. Cohen (1977) wrote that $r$-values of this magnitude reflect a medium effect size. Effect sizes can be interpreted in terms of the percent of non-overlap of the treated group's scores with those of the untreated group. The IAT accounted for significantly more variance in prediction of the above-mentioned measures versus selfreport measures (mean $r$ IAT $=.25$, mean $r$ self-report $=.13$ ).

Once the participant accessed the website designated in the Sona Body Image study, she/he was instructed to enter their 5-digit Sona ID number. The following instructions then appeared: — $6 u$ have opted to complete the Body Image IAT. You will 
complete IAT in which you will sort words and pictures into categories as quickly as possible. You should be able to complete the tasks in less than 10 minutes total. When you finish, you will receive your results as well as more information about the test and the performance of others."

In the next task, you will be presented with a set of words or images to classify into groups. This task requires that you classify items as quickly as you can while making as few mistakes as possible. Going too slow or making too many mistakes will result in an un-interpretable score. This part of the study will take about 5 minutes. The following is a list of category labels and the items that belong to each of those categories."

\section{Keep in mind}

- Keep your index fingers on the 'e' and 'i' keys to enable rapid response.

- Two labels at the top will tell you which words or images go with each key.

- Each word or image has a correct classification. Most of these are easy.

- The test gives no results if you go slow -- Please try to go as fast as possible.

- Expect to make a few mistakes because of going fast. That's OK.

For best results, avoid distractions and stay focused."

The IAT was scored according to the revised scoring algorithm described by Greenwald, Nosek, and Banaji (2003). An algorithm is a finite sequence of instructions, often used for calculation and data processing. It is formally a type of effective method in which a list of well-defined instructions for completing a task will, when given an initial state, proceed through a well-defined series of successive states, eventually terminating in an end-state. The algorithm produces a $D$ score which can range from -2 
to +2 . Positive $D$ scores indicate stronger associations of negative attributes with fat people compared with thin people, whereas negative $D$ scores indicate weaker associations. $D$ scores of zero indicate no difference in associations with fat people compared with thin people.

In this study, all subjects were asked to complete an obesity attitude IAT, in which the concepts of fat people (represented by the items fat, overweight, and large) and thin people (thin, slim, and skinny) were paired with the attributes good (wonderful, joyful, and excellent) and bad (terrible, nasty, and horrible). These pairings were chosen based on the use of the IAT in prior research regarding obesity and stigmatization (Teachman \& Brownell, 2001; Wang, Brownell, \& Wadden, 2004). In an unpublished manuscript, Greenwald, Uhlmann, Poehlman, and Banaji (2009) conducted a metaanalysis of the predictive validity of the IAT. The meta-analysis included findings about the validity of IAT measures in predicting intergroup discrimination (i.e., prediction of discriminatory behavior from IAT measures of attitudes and stereotypes involving race, ethnicity, gender and sexual orientation). The weighted average of the IAT-criterion correlations (ICCs), based on 122 reports that contained 184 independent samples, was $r$ $=.274$, a level conventionally characterized as low (Cohen, 1977). On average, correlations of self-report measures with Explicit-criterion measures (ECCs) were larger: $r=.361$. Other important findings were that (a) predictive validity of self-report measures (but not of IAT measures) was sharply reduced when research topics were socially sensitive, (b) IAT measures had greater predictive validity than did self-report measures for criterion measures involving interracial behavior and other intergroup 
behavior, and (c) both IAT and self-report measures showed incremental predictive validity with respect to each other.

The reliability of the IAT was demonstrated by comparison to other latencybased measures of prejudice. Teige, Schnabel, Banse, and Asendorpf (2004) conducted a study exploring the psychometric properties of the Extrinsic Affective Simon Task (EAST). In a typical EAST study, words that are colored white, blue or green are presented one by one on a screen. As in the IAT, participants are asked to respond to these words by pressing one of two keys. When the word is white, participants are asked to respond on the basis of valence by pressing one key for positive white words and another key for negative white words. As a result of these trials, it is assumed that one key becomes associated with positive valence and the other key with negative valence. When the word is colored, participants need to select one of those same responses, but this time based on the color of the word. De Houwer (2003) showed that responses to positive colored words were faster when participants pressed the positive key (i.e. the key that was also assigned to positive white words) than when they pressed the negative key (i.e. the key that was also assigned to negative white words) whereas the reverse was true for negative colored words. In principle, the EAST can be used to measure attitudes. For instance, in order to measure self-esteem (i.e. attitudes towards the concept self sene $^{\star}$, one can present colored words that are related to the concept _sedf (e.g. the first name of the participant or words such as I or MYSELF). If a participant needs less time to give positive responses to those words than to give negative responses, this would indicate that the participant has positive self-esteem (De Houwer, 2003). 
In order to test the EAST's psychometric properties, 100 participants completed trait EASTs, Implicit Association Tests (IATs), and direct self-ratings. In a direct comparison between the IAT and the EAST, the IAT out-performed the EAST. The reliability coefficients were as follows: EAST $\alpha=.19, .24$, and .19; IAT a $>.75$. Therefore, part of the IAT's acceptance as an implicit measure may be attributed to the achievement of greater reliability than other latency-based implicit measures.

Internal consistency estimates (split-half correlations or Cronbach's alphas) for the IAT measures tended to range from .70 to .90 (Greenwald \& Nosek, 2001). Across studies, the IAT shows stable test-retest reliability (median $r=.56$ ) that varies little with retest interval. Two qualifications of this conclusion are (1) only one study has examined test-retest reliability with more than a one-month gap (one year; Egloff, Schwerdtfeger \& Schmuckle, 2005); and (2) data from a variety of tasks (anxiety, racial attitudes, extroversion) that suggest possible variation in test-retest reliability by content domain is undetermined at this time (Schmukle \& Egloff, 2005). Even so, the effect of time between tests on test-retest reliability is unaffected by the presence of the outlier study. Schmukle and Egloff (2004) concluded that the IAT has satisfactory testretest reliability while also showing evidence of both trait-specific variation (an individual difference that is stable across time) and occasion-specific variation.

Revised-NEO personality inventory. The Revised NEO Personality Inventory or NEO-PI-R is a psychological personality inventory (Costa \& McCrae, 1992). The original version (NEO) was composed of 300 items purported to be measures of the Big Five Factors: Conscientiousness (C), Agreeableness (A), Neuroticism (N), Openness to Experience (O), and Extraversion (E). Additionally, the test measures six subordinate 
dimensions (known as 'facets') of each of the "Big Five" personality factors. The NEOPI-R consists of 240 items; responses are recorded on a five-point, Likert-type scale ranging from Strongly Disagree to Strongly Agree. The NEO-PI-R measures six specific traits, or facets, that define each of the five broad factor domains. Reliability and validity estimates can be found in the manual (Costa \& McCrae, 1992). Internal consistency information (measured by test-retest correlations) of the NEO presented in the manual was derived from the full job performance sample $(n=1,539)$. The internal consistency of the $\mathrm{NEO}$ was high, at: $\mathrm{N}=.92, \mathrm{E}=.89, \mathrm{O}=.87, \mathrm{~A}=.86, \mathrm{C}=.90$. The internal consistency of the facet scales ranged from .56-.81, although Costa and McCrae remind us that there are only eight items on each facet. A recent article discussing personality and eating disorders reported internal consistency reliability estimates of .69 to -.90 for the NEO PI-R facets (Eggert, Levondosky \& Klump, 2007).

Costa and McCrae's (1992) manual provides extensive information on the convergent and discriminate validity of the NEO. When compared to the Myers-Briggs Type Indicator subscale score, Introversion correlated with the NEO facets ranging from $r=-.61$ (Warmth), to $r=-.59$ (Gregariousness). Intuition correlations with the facet Fantasy ranged from at .43 to .56 . Feeling is correlated with the NEO facet Tendermindedness at 0.39. Additionally, the NEO and the Minnesota Multiphasic Personality Inventory correlations ranged from $\mathrm{r}=.36$ (the NEO facet Tender-mindedness and the MMPI-2 scale Social) to $r=.66$ (NEO facet Gregariousness and MMPI-2 schizoid scale). When validated against the Self Directed Search, correlations ranged from $r=.36$ (Tender-mindedness and Investigative) to $\mathrm{r}=.56$ (Aesthetic and Artistic). It seems that 
these instruments measure similar constructs; perhaps they have a common ancestry in their development through psycho-lexical means.

Recent studies have investigated predictive criterion validity of the NEO, utilizing all five domain scales. Conard (2005) found that Conscientiousness significantly predicted the GPA of college students, over and above using SAT scores alone. CanoGarcia and his colleagues in 2005 correlated a Spanish version of the NEO to predict teacher burnout in Sevilla, Spain. Neuroticism was related to the -emotional exhaustion" factor of burnout at $\mathrm{r}=0.44$, and Agreeableness related to the personal accomplishment" factor of burnout (which is negatively scored when predicting burnout) at $r=0.36$. Wang, Jome, Haase, and Bruch (2006) found that among minority students Extraversion was correlated with Career Decision Making Self- efficacy (CDMSE) at $r=0.30$, and that Neuroticism was strongly related to Career Commitment while controlling for CDMSE $(r=0.42)$. Lastly, Korukonda (2007) reported that Neuroticism was positively related to computer anxiety, while Openness and Agreeableness were negatively related.

\section{Research Design}

The research question asked in this dissertation is fo what extent are the NEOPI-R scales (Conscientiousness, Agreeableness, Neuroticism, Openness to Experience, and Extraversion) related to anti-fat attitudes?" The nature of this question required a descriptive correlational design (Heppner \& Heppner, 2004) because the purpose of the study was to investigate relationships between constructs, namely the Big Five factors and anti-fat bias. Descriptive quantitative designs involve identification of the characteristics of an observed phenomenon or the exploration of correlations among two or more phenomena (Leedy \& Ormrod, 2005). Within descriptive designs there is no 
manipulation or modification of the variables being examined; the focus of this type of study is to examine relationships. Descriptive designs are not meant to establish cause and effect relationships.

Dependent and independent variables. The independent predictor variables were the NEO $-\mathrm{PI}-\mathrm{R}$ factor scores (personality scales) and the dependent criterion variables were the IAT and AAQ (anti-fat measures) total scores and the AAQ subscale scores. The relationship between personality and anti-fat bias was addressed through the use of a non-experimental design. There was one group of participants; all completed the three measures (NEO- PI-R, IAT, and AAQ). The goal of the research was to examine the relationship or correlation of two variables; personality traits (as measured by the NEOP-R) and anti-fat bias (as measured by the IAT and AAQ).

The measurements that were employed will provide numerical data reflecting the presence/degree of personality characteristics and anti-fat bias. Statistical analyses, described below, were conducted to determine to what degree personality and anti-fat bias are related.

\section{Research Questions/Hypotheses}

Research question 1. To what extent did the NEO-PI-R scale scores (Conscientiousness, Agreeableness, Neuroticism, Extraversion, and Openness to Experience) predict Anti-fat Attitude Questionnaire scores (Dislike, Fear of Fat, Willpower, and Total Scores)?

Hypothesis 1a. It was hypothesized that the NEO-PI- R subscale Agreeableness would be a significant predictor of the AAQ total score and the Willpower 
Subscale Score. Specifically, low Agreeableness scores on the NEO-PI-R would be associated with high AAQ Total Scores, as well as high Willpower Scale Scores.

Hypothesis 1 b. It was hypothesized that the NEO-PI- $\mathrm{R}$ subscale Openness to Experience would be a significant predictor of the AAQ total score and the Willpower Subscale Score. Specifically, low Openness to Experience scores on the NEO-PI-R would be associated with high AAQ Total Scores, as well as high Willpower Scale Scores.

Research question 2. To what extent did the NEO-PI- $\mathrm{R}$ scales (Conscientiousness, Agreeableness, Neuroticism Extraversion, and Openness to Experience) predict the IAT $D$ Scores?

Hypothesis 2a. It was hypothesized that the NEO- $-\mathrm{PI}-\mathrm{R}$ subscale Agreeableness score would be a significant predictor of the IAT $D$ Score.

Hypothesis $2 \mathrm{~b}$. It was hypothesized that the NEO-PI- R subscale Openness to Experience score would be a significant predictor of the IAT $D$ Score.

\section{Statistical Analyses}

The participants were asked to provide demographic information, including age, sex, class rank, major field of study, height, weight and ethnicity. In order to obtain a clearer picture of the demographic data, descriptive statistics were calculated for each of the above-mentioned variables. These variables were analyzed along with the AAQ Total and subscale scores and IAT $D$ scores.

Three major analyses were performed in order to test the three research hypotheses. For Research Question 1, four Stepwise Multiple Regressions were computed to test the hypotheses that the NEO- $-\mathrm{PI}-\mathrm{R}$ subscales Agreeableness and 
Openness to Experience were significant predictors of the AAQ Total Score and the Willpower Subscale Score. Each of the NEO-PI-R scales (C., A., N., O, and E.) was included as predictor variables, and the AAQ Total and Dislike, Fear of Fat, and Willpower Scores as the criterion variables.

For Research Question 2, a Stepwise Multiple Regression was computed to test the hypotheses that the NEO-PI- R subscales Agreeableness and Openness to Experience were significant predictors of the IAT $D$ Score. Each of the NEO-PI-R scales (C., A., N., O, and E.) was utilized as predictor variables, and the IAT $D$ score as the criterion variable.

Multiple regression analyses were utilized in order to test research hypotheses 1 and 2 because it was hypothesized that the independent variables/predictor variables (NEO_- PI— R scale scores) would predict the dependent measures/criterion variables (Anti-fat Attitude Questionnaire scores, IAT D scores). The goal was to determine how much variance of the criterion variable was accounted for by the predictor variables. Breakwell, Hammond, Fife-Shaw, and Smith (2006) indicate that a stepwise regression may be best suited to address this issue. This procedure uses all the possible predictors and removes them one at a time, until a more parsimonious but almost equally accurate solution results. This method provided a multiple correlation coefficient that represents the correlation between the composite of the predictor variables and the criterion variables. Thus, the procedure determined which of the NEO-PI-R scales (C., A., N., O., and E.) would be the best predictor(s) of AFA and IAT scores.

For Research Question 3, the analysis strategy involved computation of Pearson correlation coefficients for: 1) the NEO-PI-R scales (C., A., N., O., and E.) with the 
demographic variables; 2) Anti-fat Attitude Questionnaire scores (Dislike Scale, Fear of Fat Scale, Willpower Scale, and Total Scale) with the demographic variables; and 3) the IAT $D$ scores with the demographic variables. A correlation matrix demonstrated the inter-correlations among these variables. 


\section{Chapter 4: Results}

This chapter describes and summarizes the statistical analyses conducted to evaluate the research questions and hypotheses set forth in previous chapters. The chapter begins with a description of participant demographics. A summary of the differences between independent and dependent variable scores across the demographic variables follows. Finally, the remaining data analyses focus on the research questions proposed in Chapter 3.

\section{Participant Characteristics}

The following tables highlight the demographic characteristics of the research sample. The participants were asked to provide demographic information including age, sex, class rank, major field of study, height, weight, and ethnicity. The majority of the participants were females, $82 \%$, (Table 1) who were 19 years old, 36\%, (Table 2). Eighty-two percent of the participants identified themselves as Caucasian (Table 3).

Twenty three students were in their first year of university study, 107 students were in their second year, 66 students were in their third year, and 28 were fourth-year students. The majority of students (65) identified their major field of study as psychology, while 22 indicated they were nursing majors, 19 reported they were exercise

physiology majors, 13 were biology majors, 11 were education majors, 10 were sport and exercise psychology majors, and nine were special education, English, and elementary education majors, respectively. The remaining 70 participants represented thirty-three different fields of study (Table 4). 
Table 1.

Gender

\begin{tabular}{llrrrr}
\multicolumn{6}{c}{ Gender } \\
\hline \hline \multirow{6}{*}{ Valid } & Females & 194 & 79.2 & 81.9 & \multicolumn{2}{c}{$\begin{array}{c}\text { Cumulative } \\
\text { Percent }\end{array}$} \\
& Males & 43 & 17.6 & 18.1 & 100.0 \\
& Total & 237 & 96.7 & 100.0 & \\
Missing & System & 8 & 3.3 & & \\
Total & & 245 & 100.0 & & \\
\hline \hline
\end{tabular}

Table 2.

Age

\begin{tabular}{|c|c|c|c|c|c|}
\hline \multicolumn{6}{|c|}{ Age } \\
\hline & & Frequency & Percent & Valid Percent & $\begin{array}{c}\text { Cumulative } \\
\text { Percent }\end{array}$ \\
\hline \multirow[t]{13}{*}{ Years } & 18 & 20 & 8.2 & 8.5 & 8.5 \\
\hline & 19 & 84 & 34.3 & 35.6 & 44.1 \\
\hline & 20 & 67 & 27.3 & 28.4 & 72.5 \\
\hline & 21 & 29 & 11.8 & 12.3 & 84.7 \\
\hline & 22 & 19 & 7.8 & 8.1 & 92.8 \\
\hline & 23 & 5 & 2.0 & 2.1 & 94.9 \\
\hline & 24 & 4 & 1.6 & 1.7 & 96.6 \\
\hline & 25 & 1 & .4 & .4 & 97.0 \\
\hline & 29 & 2 & .8 & .8 & 97.9 \\
\hline & 30 & 3 & 1.2 & 1.3 & 99.2 \\
\hline & 34 & 1 & .4 & .4 & 99.6 \\
\hline & 62 & 1 & .4 & .4 & 100.0 \\
\hline & Total & 236 & 96.3 & 100.0 & \\
\hline Missing & System & 9 & 3.7 & & \\
\hline Total & & 245 & 100.0 & & \\
\hline
\end{tabular}


Table 3.

\section{Ethnicity}

\begin{tabular}{|c|c|c|c|c|c|}
\hline \multicolumn{6}{|c|}{ Ethnicity } \\
\hline & & Frequency & Percent & $\begin{array}{c}\text { Valid } \\
\text { Percent } \\
\end{array}$ & $\begin{array}{c}\text { Cumulative } \\
\text { Percent }\end{array}$ \\
\hline & Caucasian & 202 & 82.4 & 89.8 & 89.8 \\
\hline & African & 6 & 2.4 & 2.7 & 92.4 \\
\hline & American & & & & \\
\hline & Middle Eastern & 3 & 1.2 & 1.3 & 93.8 \\
\hline & Chinese & 1 & .4 & .4 & 94.2 \\
\hline & Hispanic & 3 & 1.2 & 1.3 & 95.6 \\
\hline & Asian & 2 & .8 & .9 & 96.4 \\
\hline & Multi-cultural & 6 & 2.4 & 2.7 & 99.1 \\
\hline & Japanese & 1 & .4 & .4 & 99.6 \\
\hline & Native & 1 & .4 & .4 & 100.0 \\
\hline & American & & & & \\
\hline & Total & 225 & 91.8 & 100.0 & \\
\hline Missing & System & 20 & 8.2 & & \\
\hline Total & & 245 & 100.0 & & \\
\hline
\end{tabular}

Table 4.

Class Rank

Class Rank

\begin{tabular}{llrrrr}
\hline \hline & & & & \multicolumn{2}{c}{$\begin{array}{c}\text { Cumulative } \\
\text { Percent }\end{array}$} \\
\hline Year & 1 & Frequency & Percent & Valid Percent & 9.8 \\
& 23 & 9.4 & 9.8 & 54.9 \\
& 2 & 106 & 43.3 & 45.1 & 83.0 \\
& 3 & 66 & 26.9 & 28.1 & 94.9 \\
& 4. & 28 & 11.4 & 11.9 & 100.0 \\
& 5 & 12 & 4.9 & 5.1 & \\
Missing & Sotal & 235 & 95.9 & 100.0 & \\
Total & System & 10 & 4.1 & & \\
\hline \hline
\end{tabular}


Results of Data Analyses

Preliminary analyses were conducted to determine if scores on the dependent variables (AAQ Dislike Scale, Fear of Fat Scale, Willpower Scale, and Total Scale scores as well as the IAT $D$ scores) and the independent variable, NEO- $-\mathrm{PI}-\mathrm{R}$ scales (Conscientiousness, Agreeableness, Neuroticism, Openness to Experience, and Extraversion.) differed across demographic factors. The analysis strategy involved computation of Pearson correlation coefficients, presented in Table 5.

Table 5.

Correlational Matrix of the IV and DVs Across Demographic Characteristics.

\begin{tabular}{llcccccc}
\hline \multicolumn{7}{c}{ Correlations $^{\mathrm{a}}$} \\
\hline \hline \multirow{2}{*}{ AAQ_D } & AAQ_D & AAQ_F & AAQ_W & AAQ_TOT & N & \multicolumn{1}{c}{ E } \\
& Pearson Correlation & 1 & $.321^{* *}$ & $.506^{* *}$ & $.851^{* *}$ & -.005 & .027 \\
& Sig. (2-tailed) & & .000 & .000 & .000 & .945 & .718 \\
\hline \multirow{2}{*}{ AAQ_F } & Pearson Correlation & $.321^{* *}$ & 1 & $.497^{* *}$ & $.713^{* *}$ & .145 & .071 \\
& Sig. (2-tailed) & .000 & & .000 & .000 & .054 & .346 \\
\hline \multirow{2}{*}{ AAQ_W } & Pearson Correlation & $.506^{* *}$ & $.497^{* *}$ & 1 & $.787^{* *}$ & .023 & .076 \\
& Sig. (2-tailed) & .000 & .000 & & .000 & .756 & .312 \\
\hline \multirow{2}{*}{ AAQ_TOT } & Pearson Correlation & $.851^{* *}$ & $.713^{* *}$ & $.787^{* *}$ & 1 & .058 & .066 \\
& Sig. (2-tailed) & .000 & .000 & .000 & & .439 & .382 \\
\hline N & Pearson Correlation & -.005 & .145 & .023 & .058 & 1 & $.343^{* *}$ \\
& Sig. (2-tailed) & .945 & .054 & .756 & .439 & & .000 \\
\hline E & Pearson Correlation & .027 & .071 & .076 & .066 & $.343^{* *}$ & 1 \\
& Sig. (2-tailed) & .718 & .346 & .312 & .382 & .000 & \\
\hline O & Pearson Correlation & -.040 & .070 & -.071 & -.019 & $.376^{* *}$ & $-.204^{* *}$ \\
& Sig. (2-tailed) & .600 & .351 & .345 & .805 & .000 & .006 \\
\hline A & Pearson Correlation & .015 & .070 & .048 & .050 & $.426^{* *}$ & $.273^{* *}$ \\
& Sig. (2-tailed) & .840 & .356 & .523 & .509 & .000 & .000 \\
\hline C & Pearson Correlation & -.075 & $.160^{*}$ & -.034 & .006 & $.535^{* *}$ & $-.156^{* *}$ \\
& Sig. (2-tailed) & .320 & .033 & .649 & .937 & .000 & .038 \\
\hline IAT_D & Pearson Correlation & -.038 & -.124 & -.079 & -.093 & -.024 & -.069 \\
& Sig. (2-tailed) & .618 & .099 & .292 & .219 & .754 & .362 \\
\hline
\end{tabular}




\begin{tabular}{llrrrrrr}
\hline \multicolumn{7}{c}{ Correlations } \\
\hline \multirow{2}{*}{ Age } & AAQ_D & AAQ_F & AAQ_W & AAQ_TOT & N & E \\
& Pearson Correlation & .102 & -.009 & .074 & .079 & .108 & .007 \\
& Sig. (2-tailed) & .174 & .906 & .323 & .297 & .152 & .924 \\
\hline rank & Pearson Correlation & .029 & -.029 & .000 & .006 & $.166^{*}$ & .085 \\
& Sig. (2-tailed) & .698 & .703 & 1.000 & .936 & .027 & .261 \\
\hline \multirow{2}{*}{ gender } & Pearson Correlation & .029 & -.016 & .120 & .048 & -.064 & .122 \\
& Sig. (2-tailed) & .699 & .833 & .111 & .523 & .398 & .104 \\
\hline \multirow{2}{*}{ ethnicity } & Pearson Correlation & -.033 & .066 & .007 & .008 & .041 & .049 \\
& Sig. (2-tailed) & .658 & .378 & .928 & .918 & .589 & .513 \\
\hline \multirow{2}{*}{ Field } & Pearson Correlation & -.048 & .001 & .042 & -.014 & -.060 & -.003 \\
& Sig. (2-tailed) & .527 & .993 & .577 & .853 & .424 & .972 \\
\hline \multirow{2}{*}{ Height } & Pearson Correlation & -.060 & -.057 & .013 & -.052 & .035 & .032 \\
& Sig. (2-tailed) & .427 & .448 & .859 & .494 & .642 & .670 \\
\hline \multirow{2}{*}{ Weight } & Pearson Correlation & -.029 & -.100 & .010 & -.051 & -.001 & $.159^{*}$ \\
& Sig. (2-tailed) & .702 & .182 & .891 & .500 & .986 & .034 \\
\hline \hline
\end{tabular}

${ }^{* *}$. Correlation is significant at the 0.01 level (2-tailed).

*. Correlation is significant at the 0.05 level (2-tailed).

a. Listwise $\mathrm{N}=178$

\section{Correlations $^{\mathrm{a}}$}

\begin{tabular}{|c|c|c|c|c|c|c|c|}
\hline & & 0 & $\mathrm{~A}$ & $\mathrm{C}$ & IAT_D & Age & rank \\
\hline \multirow[t]{2}{*}{ AAQ_D } & Pearson Correlation & -.040 & .015 & -.075 & -.038 & .102 & .029 \\
\hline & Sig. (2-tailed) & .600 & .840 & .320 & .618 & .174 & .698 \\
\hline \multirow[t]{2}{*}{ AAQ_F } & Pearson Correlation & .070 & .070 & $.160^{*}$ & -.124 & -.009 & -.029 \\
\hline & Sig. (2-tailed) & .351 & .356 & .033 & .099 & .906 & .703 \\
\hline \multirow[t]{2}{*}{ AAQ_W } & Pearson Correlation & -.071 & .048 & -.034 & -.079 & .074 & .000 \\
\hline & Sig. (2-tailed) & .345 & .523 & .649 & .292 & .323 & 1.000 \\
\hline \multirow[t]{2}{*}{ AAQ_TOT } & Pearson Correlation & -.019 & .050 & .006 & -.093 & .079 & .006 \\
\hline & Sig. (2-tailed) & .805 & .509 & .937 & .219 & .297 & .936 \\
\hline \multirow[t]{2}{*}{$N$} & Pearson Correlation & $.376^{* *}$ & $.426^{* *}$ & $.535^{* *}$ & -.024 & .108 & $.166^{*}$ \\
\hline & Sig. (2-tailed) & .000 & .000 & .000 & .754 & .152 & .027 \\
\hline \multirow[t]{2}{*}{$\mathrm{E}$} & Pearson Correlation & $-.204^{* *}$ & $.273^{* *}$ & $-.156^{*}$ & -.069 & .007 & .085 \\
\hline & Sig. (2-tailed) & .006 & .000 & .038 & .362 & .924 & .261 \\
\hline \multirow[t]{2}{*}{$\mathrm{O}$} & Pearson Correlation & 1 & $.319^{* *}$ & $.489^{* *}$ & .088 & $.179^{*}$ & .071 \\
\hline & Sig. (2-tailed) & & .000 & .000 & .244 & .017 & .344 \\
\hline A & Pearson Correlation & $.319^{* *}$ & 1 & .133 & .012 & .021 & .072 \\
\hline
\end{tabular}




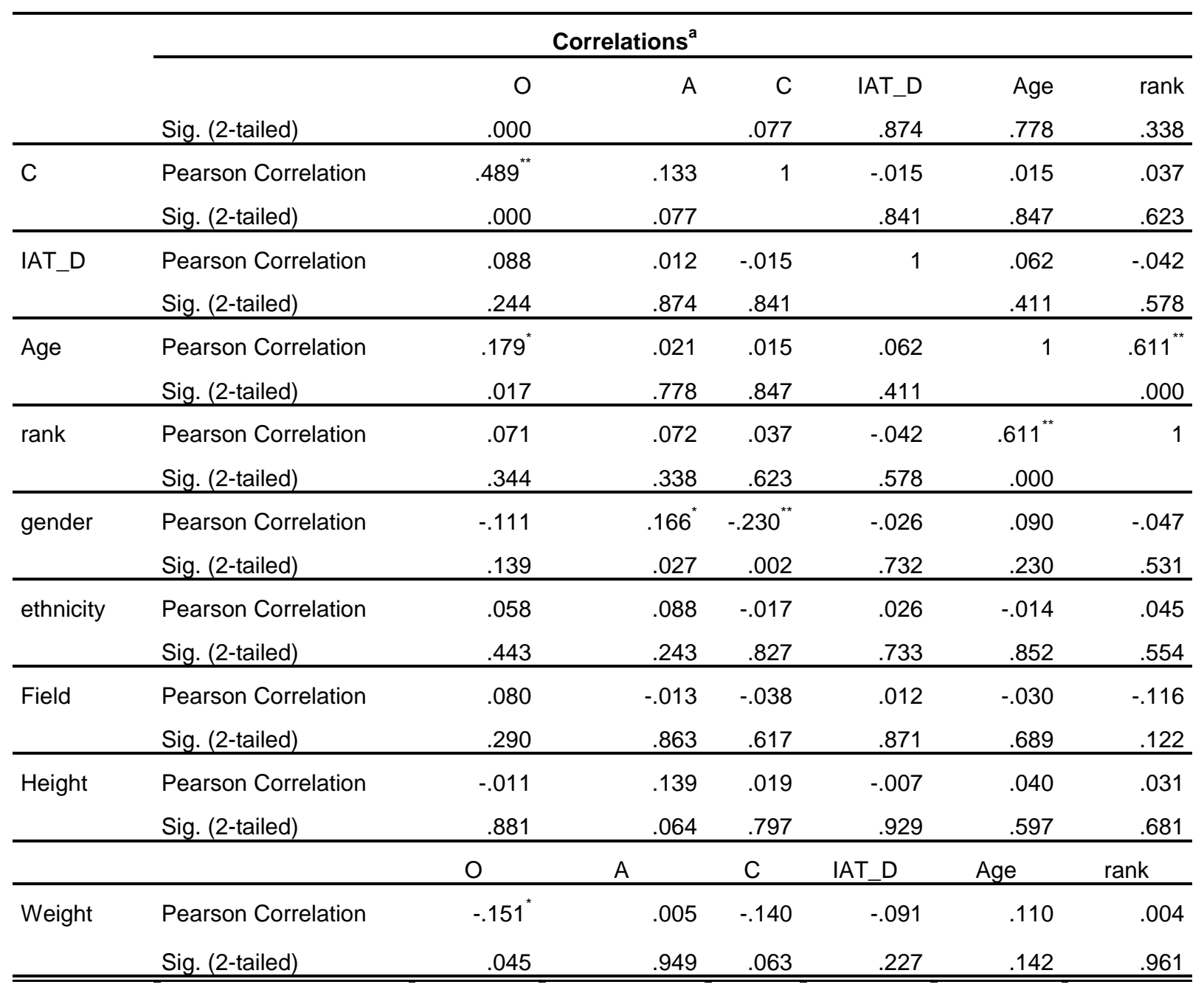

**. Correlation is significant at the 0.01 level (2-tailed).

*. Correlation is significant at the 0.05 level (2-tailed).

a. Listwise $\mathrm{N}=178$

Correlations $^{\mathrm{a}}$

\begin{tabular}{|c|c|c|c|c|c|c|}
\hline & & gender & ethnicity & Field & Height & Weight \\
\hline \multirow[t]{2}{*}{ AAQ_D } & Pearson Correlation & .029 & -.033 & -.048 & -.060 & -.029 \\
\hline & Sig. (2-tailed) & .699 & 658 & .527 & .427 & .702 \\
\hline \multirow[t]{2}{*}{ AAQ_F } & Pearson Correlation & -.016 & .066 & .001 & -.057 & -.100 \\
\hline & Sig. (2-tailed) & .833 & .378 & .993 & .448 & .182 \\
\hline \multirow[t]{2}{*}{ AAQ_W } & Pearson Correlation & .120 & .007 & .042 & .013 & .010 \\
\hline & Sig. (2-tailed) & .111 & .928 & .577 & .859 & .891 \\
\hline \multirow[t]{2}{*}{ AAQ_TOT } & Pearson Correlation & .048 & .008 & -.014 & -.052 & -.051 \\
\hline & Sig. (2-tailed) & .523 & .918 & .853 & .494 & .500 \\
\hline $\mathrm{N}$ & Pearson Correlation & -.064 & .041 & -.060 & .035 & -.001 \\
\hline
\end{tabular}




\begin{tabular}{|c|c|c|c|c|c|c|}
\hline & \multicolumn{6}{|c|}{ Correlations $^{\mathrm{a}}$} \\
\hline & & gender & ethnicity & Field & Height & Weight \\
\hline & Sig. (2-tailed) & .398 & .589 & .424 & .642 & .986 \\
\hline \multirow[t]{2}{*}{$E$} & Pearson Correlation & .122 & .049 & -.003 & .032 & $.159^{*}$ \\
\hline & Sig. (2-tailed) & .104 & .513 & .972 & .670 & .034 \\
\hline \multirow[t]{2}{*}{ O } & Pearson Correlation & -.111 & .058 & .080 & -.011 & $-.151^{*}$ \\
\hline & Sig. (2-tailed) & .139 & .443 & .290 & .881 & .045 \\
\hline \multirow[t]{2}{*}{$A$} & Pearson Correlation & $.166^{*}$ & .088 & -.013 & .139 & .005 \\
\hline & Sig. (2-tailed) & .027 & .243 & .863 & .064 & .949 \\
\hline \multirow[t]{2}{*}{ C } & Pearson Correlation & $-.230^{* *}$ & -.017 & -.038 & .019 & -.140 \\
\hline & Sig. (2-tailed) & .002 & .827 & .617 & .797 & .063 \\
\hline \multirow[t]{2}{*}{ IAT_D } & Pearson Correlation & -.026 & .026 & .012 & -.007 & -.091 \\
\hline & Sig. (2-tailed) & .732 & .733 & .871 & .929 & .227 \\
\hline \multirow[t]{2}{*}{ Age } & Pearson Correlation & .090 & -.014 & -.030 & .040 & .110 \\
\hline & Sig. (2-tailed) & .230 & .852 & .689 & .597 & .142 \\
\hline \multirow[t]{2}{*}{ rank } & Pearson Correlation & -.047 & .045 & -.116 & .031 & .004 \\
\hline & Sig. (2-tailed) & .531 & .554 & .122 & .681 & .961 \\
\hline \multirow[t]{2}{*}{ gender } & Pearson Correlation & 1 & .025 & .049 & $.437^{* *}$ & $.461^{* *}$ \\
\hline & Sig. (2-tailed) & & .742 & .520 & .000 & .000 \\
\hline \multirow[t]{2}{*}{ ethnicity } & Pearson Correlation & .025 & 1 & .009 & .067 & .058 \\
\hline & Sig. (2-tailed) & .742 & & .903 & .375 & .441 \\
\hline \multirow[t]{2}{*}{ Field } & Pearson Correlation & .049 & .009 & 1 & -.008 & $.164^{*}$ \\
\hline & Sig. (2-tailed) & .520 & .903 & & .911 & .028 \\
\hline \multirow[t]{2}{*}{ Height } & Pearson Correlation & $.437^{* *}$ & .067 & -.008 & 1 & $.380^{* *}$ \\
\hline & Sig. (2-tailed) & .000 & .375 & .911 & & .000 \\
\hline \multirow[t]{2}{*}{ Weight } & Pearson Correlation & $.461^{* *}$ & .058 & $.164^{*}$ & $.380^{* *}$ & T \\
\hline & Sig. (2-tailed) & .000 & .441 & .028 & .000 & \\
\hline
\end{tabular}

**. Correlation is significant at the 0.01 level (2-tailed).

*. Correlation is significant at the 0.05 level (2-tailed).

a. Listwise $\mathrm{N}=178$

This correlation matrix reflects five significant correlations between the NEOPI-R, AAQ or the IAT $D$ scores across the demographic variables (Research Question 3 ), at the .05 or .01 levels. However, none of these correlations explained more than $4 \%$ of the variance between the measures. Therefore, they will not be addressed. Also, there 
were no significant findings between the NEO-PI- $\mathrm{R}$ scales scores and the AAQ scale scores or IAT $D$ scores, which is consistent with the results of the regression analyses.

An examination of the correlation coefficients within the AAQ scale scores revealed a significant finding for the AAQ D scale scores and the AAQ Total scores. The corresponding correlation coefficient was .85, indicating a shared variance of $72 \%$. The AAQ is a thirteen-item instrument; seven of those items are contained in the Dislike scale. This shared variance could be a function of the overlap of items, and therefore perhaps measuring the same or similar constructs.

Two research questions were proposed based on a thorough literature review. The research questions addressed the strength of relationship between personality characteristics as measured by the NEO- $-\mathrm{PI}-\mathrm{R}$ and anti-fat attitudes as measured by the AAQ and the Weight IAT.

Research Question 1. To what extent do the NEO-PI-R scale scores (Conscientiousness, Agreeableness, Neuroticism, Extraversion, and Openness to Experience) predict Anti-fat Attitude Questionnaire scores (Dislike, Fear of Fat, Willpower, and Total Scores)?

For Research Question 1, four Stepwise Multiple Regressions were computed to test the hypotheses that the NEO-PI-R subscales Agreeableness and Openness to Experience are significant predictors of the AAQ Total Score and the Willpower Subscale Score. Each of the NEO-PI—R scales (C., A., N., O., and E.) was included as predictor variables, while the AAQ Total and Dislike, Fear of Fat, and Willpower Scores were included as criterion variables. These analyses are summarized in Tables 6-9. 
Table 6.

Summary of Regression Analyses for Personality Variables

Predicting Dislike of Obesity

\begin{tabular}{rrrrr}
\multicolumn{5}{c}{ Model Summary } \\
\hline \hline Model & $\mathrm{R}$ & R Square & Adjusted R Square Std. Error of the Estimate \\
\hline 1 & $.052^{\mathrm{a}}$ & .003 & -.019 & 11.94087 \\
\hline \hline
\end{tabular}

a. Predictors: (Constant), C, A, E, O, N

\begin{tabular}{lrrrrrr}
\multicolumn{7}{c}{ ANOVA $^{\mathrm{b}}$} \\
\hline \hline Model & & Sum of Squares & \multicolumn{1}{c}{ df } & Mean Square & F & Sig. \\
\hline 1 & Regression & 90.516 & 5 & 18.103 & .127 & $.986^{\mathrm{a}}$ \\
& Residual & 33222.170 & 233 & 142.584 & & \\
& Total & 33312.686 & 238 & & & \\
\hline \hline
\end{tabular}

a. Predictors: (Constant), C, A, E, O, N

b. Dependent Variable: AAQ_D

Coefficients $^{\mathrm{a}}$

\begin{tabular}{|c|c|c|c|c|c|c|}
\hline \multirow[t]{3}{*}{ Mod } & & \multicolumn{5}{|c|}{ Standardized } \\
\hline & & \multicolumn{2}{|c|}{ Unstandardized Coefficients } & Coefficients & \multirow[b]{2}{*}{$\mathrm{t}$} & \multirow[b]{2}{*}{ Sig. } \\
\hline & & B & Std. Error & Beta & & \\
\hline \multirow[t]{6}{*}{1} & (Constant) & 22.063 & 9.949 & & 2.218 & .028 \\
\hline & $\mathrm{N}$ & -.068 & .199 & -.033 & -.339 & .735 \\
\hline & $E$ & -.014 & .164 & -.007 & -.085 & .932 \\
\hline & $\mathrm{O}$ & -.015 & .141 & -.009 & -.107 & .915 \\
\hline & $A$ & .030 & .156 & .014 & .189 & .850 \\
\hline & C & -.045 & .172 & -.023 & -.263 & .793 \\
\hline
\end{tabular}

a. Dependent Variable: AAQ_D

Table 7.

Summary of Regression Analyses for Personality Variables

Predicting Fear of Obesity

\section{Model Summary}

\begin{tabular}{|c|c|c|c|c|}
\hline Model & $\mathrm{R}$ & R Square & $\begin{array}{l}\text { Adjusted R } \\
\text { Square }\end{array}$ & $\begin{array}{l}\text { Std. Error of the } \\
\text { Estimate }\end{array}$ \\
\hline 1 & $.115^{\mathrm{a}}$ & .013 & -.008 & 7.77032 \\
\hline
\end{tabular}

a. Predictors: (Constant), C, A, E, O, N 
ANOVA $^{b}$

\begin{tabular}{|c|c|c|c|c|c|c|}
\hline \multicolumn{2}{|c|}{ Model } & \multirow{2}{*}{$\begin{array}{l}\text { Sum of } \\
\text { Squares }\end{array}$} & \multirow[b]{2}{*}{ df } & \multirow[b]{2}{*}{ Mean Square } & \multirow[b]{2}{*}{$\mathrm{F}$} & \multirow[b]{2}{*}{ Sig. } \\
\hline & & & & & & \\
\hline \multirow[t]{3}{*}{1} & Regression & 188.182 & 5 & 37.636 & .623 & $.682^{\mathrm{a}}$ \\
\hline & Residual & 14068.035 & 233 & 60.378 & & \\
\hline & Total & 14256.218 & 238 & & & \\
\hline
\end{tabular}

a. Predictors: (Constant), C, A, E, O, N b. Dependent Variable: AAQ_F

b. Dependent Variable: AAQ_F

Coefficients $^{\mathrm{a}}$

\begin{tabular}{|c|c|c|c|c|c|c|}
\hline \multirow[t]{3}{*}{ Moc } & & \multicolumn{5}{|c|}{ Standardized } \\
\hline & & \multicolumn{2}{|c|}{ Unstandardized Coefficients } & \multirow{2}{*}{$\begin{array}{c}\text { Coefficients } \\
\text { Beta }\end{array}$} & \multirow[b]{2}{*}{$\mathrm{t}$} & \multirow[b]{2}{*}{ Sig. } \\
\hline & & B & Std. Error & & & \\
\hline \multirow[t]{6}{*}{1} & (Constant) & 11.001 & 6.474 & & 1.699 & .091 \\
\hline & $\mathrm{N}$ & -.007 & .129 & -.006 & -.057 & .954 \\
\hline & $E$ & .078 & .107 & .059 & .730 & .466 \\
\hline & $\mathrm{O}$ & -.016 & .092 & -.014 & -.169 & .866 \\
\hline & $A$ & -.028 & .101 & -.020 & -.280 & .779 \\
\hline & C & .150 & .112 & .117 & 1.345 & .180 \\
\hline
\end{tabular}

a. Dependent Variable: AAQ_F

Table 8.

Summary of Regression Analyses for Personality Variables

Predicting Obesity Attribution (AAQ W scale)

Model Summary

\begin{tabular}{rrrrr}
\hline \hline Model & $\mathrm{R}$ & $\mathrm{R}$ Square & Adjusted R Square & Std. Error of the Estimate \\
\hline 1 & $.111^{\mathrm{a}}$ & .012 & -.009 & 6.38600 \\
\hline \hline
\end{tabular}

a. Predictors: (Constant), C, A, E, O, N

\section{ANOVA $^{\mathrm{b}}$}

\begin{tabular}{llrrrrr}
\hline \hline Model & & Sum of Squares & df & Mean Square & F & \multicolumn{1}{c}{ Sig. } \\
\hline 1 & Regression & 117.946 & 5 & 23.589 & .578 & $.717^{\mathrm{a}}$ \\
& Residual & 9501.979 & 233 & 40.781 & & \\
& Total & 9619.925 & 238 & & & \\
\hline \hline
\end{tabular}

a. Predictors: (Constant), C, A, E, O, N

b. Dependent Variable: AAQ_W 


\section{Coefficients $^{\mathrm{a}}$}

\begin{tabular}{|c|c|c|c|c|c|c|}
\hline \multirow[t]{3}{*}{ Mode } & & \multicolumn{5}{|c|}{ Standardized } \\
\hline & & \multicolumn{2}{|c|}{ Unstandardized Coefficients } & \multirow{2}{*}{$\begin{array}{c}\text { Coefficients } \\
\text { Beta } \\
\end{array}$} & \multirow[b]{2}{*}{$\mathrm{t}$} & \multirow[b]{2}{*}{ Sig. } \\
\hline & & B & Std. Error & & & \\
\hline \multirow[t]{6}{*}{1} & (Constant) & 14.378 & 5.321 & & 2.702 & .007 \\
\hline & $\mathrm{N}$ & -.055 & .106 & -.050 & -.517 & .605 \\
\hline & $E$ & .048 & .088 & .045 & .548 & .584 \\
\hline & $\mathrm{O}$ & -.079 & .076 & -.084 & -1.038 & .300 \\
\hline & $A$ & .094 & .083 & .083 & 1.132 & .259 \\
\hline & $\mathrm{C}$ & .047 & .092 & .044 & .511 & .610 \\
\hline
\end{tabular}

a. Dependent Variable: AAQ_W

Table 9.

Summary of Regression Analyses for Personality Variables

Predicting Obesity Bias (AAQ Total Scores)

Model Summary

\begin{tabular}{rrrrr}
\hline \hline Model & $\mathrm{R}$ & $\mathrm{R}$ Square & Adjusted R Square & Std. Error of the Estimate \\
\hline 1 & $.051^{\mathrm{a}}$ & .003 & -.019 & 20.81705 \\
\hline \hline
\end{tabular}

a. Predictors: (Constant), C, A, E, O, N

ANOVA $^{\text {b }}$

\begin{tabular}{llrrrrr}
\hline \hline Model & & Sum of Squares & \multicolumn{1}{c}{ df } & Mean Square & F & \multicolumn{1}{c}{ Sig. } \\
\hline 1 & Regression & 262.257 & 5 & 52.451 & .121 & $.988^{\text {a }}$ \\
& Residual & 100970.446 & 233 & 433.350 & & \\
& Total & 101232.703 & 238 & & & \\
\hline \hline
\end{tabular}

a. Predictors: (Constant), C, A, E, O, N

b. Dependent Variable: AAQ_TOT 


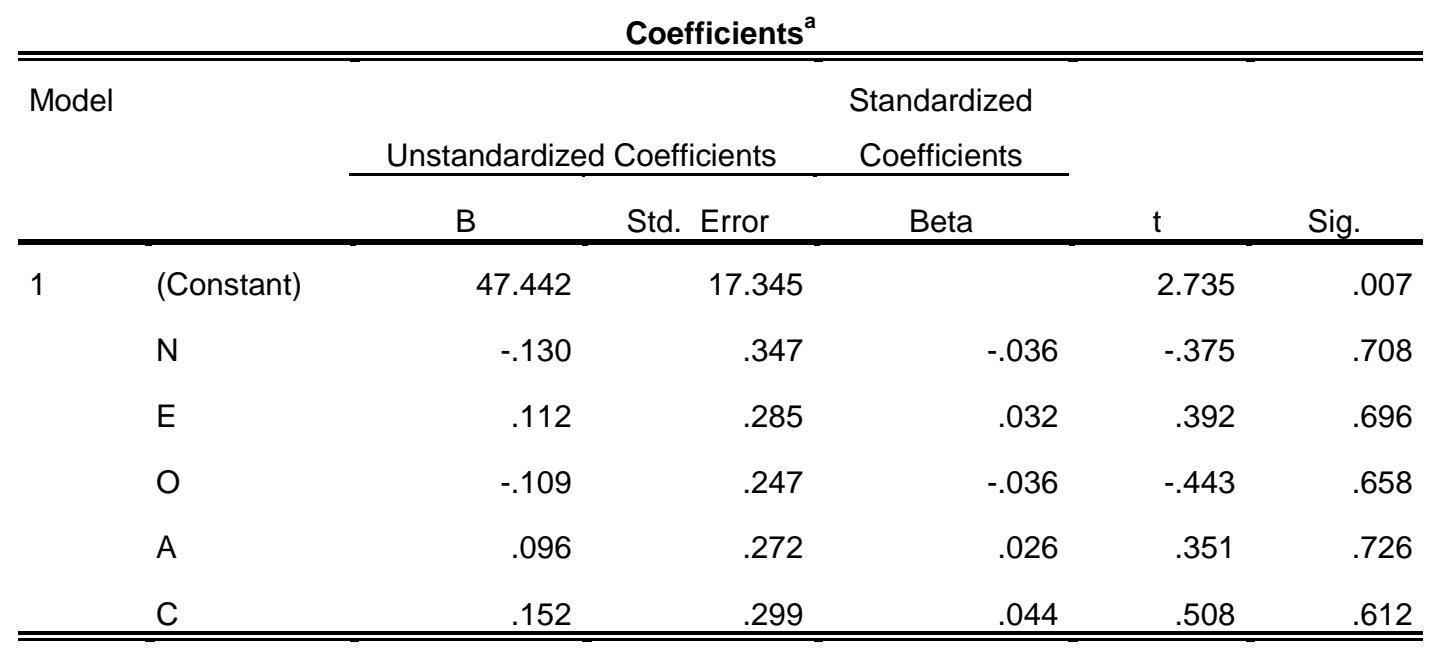

a. Dependent Variable: AAQ_TOT

Tables 6-9 contain the results of four regression analyses computed with the NEO $-\mathrm{PI}-\mathrm{R}$ scale scores (C., A., N., O, and E.) as predictor variables and the AAQ scale (Dislike, Fear of Fat, Willpower, and Total Scores) scores as criterion variables. These analyses did not yield significant findings, thus failing to support the hypotheses in research question one.

Research Question 2. To what extent did the NEO-PI-R scales (Conscientiousness, Agreeableness, Neuroticism Extraversion, and Openness to Experience) predict the IAT D Scores? A Stepwise Multiple Regression was computed to test the hypothesis that the NEO-PI-R subscales Agreeableness and Openness to Experience are significant predictors of the IAT $D$ Score. Each of the NEO-PI-R scales (C., A., N., O, and E.) has been utilized as predictor variables, and the IAT $D$ score as the criterion variable. These analyses are summarized in Table 10. 
Table 10.

Summary of Regression Analyses for Personality Variables

Predicting Obesity Bias (IAT D score)

Model Summary

\begin{tabular}{rrrrr}
\hline \hline Model & $\mathrm{R}$ & $\mathrm{R}$ Square & Adjusted R Square Std. Error of the Estimate \\
\hline 1 & $.137^{\mathrm{a}}$ & .019 & -.006 & .45210 \\
\hline \hline
\end{tabular}

a. Predictors: (Constant), C, A, E, O, N

\begin{tabular}{llrrrrr}
\multicolumn{7}{c}{ ANOVA $^{\mathrm{b}}$} \\
\hline \hline Model & & Sum of Squares & \multicolumn{1}{c}{ df } & Mean Square & F & Sig. \\
\hline 1 & Regression & .760 & 5 & .152 & .744 & $.591^{\mathrm{a}}$ \\
& Residual & 39.856 & 195 & .204 & & \\
& Total & 40.617 & 200 & & & \\
\hline \hline
\end{tabular}

a. Predictors: (Constant), C, A, E, O, N

b. Dependent Variable: IAT_D

Coefficients $^{\mathrm{a}}$

\begin{tabular}{|c|c|c|c|c|c|c|}
\hline \multirow[t]{3}{*}{ Mode } & & \multicolumn{5}{|c|}{ Standardized } \\
\hline & & \multicolumn{2}{|c|}{ Unstandardized Coefficients } & \multirow{2}{*}{$\frac{\text { Coefficients }}{\text { Beta }}$} & \multirow[b]{2}{*}{$\mathrm{t}$} & \multirow[b]{2}{*}{ Sig. } \\
\hline & & B & Std. Error & & & \\
\hline \multirow[t]{6}{*}{1} & (Constant) & .774 & .411 & & 1.883 & .061 \\
\hline & $\mathrm{N}$ & -.002 & .008 & -.019 & -.182 & .856 \\
\hline & $E$ & -.007 & .007 & -.089 & -1.003 & .317 \\
\hline & $\mathrm{O}$ & .006 & .006 & .096 & 1.088 & .278 \\
\hline & $A$ & .002 & .007 & .022 & .264 & .792 \\
\hline & C & -.007 & .007 & -.086 & -.902 & .368 \\
\hline
\end{tabular}

a. Dependent Variable: IAT_D

A regression analysis conducted with the NEO-PI- $\mathrm{R}$ scale scores (C., A., N., O, and E.) as predictor variables and the IAT $D$ scores as criterion variables failed to support the hypothesis posited in question two.

Table 11 provides descriptive statistics of the dependent and independent variable scores. The AAQ F, W and Total scores were negatively skewed and the standard deviations were greater than the means. Table 12 displays the combined completion times (in minutes) for the NEO-PI- $\mathrm{R}$ and the AAQ. The NEO $-\mathrm{PI}-\mathrm{R}$ manual (Costa 
\& McCrae, 1992) suggests that the usual completion time for the NEO-PI- R alone is 30-40 minutes. The importance of the Table 11 findings will be discussed further in Chapter 5.

Table 11 .

Descriptive Statistics of IV and DVs.

Std.

$\mathrm{N} \quad$ Range MinimumMaximumMean DeviationVarianceSkewness

Std.

StatisticStatisticStatistic Statistic StatisticStatistic Statistic StatisticError

\begin{tabular}{|c|c|c|c|c|c|c|c|c|}
\hline AAQ_D & 239 & 49.00 & .00 & 49.00 & 16.217611 .83086 & 139.969 & .561 & .157 \\
\hline AAQ_F & 239 & 27.00 & .00 & 27.00 & 18.71977 .73951 & 59.900 & -.914 & .157 \\
\hline AAQ_W & 239 & 27.00 & .00 & 27.00 & 15.75736 .35766 & 40.420 & -.442 & .157 \\
\hline AAQ_TOT & 239 & 96.00 & .00 & 96.00 & 50.694620 .62395 & 425.347 & -.236 & .157 \\
\hline $\mathrm{N}$ & 240 & 30.00 & 40.00 & 70.00 & 54.52505 .77103 & 33.305 & .199 & .157 \\
\hline $\mathrm{E}$ & 240 & 32.00 & 22.00 & 54.00 & 35.19585 .88089 & 34.585 & .372 & .157 \\
\hline $\mathrm{O}$ & 240 & 64.00 & 21.00 & 85.00 & 52.05426 .82853 & 46.629 & .057 & .157 \\
\hline A & 240 & 37.00 & 26.00 & 63.00 & 46.88755 .56362 & 30.954 & -.261 & .157 \\
\hline $\mathrm{C}$ & 240 & 33.00 & 36.00 & 69.00 & 50.06256 .02368 & 36.285 & .383 & .157 \\
\hline IAT_D & 202 & 2.13 & -.67 & 1.46 & $.5191 \quad .44963$ & .202 & -.294 & .171 \\
\hline $\begin{array}{l}\text { Valid N } \\
\text { (listwise) }\end{array}$ & 200 & & & & & & & \\
\hline
\end{tabular}

The measures of dispersion findings denoted in Table 11 indicate that the AAQ Willpower, Fear of fat, and Total scale scores are negatively skewed, as are the IAT $D$ scores. Skew was not present among the NEO-PI-R scale scores. The mean scores for the NEO-PI-R scales are within the -average range" and below the cut-off scores that suggest clinical significance, according to the authors (Costa and McCrae, 1992). These scores suggest that, as a group, the students in this sample did not significantly or 
strongly identify with the personality characteristics Conscientiousness, Agreeableness, Neuroticism, Openness to Experience, or Extraversion.

Table 12.

Descriptive Statistics of NEO-PI-R and AAQ

completion times.

\begin{tabular}{|c|c|c|}
\hline $\bar{N}$ & Valid & 244 \\
\hline \multirow{2}{*}{\multicolumn{2}{|c|}{ Missing }} & 1 \\
\hline & & 29.8852 \\
\hline \multicolumn{2}{|c|}{ Median } & 26.5000 \\
\hline \multicolumn{2}{|c|}{ Mode } & $20.00^{a}$ \\
\hline \multicolumn{2}{|c|}{ Skewness } & 1.904 \\
\hline \multicolumn{2}{|c|}{ Std. Error of Skewness } & .156 \\
\hline \multicolumn{2}{|c|}{ Kurtosis } & 5.229 \\
\hline \multicolumn{2}{|c|}{ Std. Error of Kurtosis } & .310 \\
\hline
\end{tabular}

a.ultiple modes exist. The smallest value is shown

Table 12 reflects the mean, median and mode scores for the participants combined completion time for the NEO-PI- $\mathrm{R}$ and AAQ scales. Costa and McCrae (1992) reported that the average completion time for the NEO-PI- $\mathrm{R}$ is $30-40$ minutes, whereas the total average completions time for participants in this study was just under 30 minutes. The implications of the findings in this study will be addressed in the next chapter.

Summary of the Results

The results of the analyses performed within this study suggest that no significant relationships exist between the dependent variables (AAQ total, AAQ D, AAQ F, and AAQ W scores or the IAT $D$ scores) and the independent variables, the NEO-PI-R scales (C., A., N., O., and E.). Some of the correlation coefficients calculated across the dependent variables, independent variables, and the demographic variables did reflect some small to large effect sizes, which accounted for little variance. The implications of the findings of this study will be addressed in greater detail in the next chapter. 


\section{Chapter 5: Discussion}

This chapter will discuss the implications of the results presented in Chapter 4. First, the findings of the regression analyses will be discussed in reference to possible explanations of the findings and their divergence from the previous literature. Next, limitations of the study will be reviewed. Finally, recommendations and implications will be made for clinical applications and future research.

\section{Findings}

The purpose of this study was to investigate the relationship between personality characteristics and bias toward individuals who are obese. The research findings of this study do not indicate that significant relationships exist between the Big Five personality characteristics, Conscientiousness, Agreeableness, Neuroticism, Openness to Experience, and Extraversion, and anti-fat bias as measured by the Anti-Fat Attitudes Questionnaire (AAQ) and a Weight Implicit Association Test (IAT). Hypothesis 1A predicted that low Agreeableness scores on the NEO-PI—R would be associated with high AAQ Total Scores, as well as high Willpower scale scores. This hypothesis was not supported by the findings of this study; a significant relationship between Agreeableness and anti-fat bias could not be established. Regression analyses failed to confirm significant relationships between the predictor variables (C., A., N., O., and E) and the criterion variables (AAQ Total, and AAQ Dislike, Fear of Fat and Willpower scores). Personality characteristics did not significantly predict bias toward individuals who are assumed to be obese.

Additionally, Hypothesis 1B predicted that low Openness to Experience scores 
would predict anti-fat bias as measured by high AAQ Total Scores and high Willpower scale scores. The results did not support this hypothesis; no significant relationships between these variables were discovered through regression analyses performed with the above-mentioned predictor and criterion variables.

Hypothesis 2A was that the NEO-PI—R subscale Agreeableness score would be a significant predictor of the IAT $D$ Score. This hypothesis was not supported by the results of this study as regression analyses failed to significantly correlate Agreeableness with anti-fat bias as measured by the IAT. Agreeableness, as measured by the NEO$\mathrm{PI}-\mathrm{R}$ did not predict anti-fat bias.

Similarly, Hypothesis $2 \mathrm{~B}$ posited that the NEO- $-\mathrm{PI}-\mathrm{R}$ subscale Openness to Experience score would be a significant predictor of the IAT $D$ Score. Again, the hypothesis was not supported by these research findings; Openness to Experience did not significantly predict anti-fat bias as measured by the IAT $D$ scores. The regression analyses failed to confirm significant relationships between the predictor variables $(\mathrm{C}$., A., N., O., E) and the criterion variable (IAT $D$ scores).

One explanation for these findings is that personality characteristics are simply not predictors of obesity bias and they are not related. Obesity bias may be predicted by or related to something other than personality. Perhaps obesity bias is different from other types of prejudice. The absence of significant findings may result from an interaction between the methodology utilized and personality theory as defined for the purposes of this study. It is this author's opinion that this is the most cogent explanation. Perhaps for the purposes of this research, personality should be conceptualized with greater richness or complexity than the Big Five model permits. This modification, along 
with suggested changes for future research will be addressed later in this chapter.

The findings of this research study conflict with previous studies utilizing the $\mathrm{NEO}-\mathrm{PI}-\mathrm{R}$ to predict prejudice toward other groups, which is puzzling. Prior investigations of prejudice or bias against "out-groups" utilizing the Big Five factors (Ekehammar \& Akrami, 2003, 2004, 2007; Saucier \& Goldberg, 1998) through administration of the NEO $-\mathrm{PI}-\mathrm{R}$ found significant negative correlations between Agreeableness and Openness to Experience with generalized prejudice; similar results were reported by Flynn (2005).

The mean scores of the NEO—PI—R scales (Table 11) for this sample may contribute to understanding the lack of significant findings. As stated previously, it appears that the means for C., A., N., O., and E. are not clinically significant. It stands to reason these scale scores cannot correlate with other measures as they demonstrate little variability; their proximity to each other does not allow for differentiation and potential correlation with anti-fat measures. The participants seem to have similar personality characteristics with little distinctiveness. Simply put, there is little for anti-fat bias to correlate with because participant personalities are so similar.

Obesity bias has been observed across age groups, having been demonstrated in children as young as four years of age (Turnbull, Heaslip, \& McLeod, 2000). Klaczynski, Goold, and Mudry (2004) studied stereotypes toward obesity, self-esteem, and ideal "thinness" among college students, noting that obesity bias existed in their sample. Likewise, anti-fat bias appears to exist in the present study‘s sample as well. An interesting finding involved examination of the anti-fat measures of the AAQ scales. Crandall (personal communication, January 29, 2011) reported that mean scores or -eut- 
offs" across groups have not been established for the AAQ. While the AAQ scores in this study were not subjected to statistical analyses, Crandall indicated he orders scores along dimensions measured by the subscales; higher scores suggest more bias. In this study each AAQ scale score, with the exception of AAQ D, are negatively skewed, as was the IAT $D$ scores. Qualitatively, a negative skew indicates that the tail on the left side of the probability density function is longer than the right side and the bulk of the values (including the median) lie to the right of the mean. The mass of the distribution is concentrated on the right and it has relatively few low values, and consequently a greater number of higher values. Therefore, the results suggest that the anti-fat bias scores for this sample are elevated, and indicate that: 1) this sample fears becoming fat, 2) ascribes the lack of willpower to obesity, and 3) is biased against obesity.

In addition to anti-fat bias, the college students participating in this study identified with a fear of being fat (AAQ F scores) and the ascription of willpower to obesity (as measured by the AAQ Willpower scores). The findings of fear of becoming fat in this study corroborate the results of a study by the Rudd Center for Food Policy and Obesity at Yale University (Schwartz, et al. 2006), reporting respondent aversion to obesity. The research showed that almost half of the respondents surveyed would shorten their lives a year rather than be obese. The opinions of the students in the current study also reflect fears of becoming obese, although this study did not measure the lengths to which these participants would go to avoid obesity.

The students in this study ascribed willpower as a cause of obesity which is consistent with the findings of Crandall, et al., (2001). These authors noted that controllability (willpower) is a significant factor in anti-fat prejudice. As in previously 
cited research, participants in this study also seem to hold obese individuals responsible for their condition, as indicated by their AAQ Willpower scores. Attribution theory posits that people will ascribe internal loci of control to others' failures and an external locus of control to their successes. In this study, the students attributed willpower (lack of) to the obese person's weight, which is consistent with the tenets of attribution theory.

Additional correlation analyses were performed to examine the independent and dependent variables across the demographic variables. The demographic variables (Class Rank, Age, Gender, Ethnicity, Height, and Weight) were not significantly correlated with the NEO - PI-R scales or the AAQ scores. Personality and anti-fat bias is not significantly correlated with any of the demographic variables included in this study.

\section{Limitations}

One of the limitations, the generalizability of the results of this study, may be a function of the participant pool and several threats to the validity of the results are discussed. The use of college students was appropriate given the nature of the study and because researchers use these types of measures frequently with college populations. The participants in this study were primarily 19 -year-old, Caucasian females. However, this could result in some limitations due to a variety of selection effects (Cook \& Campbell, 1979). First, the attitudes and biases of this population may not be representative of a wide spectrum of society and the generalizability of these findings may be limited for several reasons. The age, ethnicity, and education level of some of the participants are similar (19-year-old Caucasian females enrolled in their second year of college) and perhaps people of different ages or ethnicity do not share their opinions. The opinions of the participants in this sample may be the result of demand characteristics of the study. 
The study solicitation was titled Body Image" and perhaps this title attracted participants with specific concerns and/or opinions about body image in general and particularly their own body image. Also, the use of this title may have led some students to assume that the purpose of this study was to confirm societal preferences for thinness and they responded to the items accordingly. As stated earlier, Sorbara and Geliebter (2002) reported that Caucasian females were more sensitive to body image dissatisfaction than African American or Hispanic women (potential interaction selection effects). Therefore, other ethnic groups may not share the opinions of this sample. The developmental level or maturation of this sample may have interacted with the above-mentioned ethnic sensitivity. Perhaps 19-year-old females are more susceptible to societal influence and feel the pressure to be thin more acutely than their older counterparts, thus affecting their responses to anti-fat items.

Second, male undergraduate students or those majoring in other disciplines may not share the attitudes of the majority of this sample, female undergraduate psychology students. Third, those students enrolled at other universities may not share the attitudes of these students. Fourth, it may be that the participants in this study were not representative of individuals who chose not to become involved in this research, another form of sampling bias. Fifth, perhaps students who are not interested in participating in psychology research espouse different opinions about obesity or identify with different personality characteristics. Sixth, the United States has a growing multicultural population. The potential homogeneity of participants in this study may not reflect the attitudes of the larger population. Finally, this study included a population that could be 
considered a convenience sample, which presents inherent risks to applying these findings to the U.S. population as a whole.

Second, it seems possible that the personality scores were affected by the time participants took to complete the questionnaires. For example, the calculated mode for completing these questionnaires (NEO-PI- R and AAQ) was 20.26 minutes; the median was 26 minutes and the average was 30 minutes. Costa and McCrae (1992) suggested that the usual completion time for the NEO-PI- $\mathrm{R}$ alone is $30-40$ minutes. It may be that the participants chose to respond quickly in the interest of saving time, without careful consideration of item content. Therefore, their responses and these results may not accurately reflect their actual opinions.

Third, given the nature of the surveys, it may be possible that the participants were apprehensive of evaluation of their biases. The participants may have chosen to downplay their bias toward obesity, in the interest of seeming unbiased. Holmes (2009) conducted research examining the effects of social desirability on measures of prejudice scores. Holmes noted that several measures of prejudice are designed to reduce the transparent nature of their items. The participants were asked to complete four measures; the Old-Fashioned Racism Scale, the Symbolic Racism Scale, the Color-Blind Racial Attitudes Scale, and the Modern Racism Scale. The participants were given one of three instruction sets prior to completing the questionnaires. The fypical” instructions were the standard instructions that accompany these measures. Two other groups of participants were instructed to respond to the items so as to either attempt to appear very biased (-bad") or highly unbiased (-good").

Holmes (2009) found that several measures were quite transparent." The author 
noted that regardless of whether the scale in question contained overt references to explicit racial bias or more veiled items consistent with more subtly biased attitudes, participants were equally capable of identifying the social implications of scale items and manipulating their responses accordingly.

A study of religious orientation, prejudice, and social desirability was conducted by Batson, Naifeh and Pate (1978). These authors wondered if prejudice among individuals from different religious orientations was mediated by social desirability. The researchers administered paper/pencil and behavioral measures of prejudice to individuals who identified as intrinsic (religion as an end in itself) and extrinsic (religion as a means to some other end) believers. They discovered that scores of intrinsic measures of religious orientation correlated negatively with measures of racial bias to a greater degree than extrinsic measure scores. However, the intrinsic scores also correlated with a measure of social desirability. When controlled for social desirability behaviorally, the relationship between an intrinsic orientation and racial bias was positive.

Consequently, participants in this study may have been able to assess the transparent nature of the AAQ and respond in a manner to seem unbiased. This may explain the AAQ Dislike scale score results. These scores suggested that the participants in this study did not indicate they disliked individuals who are obese. In our society where political correctness is valued, it may be gauche to admit that one dislikes individuals who are obese. Thus the participants may have responded in a sociallyappropriate manner to give the appearance of being unbiased.

Fourth, web-based surveys may be subject to a self-selection bias, a potential for 
sampling error. This type of research instrument may be attractive to individuals who are different (in terms of bias or personality traits) from students who choose other types of research involvement. Also, students with an interest in body image may have been more inclined to participate than others, in light of the description of this study. Thus it was difficult to determine if the observed differences were true differences from the sampling population (Heppner et al., 1999).

A fifth limitation is that this study relied in part on self-report data, which may have been subject to environmental distractions, data distortion, respondents guessing at the hypothesis, and order effects (Heppner et al., 1999). This study attempted to overcome these limitations through the informed consent process, survey construction, data screening procedures, and counter-balancing. Informed consent information was provided to explain the nature of the research, while attempting to lead the participants away from guessing the actual hypotheses. The NEO-PI- $-\mathrm{R}$ construction arranges one item from each of the 30 facet scales consecutively, in eight repeating cycles. This reduces the transparency of the questionnaire. Potential data distortion was addressed through data screening procedures including checks for the accuracy of the data, screening for missing data, examining the normality of the distribution and the presence of outliers. The application of counter-balancing reduces order effects by alternating the presentation of the measures, thereby reducing the effects that completing one measure may have on responses for subsequent ones. Finally, the results of this study may be influenced by selection bias and consequently affects the generalizability of these results. Recommendations and Implications for Future Research and Clinical Applications

The findings of this study did not confirm the hypotheses; personality 
characteristics did not significantly predict anti-fat bias. In light of the literature review conducted for this research, these results are inconsistent with similar studies and are unexpected. As stated earlier, the literature indicates: 1) that personality characteristics (Agreeableness and Openness to Experience) predict generalized prejudice toward other out-groups; and 2) obesity and obesity bias are present among U.S. citizens and specifically within the college population. Therefore, it seems reasonable to hypothesize that these personality characteristics would predict obesity bias within the college population included in this study. The following suggestions are offered to advance research regarding personality and anti-fat bias.

Participants. The literature review for this research indicated that there were no previous studies investigating personality characteristics that predict obesity bias. As this was seemingly the first study of its kind, additional research is needed. Future research could consider repeating this study with a more heterogeneous sample. However, it might be useful to replicate this study using a sample of students from geographically diverse institutions or even nonstudents who reflect a range of ages and socioeconomic levels. Perhaps a larger sample size, including participants from two or more universities would be prudent.

Measures. Future researchers may want to administer the paper and pencil version of the NEO $-\mathrm{PI}-\mathrm{R}$, which would require a test administrator to be present. The presence of the researcher may influence the participants to perhaps be more diligent and spend more time completing the questionnaires. The presence of the researcher may cause the students to contemplate their responses, which may result in personality profiles that reflect greater variability of personality scores and thus, different research 
results.

Another direction for future research might include the use of different measures of personality and anti-fat bias than those administered in this study. Although the $\mathrm{NEO}-\mathrm{PI}-\mathrm{R}$ has been used in previous research regarding prejudice and personality characteristics, alternative measures such as the 16 Personality Factors (16-PF) or the California Personality Inventory (CPI) could be considered (both are derived from the Big Five theory). These instruments may measure personality traits that are unique and different from the NEO- $-\mathrm{PI}-\mathrm{R}$ and consequently may be better predictors of anti-fat bias. The 16-PF may be preferable for use within the college population due to shorter administration time.

This study of personality and anti-fat bias was conducted through administration of the NEO $-\mathrm{PI}-\mathrm{R}$, a personality measure created from the Big Five theory of personality. Prior research concerning prejudice and personality characteristics utilizing the NEO $-\mathrm{PI}-\mathrm{R}$ found that Agreeableness and Openness to Experience accounted for the most variance when determining which personality factors best predicted prejudice. This study was conducted under the assumption that the NEO-PI-R personality scales measured what they were purported to measure, namely Agreeableness and Openness to Experience. Although this instrument has been correlated with other types of prejudice, it may be that these scales measure other or additional qualities that do not correlate with anti-fat bias.

Likewise, alternate paper and pencil measures of anti-fat bias could be administered along with measures of social desirability. Other anti-fat bias measures may include scales that are correlated with personality characteristics. Social desirability 
measures may provide more knowledge about the interplay between expressed bias toward people who are obese and the desire to appear unprejudiced.

As such, additional research in this area could consider the use of subtler measures of anti-fat bias. There are a variety of new techniques that have been utilized in studies of prejudice. One of the more controversial methods is referred to as symbolic or modern racism (Kinder, 1986; Sears, Sidanius, \& Bobo, 2000; Sniderman \& Tetlock, 1986). These measures include self-report scales designed to assess more indirect forms of hostility, such as resentment of welfare abuse and dislike of busing and affirmative action, and that can be justified by appeals to traditional American values such as selfreliance and individual responsibility. A similar approach could be applied to the study of obesity bias. Potential measures of this nature might assess the respondents' attitude toward individuals who are obese paying for one airline seat when they may require two; resentment towards obese individuals who necessitate more space and perhaps result in crowding or encroachment of personal space on modes of public transportation. These subtler measures may correlate with personality measures in ways not observed in the current study.

Most recently and perhaps the most methodologically and theoretically sophisticated approach to developing subtler means of assessing prejudice are measures of implicit prejudice that explore the associative linkages in memory between words with positive or negative valence and racial stimuli (Fazio \& Olson, 2003). Arkes and Tetlock (2004) conducted a study of racial prejudice using two instruments; the IAT and the affective priming technique. The latter requires participants to categorize positive and negative target stimuli (e.g., words) according to their valence. Shortly before each 
target, a positive or negative prime stimulus is presented, with the valence of prime and target being varied orthogonally, meaning that the stimuli are not correlated with each other. Typically, mean response times (and/or error rates) are lower in congruent trials (i.e., prime and target are of same valence) compared to incongruent trials (i.e., prime and target are of different valence). Arkes and Tetlock questioned the supposition that differential reaction times to racial stimuli (images of Caucasians and African Americans) indicated prejudice. They suggest that prior research findings make an inferential leap from differential reaction times to the presence of prejudice. Their study suggested that reaction times might reflect shared cultural stereotypes rather than personal animus, and the affective negativity attributed to participants may be due to cognitions and emotions that are not necessarily prejudiced. These authors proposed that some individuals may appear to be "prejudiced" toward some groups but in fact may be pessimistic or negative towards people in general.

Graziano, Bruce, Sheese and Tobin, (2007) concur that researchers may not be solely evaluating prejudice in their studies of bias but negativity also, and they believe a distinction exists between prejudice and negativity. This distinction suggests that prejudice cannot be assessed solely through the examination of differences in reactions to out-group persons but also through the examination of differential reactions to out-group persons relative to in-group targets. Therefore, future research should investigate prejudice and negativity toward individuals who are obese. The IAT detected bias in this study and future researchers could include additional instruments that measure anti-fat negativity/bias along with the IAT. This may assist researchers to gain more insight into the potential variance shared between bias and affective negativity. 
Attribution theory. Future research could be conducted regarding attribution theory and obesity. An investigation of the fundamental attribution error" among individuals who are obese could be conducted. A study of this nature would investigate if the fundamental attribution error applies to the ascription of controllability of obesity for self and others. Furthermore, it may be useful to conduct similar research regarding weight loss and attribution. How would individuals who are obese attribute weight loss success for themselves and other obese individuals?

Prejudice. Researchers should investigate the possibility that obesity bias is unique and different from other forms of prejudice. Ekehammar and Akrami (2003) reported that four types of prejudice (racism, sexism, prejudice toward Gays, and prejudice toward mentally disabled people) are highly correlated and form one single factor of prejudice as a unit of personality, or, as Allport concluded, The evidence we have reviewed constitutes a very strong argument for saying that prejudice is basically a trait of personality. When it takes root in life it grows like a unit. The specific object of prejudice is more or less immaterial" (1954, p.73). This author disagrees with this position; the findings of this study might suggest that obesity bias is not trait of personality as personality could not account for obesity bias.

However, it may be that obesity prejudice is somehow distinct from other forms of bias and cannot be included in a generalized measure of prejudice or viewed in the same way as other forms of prejudice against other "out-groups." The study of obesity bias may require researchers to evaluate factors beyond attributions of controllability, cultural norms and group membership. Could it be that humans are genetically predisposed to dislike obesity because it may have reduced survival rates among our 
earliest ancestors?

Personality theory. Previously, the validity of the NEO-PI—R personality scales was cited as a potential limitation for this study. On a larger scale, beyond the validity of this measure looms the possibility that the Big Five personality theory may not adequately conceptualize the complexities of personality. The NEO-PI-R was designed to measure personality as defined by the Big Five theory; what if this theory is inaccurate or incomplete? Is it possible that obesity bias can be predicted by personality characteristics or qualities that are beyond the scope of the Big Five personality theory?

In 2009, Mischel published his reflections on the development of personality theory since his initial treatise in 1968. In his review of the development of personality theory and personality science, the author questions factor analytic and psycho-lexical approaches to personality measurement, championed by proponents of the Big Five theory. Mischel wondered if the study and conceptualization of the richness of personality would be encumbered by the simplistic limits of adjective-derived traits. Mischel wrote that he feared "that the human personality and our science was in danger of becoming headless, brainless, self-less, de-contextualized from the social world, lacking an unconscious, and missing an emotional/motivational system" (p. 285). The author's concerns give pause to the -be-all-end-all" nature of this theory of personality; perhaps obesity bias and personality would be better measured through a different conceptual lens.

Mischel suggested that personality science consider the individual as an interactive system, rather than merely a reductionistic set of traits, or "operationalized variables." The author espouses a view of personality within the context of an 
individual's distinctive social -- cognitive -- affective system. This conceptualization allows for dynamic interactions between individual thoughts, feelings and social contexts, perhaps akin to complexity theory. A complex system is one in which numerous independent elements continuously interact and spontaneously organize and reorganize themselves into more and more elaborate structures over time. Additionally, the cognitive -- affective components of Mischel's theory liken to attribution theory (the interplay between thoughts, feelings and development of attributions and understanding the behavior of self and others). Mischel's model may be viewed as the natural progression of attribution theory and the author might argue that attributions are part of personality, not the result of it.

Mischel's approach to the study of personality may be a valuable tool in understanding the relationship between personality and anti-fat bias. The findings of the present study suggest that college students ascribe controllability as a causal agent to obesity. The research conclusions of O`Brien, Puhl, Latner, Mir, and Hunter (2010) indicate that bias towards individuals who are obese can be mediated by psychologicaleducation regarding genetic determinants of obesity.

O'Brien, et al., (2010) conducted an experiment which sought to reduce implicit and explicit anti-fat prejudice in pre-service health students. Health promotion/public health bachelor degree program students $(n=159)$ were randomized to one of three tutorial conditions. One condition presented an obesity curriculum on the controllable reasons for obesity (i.e., diet/exercise). A prejudice reduction condition presented evidence on the uncontrollable reasons for obesity (i.e., genes/environment); whereas a neutral (control) curriculum focused on alcohol use in young people. Measures of 
implicit and explicit anti-fat prejudice, beliefs about obese people, and dieting, were taken at baseline and post-intervention. These researchers found that anti-fat prejudice was mediated by causal attribution; bias could be reduced or exacerbated dependent upon the presented causal agent. When genetic and environmental factors for obesity were introduced, anti-fat bias decreased.

In light of these findings and the theory of personality proposed by Mischel, future researchers should investigate the social -- cognitive -- affective dynamics of antifat bias. O'Brien, et al., (2010) altered anti-fat bias through redefining attribution, but what is the nature of the mechanism that causes change? In other words, can Mischel's model explain the interplay between affect, cognition (and social-context) that create bias towards obesity? Applying this theory of personality to understanding anti-fat bias seemingly offers promise for deeper understanding of a complex interaction.

\section{Clinical Applications}

Clinicians should become more knowledgeable about the genetic and environmental factors that contribute to obesity and create opportunities for educating others. Through outreach, seminars, presentations, etc., clinicians have the opportunity to reduce myths that individuals who are obese have complete control of their obesity, decrease anti-fat bias, and educate others about the stigma of obesity to change negative attitudes.

Therapists could also provide counseling to individuals who are obese.

Explanations of the genetic components may help to reduce feelings of guilt and shame caused by misattribution of causality since obese individuals may assume blame for their conditions. Talking to a therapist may help identify effective ways to cope with stigma 
and to replace self-defeating thoughts or self-blame with healthier ways of coping. Psycho-education may assist these individuals to become more self-accepting, improve their self-esteem and develop adaptive feelings, thoughts and behaviors to improve their self care. Therapists can assist these individuals to arrive at a healthy balance of change and acceptance. Therapists can also suggest that individuals who are obese obtain social support from others who are struggling with weight stigma, or from friends and family members who are supportive.

Psychologists can also become advocates and participate in public groups that protest weight stigmatization. The National Association for the Advancement of Fat Acceptance (NAAFA) is one such advocacy group which promotes size acceptance, fights weight discrimination, and publicly campaigns to challenge stigma. Weight stigma is pervasive and acceptable in our society, so transforming societal attitudes and enacting laws that prohibit discrimination based on weight are necessary to eliminate the problem of stigma toward obese individuals. This requires enormous effort and there are other important steps that can be taken by both individuals and their healthcare providers to help improve the daily functioning and well-being of obese individuals.

People who are struggling with weight stigma can begin to approach this problem by becoming advocates for themselves. Clinicians can help them in identifying situations in which they have been stigmatized because of their weight and deciding how best to handle the situation to achieve positive emotional health to help prevent additional stigma from occurring.

\section{Summary and Conclusions}

The purpose of this study was to examine if personality can differentiate 
individuals who are intolerant of obesity from those who are more accepting of individuals who are obese and contribute to the research in this area. The findings of this study are inconsistent with the findings of prior research concerning prejudice and personality. Personality characteristics (Agreeableness and Openness to Experience) did not predict anti-fat bias. These personality characteristics measured by the NEO-PI-R and incorporated in this and prior studies, have been correlated with generalized prejudice as evidenced in this study's literature review. Also, research of attribution theory and prejudice found that attribution of controllability predicted obesity bias. The results of this study validated research of attribution and bias; elevated AAQ Willpower scale scores and anti-fat bias appear to be present, although not statistically significant, in the sample of this study.

The findings of this research did not discover significant relationships between personality and obesity bias. However, this does not discount the possibility that a relationship between these variables exists, merely that they were not found in this study. In light of the research concerning personality, prejudice and obesity bias presented thus far, further research of anti-fat bias and personality characteristics seems warranted. Several recommendations were provided toward this end.

Obesity is a growing health concern within the U.S. and obesity discrimination and bias have been well documented in the literature. Clinicians are urged to increase their knowledge of obesity bias and discrimination. Strategies to reduce bias should be taught and employed by clinicians and these strategies should be developed through additional research. 
This page is intentionally blank 


\section{References}

Adderley-Kelly, B. (2007). The prevalence of overweight and obesity among undergraduate health sciences students. The Association of Black Nursing Faculty Journal, 18(2), 46-50.

Adorno, T.W., Frenkel-Brunswick, E., Levinson, D.J., \& Sanford, R.N. (1950). The authoritarian personality. New York: Harper and Row.

Age and Sex (2009). US Census Bureau Fact Finder. Retrieved 5/12/09 from http://factfinder.census.gov/servlet/STTable?

Allen, B. P., \& Potkay, C. R. (1981). On the arbitrary distinction between states and traits. Journal of Personality and Social Psychology, 41, 916-928.

Allen, B. P., \& Potkay, C. R. (1981). On the arbitrary distinction between states and traits. Journal of Personality and Social Psychology, 41, 916-928.

Allison, D.B., Fontaine, K.R., Manson, J.E., Stevens, J. \& VanItallie ,T.B. (1999). Annual deaths attributable to obesity in the United States. Journal of the American Medical Association, 282 (16), 1530-1538.

Allon, N. (1982) The stigma of overweight in everyday life. In B.B. Woldman (Ed.). Psychological Aspects of obesity (pp 130-174). New York: Van Nostrand Reinhold.

Allport, G.W. (1937). Personality: A psychological interpretation. New York: Holt. Allport, G.W. (1954/1979). The nature of prejudice. Cambridge, MA: Perseus Books. Allport, G.W., \& Kramer, B.M. (1946). Some roots of prejudice. Journal of Psychology, 22, 9-39. 
Allport, G. W., \& Odbert, H. S. (1936). Trait-names: A psycho-lexical study.

Psychological monographs, 47, 211.

Altemeyer, B. (1981). Right-wing authoritarianism. Manitoba, Canada: University Press.

Altemeyer, B. (1996). The authoritarian specter. Cambridge, MA: Harvard University Press.

Altemeyer, B. (1998). The other authoritarian personality.” In L. Berkowitz (Ed.), Advances in experimental social psychology, 30, (pp. 47-92). Orlando, FL: Academic.

American College health Association. The American College Health Association National College Health Assessment (ACHA-NCHA), spring 2006 reference group data report (abridged). Journal of American College health, 55, 195-206.

Anderson, J.W., Konz, E.C., Frederich, R.C., \& Wood, C.L. (2001). Long-term weightloss maintenance: A meta-analysis of U.S. studies. American Journal of Clinical Nutrition, 74(5), 579-584.

Anti-obesity drug no magic bullet". Canadian Broadcasting Corporation. (2007).

Retrieved on March 8, 2009 from http://www.cbc.ca/health/story/2007/01/02/rimonabant.html.

Arkes, H.R., \& Tetlock, P.E. (2004). Attributions of implicit prejudice or would Jessie Jackson fail the implicit association test?” Psychological Inquiry, 15(4), 257-278.

Arkin, R.M., Appleman, A.J., \& Berger, J.M. (1980). Social anxiety, self-presentation and the self-serving bias in causal attribution. Journal of Personality and Social Psychology, 38, 28-35. 
Asendorpf, J.B. (2003). Head to head comparison of the predictive validity of personality types and dimensions. European Journal of Personality, 17, 327-346.

Ashburn-Nardo, L., Voils, C. I., \& Monteith, M. J. (2001). Implicit associations as the seeds of intergroup bias: How easily do they take root? Journal of Personality and Social Psychology, 81, 789-799.

Atkinson, J.W. (1957). Motivational determinants of risk taking behavior. Psychological Review, 64, 359-372.

Atkinson, J.W. (1964). An introduction to motivation. Princeton, NJ: Van Nostrand.

Bagozzi, R.P. (1981). Attitudes, intentions, and behavior: A test of some key hypotheses. Journal of Personality and Social Psychology, 1981, 41(4), 607-627.

Barness, L. A., Opitz, J. M., \& Gilbert-Barness, E. (2007). Obesity: Genetic, molecular and environmental aspects. American Journal of Medical Genetics, 143A, 30163034.

Baum, C. L. \& Ford, W.F. (2004). The wage effects of obesity: a longitudinal study. Health Economics, 13, 885-899.

Batson, C.D., Naifeh, S.J., \& Pate, S. (1978). Social desirability, religious orientation and racial prejudice. Journal for the Scientific Study of Religion, 17(1), 31-41.

Bell, S.K., \& Morgan, S.B. (2000). Children's attitudes and behavioral intentions toward a peer presented as obese; does a medical explanation for obesity make a difference? Journal of Pediatric Psychology, 25(3), 137-145.

Bierly, M.M. (1985). Prejudice toward contemporary out-groups as a generalized attitude. Journal of Applied Social Psychology, 15, 188-198. 
Bleich, S., Cutler, D., Murray, C., \& Adams, A. (2008). Why is the developed world obese? Annual Review of Public Health 29, 273-295.

Bloch, E. (2003). Eating from the inside out. WITI Health. Retrieved on December 10, 2007, from http://www.witi.com/health/2003/eating.php.

Block, J. (1995). A contrarian view to the five-factor approach to personality description. Psychological Bulletin, 117(2), 187-215.

Borgatta, E. F. (1964). The structure of personality characteristics. Behavioral Science, 9, 8-17.

Borodulin, K., Laatikainen, T., Juolevi, A., \& Jousilahti, P. (2008). Thirty-year trends of physical activity in relation to age, calendar time and birth cohort in Finnish adults. European Journal of Public Health, 18 (3), 339-344.

Bouchard, T. J., Jr., \& Loehlin, J.C. (2001). Genes, evolution and personality. Behavior Genetics, 31, 243-273.

Bray, G.A. (2004). Medical consequences of obesity. Journal of Clinical Endocrinology \& Metabolism, 89 (6), 2583-2589.

Breakwell, G. M., Hammond, S., Fife-Schaw, C., \& Smith, J. (Eds.) (2006). Research methods in Psychology (3rd Ed.). Thousand Oaks, CA: Sage.

Brownson, R.C., Boehmer, T.K., \& Luke, D.A. (2005). Declining rates of physical activity in the United States: what are the contributors? Annual Review of Public Health, 26, 421-443.

Brunello, G. \& D`Hombres, B. (2007). Does body weight affect wages? Evidence from Europe. Economics and Human Biology, 5, 1-19. 
Caballero, B. (2007). The global epidemic of obesity: An overview. Epidemiology Review, 29, 1-5.

Calle, E. E., Thun, M.J., Petrelli, J.M., Rodriguez, C., \& Heath, C.W. (1999). Body-mass index and mortality in a prospective cohort of U.S. adults. New England Journal of Medicine, 341, 1097-1105.

Campbell, D., \& Stanley, J. (1963). Experimental and quasi-experimental designs for research. Chicago, IL: Rand-McNally.

Cano-García, F. J., Padilla-Muñoz, E. M., \& Carrasco-Ortiz, M.A. (2005). Personality and contextual variables in teacher burnout. Personality and Individual Differences, 38(4): 929-940.

Carr, D., \& Friedman, M.A. (2005). Is obesity stigmatizing? Body weight, perceived discrimination, and psychological well-being in the United States. Journal of Health and Social Behavior, 46, 244-259.

Carroll, S. L., Lee, R. E., Kaur, H., Harris, K. J., Strother, M. L.\& Huang, T. T. (2006). Smoking, weight loss intention and obesity-promoting behaviors in college students. The Journal of the American College of Nutrition, 25(4), 348

Cattell, R. B. (1943). The description of personality: basic traits resolved into clusters. Journal of Abnormal and Social Psychology, 38, 476-506.

Cattell, R. B., Eber, H. W., \& Tatsouka, M.M. (1970). Handbook for the Sixteen Personality Factor Questionnaire (16PF). Champaign, Illinois: I PAT.

Cawley, J. (2004). The impact of obesity on wages. The Journal of Human Resources, 39, $451-474$. 
Center for Disease Control (2008). Overweight and Obesity. Retrieved June 5, 2008, from http://www.cdc.gov/.nccdphp/dnpa/obesity/economic_consequences.htm

Chakravarthy, M.V., \& Booth, F.W. (2004). Eating, exercise, and "thrifty" genotypes: Connecting the dots toward an evolutionary understanding of modern chronic diseases. Journal of Applied Physiology, 96(1), 3-10.

Chamberlin, J. (2004). What's behind Prejudice? APA Monitor, 35(9), 34-36.

Chambliss, H. O., Finley, C. E., \& Blair, S. N. (2004). Attitudes toward obese individuals among exercise science students. Medicine and Science in Sports \& Exercise, 36 (3), 468-474.

Choi, H.K., Atkinson, K., Karlson, E.W., \& Curhan, G. (2005). Obesity, weight change, hypertension, diuretic use, and risk of gout in men: the health professionals follow-up study. Archives of Internal Medicine, 165(7), 742-748.

Clark, L.A., \& Watson, D. (1999). Temperament: A new paradigm for trait psychology. In L.A. Pervins \& O.P. Johns (Eds.), Handbook of personality: Theory and research (2nd ed., 399-423). New York: Guilford.

Cohen, J. (1977). Statistical power analysis for the behavioral sciences (rev. ed.). New York: Academic Press.

Conard, M. A. (2006). Aptitude is not enough: How personality and behavior predict academic performance. Journal of Research in Personality, 40(3), 339-346.

Cook, T.D, \& Campbell, D.T. (1979). Quasi-experimentation: design and analysis issues for field settings. New York: Houghton Mifflin

Cossrow, N., Jeffries, R. W., \& McGuire, M. T. (2001). Understanding weight stigmatization. Journal of Nutrition Education, 33(4), 208. 
Costa, P.T., \& McCrae, R.R. (1992). Normal personality assessment in clinical practice: The NEO personality inventory. Psychological Assessment, 4, 5-13.

Costa, P. T., \& McCrae, R. (1995). Solid ground in the wetlands of personality: a reply to Block . Psychological Bulletin, 117(2), 216-220.

Coy, P. (2000) Thinner paychecks for obese women? Business Week, 3705, 16.

Crandall, C.S. (1994). Prejudice against fat people: Ideology and self-interest. Journal of Personality \& Social Psychology, 66(5), 882-894.

Crandall, C.S., D‘Anello, S., Sakalli, N., Lazarus, E., Wieczorkowska, G., \& Feather, N.T. (2001). An attribution-value model of prejudice: Anti-fat attitudes in six nations. Society for Personality and Social Psychology, 27, 30-37.

Davis, E. (2003). The consequences of childhood obesity. Australian Journal of Psychology, 55, 175.

Davis, K.L. (1998). Fat bias among psychologists: Impact of client weight on clinical judgments and treatment planning. Dissertation Abstracts International, 58(7-B), 3918.

De Houwer, J. (2003b). The extrinsic affective Simon task. Experimental Psychology, 50, $77-85$.

Dictionary.com. (2009). Discrimination. Retrieved on July, 21, 2009 from http://dictionary.reference.com/browse/discrimination.

Dictionary.com. (2009). Prejudice. Retrieved on July, 21, 2009 from http://dictionary.reference.com/browse/prejudice 
Digman, J. M., \& Takemoto-Chock, N. K. (1981). Factors in the natural language of personality: Re-analysis, comparison and interpretation of six major studies. Multivariate Behavioral Research, 16(2), 149-170.

Duckitt, J. (1992). The social psychology of prejudice, New York: Praeger.

Duckitt, J., Wagner, C., Du Plessis, I., \& Birum, I. (2002). The psychological bases of ideology and prejudice: Testing a dual process model. Journal of Personality and Social Psychology, 83, 75-93.

Edwards. P., \& Roberts, I. (2008). Obesity adds to global warming. Reuters. Retrieved 6/9/2008 from http://msnbc.msn.com/id/24666022.

Eggert, J., Levendosky, A., \& Klump, K. (2007). Relationships among attachment styles, personality characteristics, and disordered eating. International Journal of Eating Disorders, 40(2), 149-155.

Egloff, B., Schwerdtfeger, A., \& Schmukle, S. (2005). Temporal stability of the Implicit Association Test-Anxiety. Journal of Personality Assessment, 84 (1), 82-88.

Ekehammar, B., \& Akrami, N. (2003). The relation between personality and prejudice: A variable versus a person-centered approach. European Journal of Personality, 17, $449-464$.

Ekehammar, B., Akrami, N., Gylje, M., \& Zakrisson, I. (2004). What matters most to prejudice: Big five personality, social dominance orientation or right-wing authoritarianism? European Journal of Personality, 18, 463-482.

Ekehammar, B, \& Akrami, N. (2007). Personality and prejudice: From the Big Five personality factors to facets. Journal of Personality, 75, 899-925. 
Farooqi, S., \& O'Rahilly, S. (2006). Genetics of obesity in humans. Endocrinology Review, 27 (7), 710-718.

Fazio, R. H., \& Olson, M. A. (2003). Implicit measures in social cognition research: Their meaning and use. Annual review of psychology, 54, 297-327.

First Federal Obesity Clinical Guidelines Released (1998). National Institutes of Health. Retrieved 6/11/2008 from http://www.nhlbi.nih.gov/new/press/obere14f.htm.

Fiske, D. W. (1949). Consistency of the factorial structures of personality rating from different sources. Journal of Abnormal and Social Psychology, 44, 329-344.

Fiske, S.T. (1998). Stereotyping, prejudice and discrimination. In D.T. Gilbert, S.T., Fiske, and J. Lindzey (Eds.), The Handbook of Social Psychology (4th Ed.), Vol. 2, 357- 411. New York: McGraw Hill.

Fiske, S.T., Cuddy, A.J., Glick, P., \& Xu, J. (2001). A model of (often mixed) stereotype content: Competence and warmth respectively follow from perceived status and competition. Journal of Personality and Social Psychology, 14, 878-902.

Flegal, K.M., Carroll, M.D., Ogden, C.L., \& Johnson, C.L. (2002). Prevalence and trends in obesity among US adults, 1999-2000. Journal of the American Medical Association, 288, 1723-1727.

Flynn, F.J. (2005). Having an open mind: The impact of openness to experience on interracial attitudes and impression formation. Journal of Personality and Social Psychology, 88, 816-826.

Fonda, S. (2000) Fat is a financial issue: Summary of study, economic and employment outcomes of obesity in middle-aged women and men. Economist, 357, 93. 
Gabriel, I. U. (2006). Obesity. Retrieved on 09-29-2008 from http://www.emedicine.com/med/TOPIC1653.htm.

Garza, A. (2007). How can personality be classified? Retrieved 7/3/2007 from http://serendip.brnmawr.edu/bb/neuro/neuro 06/webz/agaa.htm.

Gleitman, H., Friedlund, A., \& Reisberg, D. (2004). Personality. Psychology. 6th Ed. New York: W.W. Norton.

Goffman, E. (1963). Stigma: Notes on the management of spoiled identity. Englewood Cliffs, NJ, Prentice-Hall.

Goldberg, L. R. (1981). Language and individual differences: The search for universals in personality lexicons. In L. Wheeler (Ed.), Review of Personality and Social Psychology, 2, 141-165. Beverly Hills, California: Sage.

Gortmaker, S.L., Must, A., Sobol, A.M., Peterson, K., Colditz, G.A., \& Dietz, W.H. (1996). Television viewing as a cause of increasing obesity among children in the United States, 1986-1990. Archives of Pediatric and Adolescent Medicine, 150 (4), 356-62.

Graham, S. \& Folkes, V.S. (1990). Attribution theory: Applications to achievement, mental health, and interpersonal conflict. New Jersey: Lawrence Erlbaum Associates.

Graziano, W.G., Bruce, J., Sheese, B.E., \& Tobin, R.M. (2007). Attraction, personality and prejudice: liking none of the people most of the time. Journal of Personality and Social Psychology, 93, (4), 565-582.

Greenberg, D.R., \& LaPorte, D. J. (1996). Racial differences in body type preferences of men for women. International Journal of Eating Disorders, 19(3), 275. 
Greenwald, A.G., Banaji, M.R., Rudman, L.A., Farnham, S.D., Nosek, B.A., \& Mellott, D.S. (2002). A unified theory of implicit attitudes, stereotypes, self-esteem, and self concept. Psychological Review, 109, 3-25.

Greenwald, A.G., McGhee, D.E., \& Schwartz, J.K.L. (1998). Measuring individual differences in implicit cognition: The Implicit Association Test. Journal of Personality and Social Psychology, 74, 1464-1480.

Greenwald, A.G., \& Nosek, B.A. (2001). Health of the Implicit Association Test at age 3. Zeitschrift fur Experiementelle Psychologie, 48, 85-93.

Greenwald, A.G., Nosek, B.A. \& Banaji, M.R. (2003). Understanding and using the Implicit Association Test: improved scoring algorithm. Journal of Personality and Social Psychology, 85(2), 197-216.

Greenwald, A.G., Poehlman, T.A., Uhlmann, E., \& Banaji, M.R. (2009). Understanding and using the Implicit Association Test: III. Meta-analysis of predictive validity. Journal of Personality and Social Psychology, 97(1)17-41.

Grundy, S.M. (2004). Obesity, metabolic syndrome, and cardiovascular disease. Journal of Clinical Endocrinology \& Metabolism, 89 (6): 2595-2600.

Guimond, S. (2000). Group socialization and prejudice: The social transmission of intergroup attitudes and beliefs. European Journal of Social Psychology, 30, 335-354.

Guimond, S., Dambrun, M., Michinov, N., \& Duarte, S. (2003). Does social dominance generate prejudice? Integrating individual and contextual determinants of intergroup cognitions. Journal of Personality and Social Psychology, 84, 697-721.

Harris, M. B., Walters, L. C. \& Waschull, S. (1991). Altering attitudes and knowledge about obesity. Journal of Social Psychology, 131(6), 881-884. 
Hartley, E. L. (1946). Problems in prejudice. New York: Kings Crown.

Hassel, T. D., Amici, C. J., \& Thurston, N.S. (2001). Client weight as a barrier to nonbiased clinical judgment. Spirituality \& Christianity, 20(2), 145-161.

Haslam, D.W., \& James, W.P. (2005). Obesity. Lancet 366 (9492): 1197-1209.

Heaven, P. C. L., \& Bucci, S. (2001). Right-wing authoritarianism, social dominance orientation and personality: An analysis using the IPIP measure. European Journal of Personality, 15, 49-56.

Hebl, M. R., \& Heatherton, T. F. (1998). The stigma of obesity in women: The difference is black and white. Personality \& Social Psychology Bulletin, 24(4), 417-426.

Heffner Media Group. (2008). Attribution and attraction. Retrieved 5/25/2008 from http://allpsych.com/psychology101/attribution_attraction.html.

Heider, F. (1944). Social perception and phenomenal causality. Psychological Review, $51,358-374$.

Heider, F. (1958). The psychology of interpersonal relations. New York: Wiley.

Heppner, P. P., \& Heppner, M. J. (2004). Writing and publishing your thesis, dissertation and research: A guide for students in the helping professions. Belmont, CA: Brooks/Cole.

Heppner, P. P., Kivlighan, D. M., Jr., \& Wampold, B. E. (1999). Research design in counseling (2nd ed.). Belmont, CA: Wadsworth.

Herpertz, S., Kielmann, R., Wolf, A.M., Langkafel, M., Senf, W., \& Hebebrand, J. (2003). Does obesity surgery improve psychosocial functioning? A systematic review. International Journal of Obesity, 27(11), 1300-1314. 
Holmes, J.D. (2009). Transparency of self-report racial attitudes scales. Basic and Applied Social Psychology, 31, 95-101.

James, W., \& Rotter, J.B. (1958). Partial and one hundred percent reinforcement under chance and skill conditions. Journal of Experimental Psychology, 55, 397-403.

Jenks, B. A. (1998). A consideration of negative attitudes toward fat people: Associated factors and a potential change process (Doctoral Dissertation. The Fielding Institute, 1998). Dissertation Abstracts International, 58(7-B), 3968.

Johnsen, L., Spring, B., Pingatore, R., Sommerfeld, B., \& MacKirnan, D. (2002). Smoking as a subcultural? Influences on Hispanic and non-Hispanic white women's attitudes toward smoking and obesity. Health Psychology, 1, 279-287.

Kanouse, D. E. \& Hanson, L.R. (1972). Negativity in evaluations. In A.E. Jones, D.E. Kanouse, H.H. Kelley, R.E. Nisbett, S.Valins, \& B.Weiner (Eds.), Attribution: Perceiving the causes of behavior (2nd Ed.), (47-62). Morristown, N J: General Learning Press.

Kelley, H.H. (1967). Attribution theory in social psychology. In D. Levine (Ed.), Nebraska Symposium on motivation (pp. 192-238). Lincoln, NE: University of Nebraska Press.

Kinder, D. R. (1986). The continuing American dilemma: White resistance to racial change 40 years after Myrdal. Journal of Social Issues, 42, 151-171.

Klaczynski, P.A., Goold, K.W., \& Mudry, J.J. (2004). Culture, obesity stereotypes, selfesteem, and the "thin ideal": A social identity perspective. Journal of Youth \& Adolescence, 33(4) 307. 
Klassen, M.L., Clayson, D., \& Jasper, C. R. (1996) Perceived effect of a salesperson‘s stigmatized appearance on store image: An experimental study of students ${ }^{6}$ perceptions. International Review of Retail, Distribution \& Consumer Research, 6(2), 216-224.

Kopelman, P.G., Caterson, I.D., Stock, M.J., \& Dietz, W.H. (2005).Clinical Obesity in adults and children: In Adults and Children. Oxford, United Kingdom: Blackwell Publishing.

Korukondo, A.R. (2007). Differences that do matter: A dialectic analysis of individual characteristics and personality dimensions contributing to computer anxiety. Computers in Human Behavior, 23 (4): 1921-1942.

Kostanski, M., Fisher, A., \& Gullone, E. (2004). Current conceptualization for body image dissatisfaction: Have we got it wrong? Journal of Child Psychology and Psychiatry, 45(7), 1317-1325.

Kunz, N. M. (1999). Dissertation Abstracts International: Section B: The Sciences and Engineering, 59(7-B), 3773.

Lambert, A.J., \& Chasteen, A.L. (1997). Perceptions of disadvantage versus conventionality: Political values and attitudes toward the elderly versus blacks. Personality and Social Psychology Bulletin, 23, 469-481.

Lawless, J. (2008). Voight returns to royal opera. The Associated Press. Retrieved 6/17/2008 from http://www.boston.com/news/world/europe/articles2008/06/16 slimmed_down_soprano_voight.

Lawson, W. (2003). The puzzle of obese children and depression. Psychology Today, 36(4), 20. 
Leedy, P. D., \& Ormrod, J. E. (2005). Practical research: Planning and design (8th Ed.). Upper Saddle River, NJ: Prentice Hall.

Levitsky, D. A., Halbmaier, C.A., \& Mrdjenovic, G. (2004). The freshman weight gain: a modelfor the study of the epidemic of obesity. International Journal of Obesity and Related Metabolic Disorders, 28 (11), 1333-1337.

Lewin, K. (1935). A dynamic theory of personality. New York: McGraw-Hill.

Lewin, K. (1938). A conceptual representation and the measurement of psychological forces. Durham, NC: Duke University Press.

Lin, B.H., Guthrie, J., \& Frazao, E. (1999). Nutrient contribution of food away from home. In Frazão, E., Agriculture Information Bulletin No. 750: America's Eating Habits: Changes and Consequences. Washington, DC: US Department of Agriculture, Economic Research Service. 213-239. http://www.ers.usda.gov/publications/aib750/.

Lippa, R., \& Arad, S. (1999). Gender, personality and prejudice: The display of authoritarianism and social dominance in interviews with college men and women. Journal of Research and Personality, 33, 463-493.

Loscalzo, J., Fauci, A. S., Braunwald, E., Dennis, L. K., Hauser, S.L., \& Longo, D. L. (2008). Harrison's principles of internal medicine. New York: McGraw-Hill Medical.

Malik, V.S., Schulze, M.B., \& Hu, F.B. (2006). Intake of sugar-sweetened beverages and weight gain: a systematic review. American Journal of Clinical Nutrition, 84 (2), $274-288$. 
Manson, J.E., Willett, W.C., \& Stampfer, M.J. (1995). Body weight and mortality among women. New England Journal of Medicine, 333 (11), 677-685.

Maranto, C.L. \& Stenoien, A.F. (2000). Weight discrimination: a multidisciplinary analysis. Employees Responsibilities and Rights Journal, 12, 9-24.

McAdams, D.P. (1992). The five factor model in personality: A critical appraisal. Journal of Personality, 60, 329-361.

McConnell, A. R., \& Leibold, J. M. (2001). Relations among the Implicit Association Test, discriminatory behavior, and explicit measures of racial attitudes. Journal of Experimental Social Psychology, 37, 435-442.

McCrae, R. R. \& Costa, P. T. (1985). Updating Norman's adequate taxonomy: Intelligence and personality dimensions in natural language and in questionnaires. Journal of Personality and Social Psychology, 49, 710-721.

McCrae, R. R. \& Costa, P. T. (1987). Validation of the five-factor model of personality across instruments and observers. Journal of Personality and Social Psychology, $52,81-90$.

McCrae, R.R., \& Costa, P.T., Jr. (1996). Toward a new generation of personality theories: Theoretical context for the five factor model. In J. S. Wiggins (Ed.), The five factor model of personality: Theoretical perspectives (pp. 51-87). New York: Guilford.

McCrae R. R., \& Costa P. T., Jr. (1999). A five-factor theory of personality. In L. A. Pervin, and O. P. John (Eds.), Handbook of personality: Theory and research (2nd ed., 139-153). New York: Guilford. 
McFarland, S.G. (2001). Prejudiced people: Individual differences in explicit prejudice. Manuscript, Western Kentucky University.

McFarland, S.G., Ageyev, V., \& Abalakina, M. (1993). The authoritarian personality in the U.S.A and U.S.S.R.: Comparative studies. In W.F. Stone, G. Lederer, and R. Christie (Ed.), Strengths and weaknesses: The authoritarian personality today. (pp. 199-228). New York: Springer.

mdPassport. (2008). Retrieved on May 21, 2009 from http://www.medicalpost.com/therapeutics/nutrition/article.jsp?content=20080818 -121920_25640.

Miller, D.T. \& Ross, M. (1975). Self-serving biases in the attribution of causality: Fact or fiction? Psychological Bulletin, 82, 213-225.

Miller, C. T., \& Downey, K.T. (1999). A meta-analysis of heavyweight and self-esteem. Personality \& Social Psychology Review, 3(1), 68-84.

Mills, J. K., \& Andrianopoulos, G.D. (1993). The relationship between childhood onset obesity and psychopathology in adulthood. Journal of Psychology, 127(5), 547551.

Mischel, W. (1968). Personality and assessment. New York: Wiley.

Mischel, W. (1973). Toward a cognitive social learning re-conceptualization of personality. Psychological Review, 80, 252-283.

Mischel, W. (2004). Toward an integrative science of the person. Annual Review of Psychology, 55, 1-22.

Mischel, W. (2009). From personality and assessment (1968) to personality science, 2009. Journal of Research in Personality, 43, 282-290. 
Mischel, W., \& Shoda, Y. (1995). A cognitive-affective system theory of personality: Re-conceptualizing situations, dispositions, dynamics and invariance in personality structure. Psychological Review, 102, 246-268.

Mokdad, A. H., Marks, J. S., Stroup, D. F., \& Gerberding, J. L. (2004). Actual causes of death in the United States, 2000. Journal of the American Medical Association, 282(16), 1238-1245.

Musher-Eizenman, D. R., Holub, S. C., \& Miller, A.B. (2004). Body size stigmatization in preschool children: The role of control attributions. Journal of Pediatric Psychology, 29(8), 613-620.

Mustillo, S. (2003). Obesity and psychiatric disorder: Developmental trajectories. Pediatrics, 111, 851-859.

National Heart, Lung, and Blood Institute (NHLBI) (1998) (PDF). Clinical Guidelines on the Identification, Evaluation, and Treatment of Overweight and Obesity in Adults. International Medical Publishing, Inc. http://www.nhlbi.nih.gov/guidelines/obesity/ob_gdlns.pdf.

National Institutes of Health (1998). First federal obesity clinical guidelines released. Retrieved June 11, 2008 from http:nhlbi.nih.gov/new/press/obere14f.htm National Institute for Health and Clinical Excellence. (2006). Obesity: the prevention, identification, assessment and management of overweight and obesity in adults and children. Retrieved June 11, 2008 from http://www.nice.org.uk/cg43.

Nelson, T. F., Gortmaker, S. L., Subramanian, S. V., Cheung, L., \& Wechsler, H. (2007). Disparities in overweight and obesity among US college students. American Journal of Health Behavior, 31(4), 363-373. 
Ness-Abramof, R.,\& Apovian, C.M. (2006). Diet modification for treatment and prevention of obesity. Endocrine, 29 (1) 5-9.

Nestle, M. \& Jacobson, M.F. (2000). Halting the obesity epidemic: A public health policy approach. Public Health Report 115 (1), 12-24.

Newsletter 2000.Retieved on May 21, 2009 from http://www.esst.org/newsletter2000.htm

Norman, W. T. (1963). Toward an adequate taxonomy of personality attributes:

Replicated factor structure and peer nomination personality ratings. Journal of Abnormal and Social Psychology, 6, 574-583.

Norman, W. T. (1967). 2,800 personality trait descriptors: Normative operating characteristics for a University population. Department of psychology, University of Michigan, Ann Arbor, M I.

Nosek, B.A., Greenwald, A.G., \& Banaji, M.R. (2007). The Implicit Association Test at age 7: A methodological and conceptual review (pp. 265-292). In J.A. Bargh (Ed.), Automatic processes in social thinking and behavior. Psychology Press.

Obesity Action Coalition. (2008). Obesity and stigma. Retrieved 6/5/2008 from http:obesityaction.org/aboutobesity/obesity/stigma.php.

O‘Brien, K.S., Puhl, R.M., Latner, J.D., Mir, A.S., \& Hunter, J.A. (2010). Reducing antifat prejudice in pre-service health students: a randomized trial. Obesity, Vol. $18(11), 2138-2144$.

Olby, B.C. (2003). Perceived attractiveness and personality attributes: A gender and racial analysis. Dissertation Abstracts International: Section B: The Sciences \& Engineering, 63(9-B), 4420. 
Olsen, N.J., \& Heitmann, B.L. (2009). Intake of calorically sweetened beverages and obesity. Obesity Review 10(1), 68-75.

Overweight and Obesity. (2008). Center for Disease Control. Retrieved 6/9/2008 from http://www.cdc.gov/nccdphp/dnpa/obesity/economic_consequences.htm.

Pagán, J.A., \& Dávila, A. (1997). Obesity, occupational attainment and earnings. Social Science Quarterly, 78(3), 756-770.

Pargman, D. (1969). The incidence of obesity among college students. The Journal of School Health, 39(9), 621-630.

Paunonen, S.V. (1998). Hierarchical organization of personality and prediction of behavior. Journal of Personality and Social Psychology, 74, 538-556.

Paunonen, S.V., \& Ashton, M.C. (2001). Big Five factors and facets and the prediction of behavior. Journal of Personality and Social Psychology, 81, 524-539.

Peeters, A., Barendregt, J.J., Willekens, F., Mackenbach, J.P., Al Mamun, A., \& Bonneux, L. (2003). Obesity in adulthood and its consequences for life expectancy: A life-table analysis. Annals of Internal Medicine, 138(1), 24-32.

Perez-Lopez, M. S., Lewis, R.J., \& Cash, T. F. (2001). The relationship of anti-fat attitudes to other prejudicial and gender-related attitudes. Journal of Applied Social Psychology, 31(4), 683-697.

Pierce, J. W., \& Wardle, J. (1996). Body size, parental appraisal, and self-esteem in blind children. Journal of Child Psychology \& Psychiatry \& Allied Disciplines, 37(2), 205-212. 
Pingatore, R., Dugoni, B. L., \& Tindale, R. (1994) Bias against overweight job applicants in a simulated employment interview. Journal of Applied Psychology, 79, 909917.

Pollan, M. (2007). You Are What You Grow. Retrieved on 4/4/2009 from http://www.nytimes.com/2007/04/22/magazine/22wwlnlede.t.html?ex=11860272 00\&en=bbe0f6a $2 \mathrm{c} 10 \mathrm{e} 3 \mathrm{~b} 3 \mathrm{c} \& \mathrm{ei}=5070$.

Pool, R. (2001). Fat: fighting the obesity epidemic. Oxford, United Kingdom: Oxford University press.

Pratto, F., Sidanius, J., Stallworth, L., \& Malle, B. (1994). Social dominance orientation: A personality variable predicting social and political attitudes. Journal of Personality and Social Psychology, 67, 471-483.

Prose, F. (2003). Gluttony: The seven deadly sins.: Oxford University Press.

Puhl, R. (2001). Bias, discrimination and obesity. Obesity Research, 9 (12), 788-805.

Quinn, D. M. (1999). The Protestant ethic and the stigma of overweight (self-esteem, depression and anxiety). Dissertation Abstracts International: Section B: The Journal of Sciences \& Engineering, 60(5-B), 2412.

Quinn, D. M., \& Crocker, J. (1999). When ideology hurts: Effects of belief in the Protestant ethic and feeling overweight on the psychological well-being of women. Journal of Personality \& Social Psychology, 77(2), 402-414.

Reynolds, K.J., Turner, J.C., Haslam, S.A., \& Ryan, M.K. (2001). The role of personality and group factors in explaining prejudice. Journal of Experimental Social Psychology, 37, 427-434. 
Rogge, M.M. (2004). Obesity, stigma and civilized oppression. ANS Advanced Nursing Science, 27(4), 301-315.

Rosén, T., Bosaeus, I., Tölli, J., Lindstedt, G., \& Bengtsson, B.A. (1993). Increased body fat mass and decreased extracellular fluid volume in adults with growth hormone deficiency. Clinical Endocrinology, 38 (1), 63-71.

Rosenheck, R. (2008). Fast food consumption and increased caloric intake: a systematic review of a trajectory towards weight gain and obesity risk. Obesity Review, 9(6): $535-547$.

Rothblum, E.D., Brand, P.A., \& Miller, C.T. (1990). The relationship between obesity, employment discrimination and employment-related victimization. Journal of Vocational Behavior, 37(3), 251-266.

Rotter, J.B. (1966). Generalized expectancies for internal versus external control of reinforcement. Psychological Monographs, 80. (whole No. 609).

Saporta, I., \& Halpern, J. J. (2002). Being different can hurt: effects of deviation from physical norms on lawyers` salaries. Industrial Relations, 41, 442-466.

Satcher, D. (2001). The Surgeon General's Call to Action to Prevent and Decrease Overweight and Obesity. U.S. Dept. of Health and Human Services, Public Health Service, Office of Surgeon General. Retrieved April 4, 2009 from http://www.ncbi.nlm.nih.gov/books/bv.fcgi?rid=hstat5.chapter.2.

Saucier, G., \& Goldberg, L. R. (1996). The language of personality: Lexical perspectives on the five factor model. In J. S. Wiggins (Ed.), The five-factor model of personality: Theoretical perspectives, 21- 50. New York: Guilford Press. 
Saucier, G., \& Goldberg, L.R. (1998). What is beyond the Big Five? Journal of Personality, 66, 395-424.

Saulsman, L. M. \& Page, A. C. (2004). "Corrigendum to the five factor model in personality disorder and empirical literature: a meta-analytic review." Clinical Psychology Review, 23, 1055-1085.

Schmitt, M.T., Branscombe, N.R., \& Kappen, D.M. (2003). Attitudes toward group based inequality: Social dominance or social identity? British Journal of Social Psychology, 42(2), 161-187.

Schmukle, S. \& Egloff, B. (2004). Does the Implicit Association Test for assessing anxiety measure trait and state variance? European Journal of Psychological Assessment, 18 (6), 483-494.

Schmukle, S. \& Egloff, B. (2005). A latent state-trait analysis of explicit and implicit personality measures. European Journal of Psychological Assessment, 21(2), 100107.

Schwartz, M.B., Vartanian, L. R., Nosek. B.A., \& Brownell, K. (2006). The influence of one's own body weight on implicit and explicit anti-fat bias. Obesity,14(3), 440447.

Schwarz, S. ( 2007). Obesity. Retrieved on March 15, 2009 from http://www.emedicine.com/med/TOPIC1653.htm.

ScienceDaily (2007). College students face obesity, high blood pressure, metabolic syndrome. Retrieved March 8, 2009, from http//:wwwsciencedaily.com/releases/2007/06/070614113310.htm 
Sears, D. O., Sidanius, J.,\& Bobo, L. (2000). Racialized politics: The debate about racism in America. Chicago: University of Chicago Press.

Shick, S. M., Wing, R.R., Klem, M.L., McGuire, M.T., Hill, J.O., \& Seagle, H. (1998).

Persons successful at long-term weight loss and maintenance continue to consume a lowenergy, low-fat diet. Journal of the American Diet Association, 98(4), 408-413.

Shkolnikova, S. (2008). Weight discrimination could be as common as racial bias. USA Today. Retrieved 6/17/2008fromhttp://usatoday.com/news/health/weight/biasn.htm.

Sidanius, J., \& Pratto, F. (1999). Social dominance: An intergroup theory of social hierarchy and oppression. New York: Cambridge University Press.

Sniderman, P. M., \& Tetlock, P. E. (1986). Symbolic racism: Problems of motive attribution in political analysis. Journal of Social Issues, 42, 129-150.

Sorbara, M., \& Geliebter, A. (2002). Body image disturbance in obese outpatients before and after weight loss in relation to race, gender, binge eating, and age of onset of obesity. International Journal of Eating Disorders, 31(4), 416-424.

Spake, A. (2004). The future of fatness. U.S. News \& World Report, 136(5), 56.

Striegal-Moore, R.H., Schreiber, G.B., Pike, K.M., \& Wilfley, D.E. (1995). Drive for thinness in Black and White pre-adolescent girls. International Journal of Eating Disorders, 18(1), 59-69.

Sweeting, H.N. (2007). Measurement and definitions of obesity in childhood and adolescence: A field guide for the uninitiated. Retrieved 3/8/2009 from http://www.nutritionj.com/content/6/1/32. 
Tanofsky-Kraff, M., Yanovski, S.Z., Wilfley, D.E., Marmarosh, C., Morgan, C.M., \& Yanovski, J.A. (2004). Eating-disordered behaviors, body fat and psychopathology in overweight and normal-weight children. Journal of Consulting and Clinical Psychology. 72(1), 53-61.

Tate, D.F., Jeffery, R.W., Sherwood, N.E., \& Wing R.R. (2007). Long-term weight losses associated with prescription of higher physical activity goals. Are higher levels of physical activity protective against weight regain? American Journal of Clinical Nutrition, 85(4), 954-959.

Teachman, B.A., Gapinski, K.D., Brownell, K.D., Rawlins, M., \& Jeyaram, S. (2003). Demonstrations of implicit anti-fat bias: The impact of providing causal information and evoking empathy. Health Psychology. 22(1), 68-78.

Teige, S., Schnabel, K., Banse, R., \& Asendorpf, J. (2004). Assessment of multi implicitconcept dimensions using the Extrinsic Affective Simons Task (EAST). European Journal of Personality, 18 (6), 495-520.

Thelen, M. H., Powell, A. L., Lawrence, C., \& Kuhnert, M.E. (1992). Eating and body image concern among children. Journal of Clinical Child Psychology, 21(1), 4146.

Tickle, J., \& Heatherton, T. (2002). Research involving college students. In R. Amdur \& E. Bankert (Ed.), Institutional Review Board Management and Function. Boston: Jones and Bartlett Publishers

Tiggemann, M.A., \& Anesbury, T. (2000). Negative stereotyping of obesity in children: The role of controllability beliefs. Journal of Applied Social Psychology, 30(9), 1977-1993. 
Tillman, W.S., \& Carver, C.S. (1980). Actors' and observers` attributions for success and failure: A comparative test of predictions from Kelly's cube, self-serving bias, and positivity bias formulations. Journal of Experimental Social Psychology, 26, $18-32$.

Touster, L.O. (2000).Fat oppression: The complicity of psychology. Dissertation Abstracts International, 61(4-B), 22-25.

Trapnell, P.D. (1994). Openness versus intellect: A lexical left turn. European Journal of Personality, 8, 273-290.

Tucker, L.A., \& Bagwell, M. (1991). Television viewing and obesity in adult females. American Journal of Public Health 81(7), 908-911.

Tupes, E. C. \& Christal, R. C. (1961). Recurrent personality factors based on trait ratings (Tech. Rep.). Lackland Air Force Base, Texas: USAF.

Turnbull, J.D., Heaslip, S., \& McLeod, H.A. (2000). Pre-school children's attitudes toward fat and normal male and female stimulus figures. International Journal of Obesity, 4(12), 1705-1706.

Verkuyten, M., \& Hagendoorn, L. (1998). Prejudice and self-categorization: The variable role of authoritarianism and in-group stereotypes. Personality and Social Psychology Bulletin, 24, 99-110.

Vioque, J., Torres, A., \& Quiles, J. (2000). Time spent watching television, sleep duration and obesity in adults living in Valencia, Spain. International Journal of Obesity Related Metabolic Disorders, 24(12), 1683-1688.

Wang, S.S., Brownell, K.D., \& Wadden, T.A. (2004). The influence of the stigma of obesity on overweight individuals. International Journal of Obesity and Related 
Metabolic Disorders: Journal of the International Association for the Study of Obesity, 28, 1333-1337.

Wang, N., Jome, L. M., Haase, R. F., \& Bruch, M. A. (2006). The role of personality and career decision-making self-efficacy in the career choice commitment of college students. Journal of Career Assessment, 14(3), 312-332.

Weiner, B.P. (1980). A cognitive (attribution)—emotion—action model of motivated behavior: An analysis of judgments of health giving. Journal of Personality and Social Psychology, 2, 186-200.

Weiner, B.P. (1979). A theory of motivation for some classroom experiences. Journal of Educational Psychology, 71, 3-25.

Weiner, B. (1985). An attributional theory of achievement, motivation and emotion. Psychological Review, 92, 548-573.

Weiner, B. (1986). An attributional theory of motivation and emotion. New York: Springer-Verlag.

Weiner, B. (1990). An overview of attribution theory. In Graham, S. \& Folkes, V.S. (Eds.). Attribution theory: Applications to achievement, mental health, and interpersonal conflict.Hillsdale, NJ: Lawrence Erlbaum Associates.

Weiner, B., Frieze, I.H., Kukal, A., Reed, L., Rest, S., \& Rosenbaum, R.M. (1991). Perceiving the causes of success and failure. Morristown, NJ: General Learning Press.

Weiner, B., Frieze, I., Reed, L., Rest, S., \& Rosenbaum, R.M. (1972). Perceiving the causes of success and failure. In E.E. Jones, D.E. Kanouse, H.H. Kelley, R.E. 
Nisbitt, S. Valins, \& B. Weiner (Eds.). Attribution: Perceiving causes of behavior. Morristown, NJ: General Learning Press.

Weiner, B.P., Perry, R.P., \& Magnusson, J. (1988). An attributional analysis of reactions to stigmas. Journal of Personality and Social Psychology, 55, 738-743.

Weiss, E.C., Galuska, D.A., Kettel, K. L., Gillespie, C., \& Serdula, M.K. (2007). Weight regain in U.S. adults who experienced substantial weight loss, 1999-2002. American Journal of Preventive Medicine, 33(1), 34-40.

World Health Organization (2000).Technical report series 894: Obesity: Preventing and managing the global epidemic. Retrieved on January 10, 2009 from http://whqlibdoc.who.int/trs/WHO_TRS_894_(part1).pdf

World Health Organization (2006). Obesity and overweight. Retrieved on January 10, 2009 from http://www.who.int/dietphysicalactivity/publications/facts/obesity/en/.

World Health Organization (2008). Physical Inactivity: A Global Public Health Problem. Retrieved on February 22, 2009 from http://www.who.int/dietphysicalactivity/factsheet_inactivity/en/index.html.

Williamson, D.F., Pamuk, E., Thun, M., Flanders, D., Byers, T., \& Heath, C. (1995). Prospective study of intentional weight loss and mortality in never-smoking overweight US white women aged 40-64 years. American Journal of Epidemiology, 14(12), 1128-1141.

Wright, J.D., Kennedy-Stephenson, J., Wang, C.Y., McDowell, M.A., \& Johnson, C.L. (2004). Trends in intake of energy and macronutrients_-United States, 19712000, Morbidity and Mortality Weekly Report, 53(4), 80-92. 
Wyer, R.S., \& Frey, D. (1982). The effects of feedback about self and others on the recall and judgments of feedback-relevant information. Journal of Experimental Social Psychology, 19, 540-559.

Yu, T., \& Bowers, M. (2000). Fat accompli. People, 53(24), 101. 


\section{Appendix A}

Summary of the IAT Scoring Procedures (Greenwald, Nosek \& Banaji, 2003)

Trials 1 and 2 are practice/familiarization trials.

1. Delete trials greater than 10,000 msec.

2. Delete subjects for whom more than $10 \%$ of trials have latency less than 300 msec.

3. Compute the inclusive" standard deviation for all trials in Stages 3 and 6 and likewise in all trials for Stages 4 and 7.

4. Compute the mean latency for responses for each of stages $3,4,6$, and 7 .

5. Compute the two means differences (Mean Stage 6- Mean Stage 3) and (Mean Stage 7- Mean Stage 4).

6. Divide each difference score by its associated -inclusive" standard deviation.

7. $D=$ the equal-weight average of the two resulting ratios.

This computation is appropriate for designs in which participants must correctly classify each item before the next stimulus appears. SPSS and SAS syntax for implementing this algorithm are available at faculty.washington.edu/agg/iat_materials.htm 


\section{Appendix B}

\section{Demographics Questionnaire}

I would appreciate your providing the following information about yourself and your academic history. If you are uncomfortable completing any of the following questions, please feel free to skip those questions

1. What is your age?

2. What is your class rank? Fr., So., Jr., Sr.

3. What is your gender? Male; Female; Transgender

4. What is your ethnic/racial background?

5. What is your field of study?

6. What is your height (in inches)?

7. What is your weight (in pounds)? 


\section{Appendix C}

Informed Consent

I'm John Damm and I am a doctoral candidate in counseling psychology at West Virginia University and I' $\mathrm{m}$ conducting a dissertation research study on how people see themselves and others.

You are invited to participate in a research study that will measure personality factors and attitudes toward body types. You have been asked to participate in this study because you are undergraduates enrolled in psychology courses; you must be 18 years or older to participate.

If you decide to participate in this study, you will be asked to complete an online survey, along with demographic information about yourself and two paper-pencil questionnaires. The survey should take only 50-60 minutes to complete. Participation in this study is entirely voluntary, and completion of the survey will indicate informed consent. Although complete data sets are my goal, you are free to choose not to participate, to choose not to respond to individual items, or to discontinue participation at any time without penalty. Additional space is also provided at the end of the survey for feedback or questions.

Your responses will be kept entirely confidential. You will not be asked to include your name or any personal identification. To participate or receive additional information about the study, you can contact me at dammpsych@gmail.com to arrange a time to complete the assessments. The West Virginia University Institutional Review Board (IRB) has acknowledgement of this study on file.

Thank you for taking the time to consider participating in this study. 